
S.HEEUNIVERS/

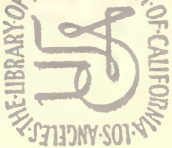

THE UNIVERSIY

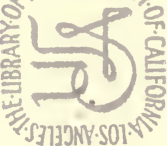

AHELIBRARYOF.

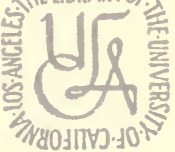

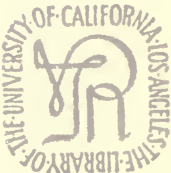

S.HHEUNIVERS/Y

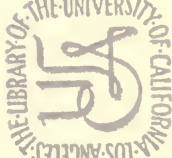

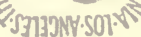

THEVNIVERSIS

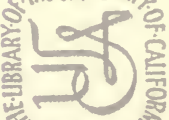

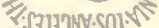
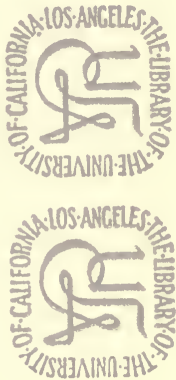

GE:IBRARYOF.
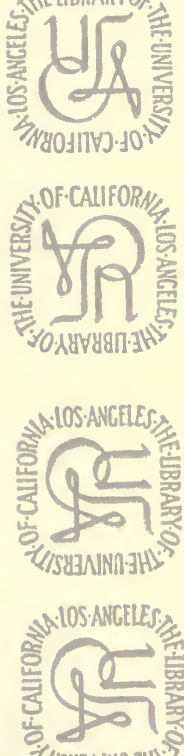

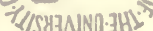

ANELLBRARYOOF.

MIE.LIB
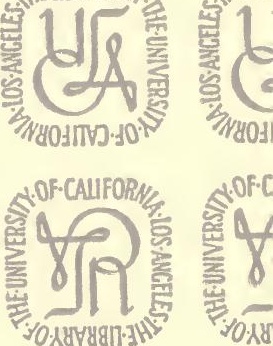

SHEUNIVERS/I,
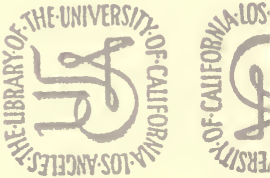

SHEVUNIVESI/

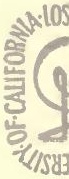

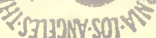

NAE.L
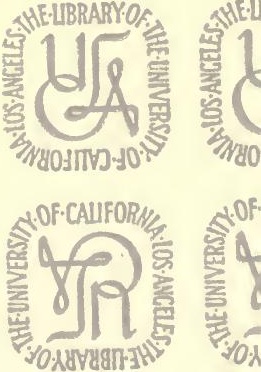

THE

International, Scientific Series

VOL. LIV. 



\section{THE MAMMALIA}

IN THEIR RELATION TO PRIMEVAL TIMES

BY

\section{OSCAR SCHMIDT}

PROFESSOR IN THE UNTVERSITY OF STRASBURG

WITH FIFTY.ONE WOODCUTS

SECOND EDITION

\section{O N D O N}

KEGAN PAUL, TRENCH, TRÜBNER \& CO. LTD. PATERNOSTER HOUSE, CHARING CROSS ROAD 1894 
MADE AND PRINTED IN GREAT BRITAIN

(The rights of translation and of reproduction are reserved) 
S355E

1894

\section{P R E F A C E.}

Is the Preface to the Third Edition of my 'Doctrine of Descent and Darwinism,' which appeared in 1883 , I quoted the opinion of a famous lawyer as to the worthlessness of science, not with the intention of refuting it, but gave it as an example of the incredible naïveté with which eminent representatives of certain pronounced religious tendencies confront the work and results of natural science. Not long afterwards I was asked by a well-known man whether my lectures on zoology, at the university, treated of Darwinism as well. What my answer was is known to all those who have taken any interest in the 'theory of descent.' To those who have an understanding of the subject, and of the aims of a scientific interpretation of the living world (which is, in 
fact, the only one possible interpretation), I offer the present work as a supplement. It will be found to contain proofs of the necessity, the truth, and the value of Darwinism as the foundation for the theory of descent, within a limited field, and is brought down to the most recent. times. Within these limits the work is complete in itself; for although the student of natural history may have become acquainted with interesting fragments of the actual science, still the subject has not before been presented in so comprehensive a manner, or in so convenient a form.

Together with my special studies of the zoology of the lower animals, I have for many years past felt myself peculiarly attracted by the advance of our knowledge of the Mammalia in their general relation to palæontology and anthropology. From year to year I have followed this advance with increased interest, and always with a view to the principal questions connected with the domain as a whole. Hence I venture to offer this work to our younger and rising scientists as, I trust, a suggestive introduction to that portion 
of the animal kingdom which stands closest to anthropology.

My materials have been drawn from original works, when and wherever they were within my reach; hence I never give extracts from extracts. I take it for granted that my readers, if not already in some measure acquainted with the forms and mode of life of the Mammalia, have at hand some such work as Brehm's 'Thierleben,' or Martin's 'Illustrirte Naturgeschichte der Thiere.' Books such as these, which nowadays occupy a prominent place in popular literature, make us acquainted with facts; but, with the exception of C. Vogt's and Specht's works on the Mammalia, they go no farther. Now, as the theory of descent has shown, light and interpretation are shed upon the Present by the Past; and thus the history of the development of animals, the history of the earth and geography, are made to confirm one another. In undertaking to give an introduction to illustrate this, I must observe that it will be possible only by overcoming a variety of difficulties, by entering upon various apparently trifling 
details-for instance, the construction of the teeth ; and these must not be regarded in themselves as merely amusing or entertaining, for, when brought into connection, these details often open up the most surprising and most wonderful prospects. By these enquiries we do not indeed arrive at the final cause of things, or at what the philosophers call the Thing Itself, but from an insight into the connection of the facts we obtain a higher arrangement for those facts. They demand an ever deeper penetration, and transport us into that creative state of enthusiasm which, by being the imaginative faculty of thinking-man, raises us above those who remain standing amid their own surroundings either in a state of blank amazement or of dull enjoyment.

I am only following the usual custom by mentioning, in conclusion, the assistance I have received from my daughter Johanna, to whose experienced hand I owe a series of original drawings, from which my illustrations have beem made.

Oscar Schmidt.

Strasberg: September, 1884. 


\section{CONTENTS.}

PAGR PREFACE • • • • • • • • • • v

I. GENERAL, INTRODUCTION.

1. The Position of Mammals in the Animal Kingdom. . 1

2. Phenomena of Convergence . . . . . . . 14

3. The Distinctive Characteristics of Mammals . • . 30

4. The Extension of Paleontological Science since Cevikr . . . . . . . . . 45

5. The Strata of the Tertiary Formation . . . . 77

II. SPECIAL COMPARISON OF THE LIVING MAMMALS AND THEIR ANCESTORS.

1. The Monotrema, Cloacal or Forked Animals • 86

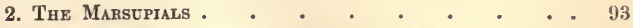

3. The Edentata, or Animals poor in Teeth • • 110

4. The Ungulata, or Hoofed Animals . . • . . 126

PAIR-HOOFED ANIMALS.

1. The Suidæ, or Pigs . . . . . 137

2. The Hippopotamus, or River Horse. . . . 144

3. The Ruminants : • • • • . 150

4. Camels . . . . . . . . . 154

5. Deer and their Kindred Forms . . . 158

6. Hollow-horned Animals, Antelopes and Oxen . . 173 


\section{ODD-HOOFED ANIMALS.}

1. PAGR

1. Tapirs and Rhinoceros - . - 190

2. The Equidæ, or Horses . . . . . 201

5. The Elephants - • • • - • • 227

6. The Strenia, or Sea-Cows . - . • . 242

7. The Cetacea, or Whales - . • . . 246

8. The Carnivora, or Flesh-eaters . • . . 259

9. The Seals . . . . . . . . 287

10. The Insectrvora, or Insect-eaters. The Rodents.

The Bats . . . . . . . . . 291

11. The Prosime, or Sem-Apes. Simiz, or Apes. The

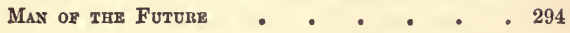

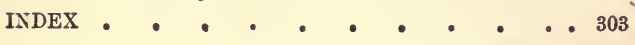




\section{ILLUSTRATIONS.}

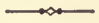

FIG.

1. Right hand of a River Tortoise . . . . . 36

2. A. Lower jaw of Plagiaulax minor $\quad$ • $\quad$ • 99

$B$. Lower jaw of Plagiaulax medius. $\quad$ • $\quad$. $\quad 99$

3. A. Lower jaw of Neoplagiaulax . • . • . 101

$B$. Lower jaw of Bettongia penicillata . . . 101

4. Skull of Diprotodon australis . . . . . 103

5. Skull of the Wombat (Phascolarctus fuscus) . . 105

6. Skull of Nototherium, side view . . . . . 105

7. Skull of Nototherium, front view . . . . 106

8. Skull of the Giant Sloth . . . . . . 113

9. Skull of the Three-toed Sloth . . . . . . 115

10. Head of Glyptodon clavipes. • . . . . 124

11. Left fore-foot of Anoplotherium . . . . 129

12. Left fore-foot of the Peccary . . . . . 130

13. Coryphodon. Right fore and hind foot . . .. 132

14. Coryphodon. Skull with brain . . . . . 134

15. A Tuberculate and a Crescentic Tooth . . . 138

16. Right fore-foot of a Pig . . . . . . 140

17. Palæochœrus typus, left upper jaw : . . . 143

18. Second lower molar of the Hippopotamus, to the right $\mathbf{1 4 5}$

19. First upper molar of the Hippopotamus, to the right . 146

20. Hippopotamus, right fore-foot . . . . 147

21. I. Right upper cheek-tooth of a Calf, before cutting the gum . . . . . . . . 153

$I I$. Right cheek-tooth of a Calf, after cutting the gum, artificially polished, from behind and the outside 153

22. Auchenia hesterna. Second left upper cheek-tooth . 157 
FIG.

23. Prox furcatus. Left antler . . . . . 160

24. A. Left fore-foot of the Red Deer . . . . 162

$B$. Left fore-foot of the Roe . . . . . 162

C. Second row of tarsals and metatarsals of Gelocus . 162

25. A. Left fore-foot of Hyæmoschus aquaticus . . 168

B. Left fore-foot of Hyopotamus . . . . . 168

26. Skull of a Short-horned Bull . . . . . 175

27. Skull of the Gazelle . . . . . . 176

28. Skull of the Bison americanus . . . . 180

29. Skull of the Anoa . . . . . . . 181

30. Skull of Cainotherium metopias . . . . 183

31. Skull of the Tapir (Tapirus americanus) . . 191

32. Back molar, below to the left, of Lophiodon parisiensis . . . . . . . . . 192

33. Skull of Elasmotherium . . . . 197

34. A. Skull of Brontotherium ingens . . . . 199

B. The same from above with a drawing of the brain. 199

35. Palæotherium. Hipparion. Horse . . . 202

36. Left hind-foot of Anchitherium . . . : . 204

37. Right upper cheek-tooth of the Horse . . . . 209

38. Foot of the fossil Horses of North America . . . 213

39. Macrauchenia patagonia . . . . . . 229

40. Polished molar of Mastodon angustidens . . 232

41. Portion of a cheek-tooth of Mastodon elephantoides . 233

42. Portion of a cheek-tooth of the Mammoth, polished sideways . . . . . . . . 235

43. Skull of Dinotherium giganteum . . . . 237

44. Skull of Dinoceras mirabile . . . . 241

45. Skull of the Delphinus lagenorhynchus, Gray - 249

46. Right fore-leg of Delphinus delphis . . . . 250

47. Tooth of Squalodon . . . . . . . . 253

48. Teeth of the Fox . . . . . . . 261

49. Lower jaw of Icticyon . . . . . . . 266

50. Skull of Tillotherium fodiens, from above . . . . 286

51. Fœtal teeth of the Greenland Seal . . . . . 290 


\title{
THE MAMMALIA
}

\section{IN THEIR 'RELATION TO PRIMEVAL TIMES.}

\author{
I. \\ GENERAL INTRODUCTION:
}

THE POSITION OF THE MAMMALIA IN THE ANTMII KINGDOM.

IT has always been considered a matter of course that the Mammalia stand at the head of the anima! kingdom. This has been the opinion of the muititude who have not given any thought whatever to the origin of living things; also of those to whom the ' idea of the creation,' or rather the empty word creation, was, and still is, the one 'comforter in need;' and again also of the majority of our students of modern biology, the advocates of the theory of descent, and their few predecessors. This agreement in the opinion expressed about the Mammalia dates from the earliest times, and is founded upon 
the high estimation in which man holds himself, an opinion which we meet with as uniformly. Man finds himself bound by every fibre within the group of the Mammalia; and as soon as he makes limself the standard by which to measure the value and the position of living creatures-and this he has every reason to do within the circle of those he is acquainted with-he cannot, when making a comparative survey, do otherwise than class them as they always have been classed.

The very obvious fact of the close affinity of the Mammalia with man, and the consequent necessity for some systematic arrangement of them, leads to the further observation that certain groups or classes of animals resemble the Mammalia in the main characteristics of form and structure more than others. Nor has there ever been any doubt as to this close 'relationship.' Ever since the days of Aristotle men have been agreed about the group of the Vertebrates, and about the succession of Fishes, Amphibians, Reptiles, Birds and Mammals. This order was naturally meant to express the gradation of perfection, and always with the supposition of the ideal to be attained in man. Hence the vertebrates, as a whole, formed the chief main division, the highest type of the animal kingdom. 


\section{THEIR POSITION IN THE ANIMAL KINGDOM. 3}

The position of the Mammalia in their connection with the other classes of vertebrates, and their special relationship with one class of them-taking the word relationship without its explanation by descent-rendered the old system extremely obscure, for the facts themselves spoke very imperfectly. The anatomical resemblance is nowhere so absolutely distinct that the descriptive method could point to the bird, or to any one of the vertebrates, as showing the closest and most numerous affinities with the Mammalia. That animals of the frog species and mammals should possess two condyles at the back of the head as the first vertebræ of the neck, and that birds, like lizards and their relatives, had only one, always seemed surprising to comparative anatomists. Yet what was to be done with this and other similar facts? We know that since the middle of the eighteenth century the idea of descent and development flickered up here and there. But the theory was unable to rise above the general conception, and even in the present century its importance was not felt by an anatomist who, in my opinion, nevertheless possessed the clearest ideas of the connection between the present and the past. I refer to the elder d'Alton. Although his interest in the subject was aroused by Goethe, it 
was Goethe again who is indebted to d'Alton for some of his most frequently quoted opinions. Goethe, in order, as it were, to keep off the profanum vulgus, gives in a mystic form what d'Alton stated unequivocally. D'Alton's famous work on skeletons also induced Goethe to discuss the subject of adaptability, and to maintain that adaptation was one of the most important factors in producing new forms. 'The animal is formed by circumstances for circumstances.'

The power of an organism to accommodate itself to the place of its abode and food-which is an undisputed phenomenon-must be all the more striking the more complicated the structure of the group of animals, and can therefore generally be more easily verified in the case of the mammal, even by the unpractised eye. As the mammal, in the first place, endeavours to satisfy its need of food, the variation called forth by the adaptation directed towards this want is expressed at first by its instruments of locomotion and mastication. It may also be said that mammals give more proof of the power of adaptation in the systematic arrangement of their parts than most of the other classes of animals, but we must not forget that this arrangement of parts, in all classes of animals, is 
THEIR POSITION IN THE ANIMAL KINGDOM. 5

almost exclusively the result of adaptation. The power of the animal to move in accordance with the peculiarity of the place of its abode, to secure its food, and to rear its offspring, is in most cases so perfect (if the imperfections are concealed) that the real purpose would seem to be the harmony of the surroundings and means of subsistence of the organism. The scientific novice as well as the dualistic philosopher finds 'a purpose in nature'a common purpose of connected systems of organs - even where the scientific inquirer sees a number of imperfections, that might more consistently with a 'purpose' have been avoided had the natura naturans wished to take a more direct road. How precarious this idea of a 'purpose in nature' is, as regards our own bodies, might, we think, be felt with every cold in the head. It is only when the adaptability has become an actual condition that the result appears to be a preordained purpose.

Those who regard the Mammalia as organisms adapted for some special purpose, and exactly in their place when and as we find them, are satisfied with a systemative manual on the subject. But, we ask, is this kind of knowledge science? Does this knowledge give us any real understand- 
ing of the subject? Can those who know the Mammalia of our day, in all the various phenomena of their life and the differences in their structure, be said to be fully enlightened as to the causes and connection of all these facts? As this has generally been taken for granted, zoology has hitherto been stigmatised by the senseless appella'tion of 'a descriptive science ;' for, in fact, it was not considered to possess the character of a science that inquires into a causal connection. As if a science could exist without having an observing as well as a descriptive part!

The descriptive zoologist need not in any way trouble himself or be astonished at anything. When, however, he has to take into consideration the scientific results of recent times, he will have to pause before a series of specially striking phenomena. This will happen, for instance, when he is about to make a preliminary comparison of the Mammalia with the rest of the Vertebrates, for he will want transition forms between the former and the latter. Buffon's opinion, that by carefully observing two organisms, however different, an uninterrupted series of transition forms will always be found, did not long hold good in face of our more strict systematic arrangement. The link 
THEIR POSITION IN THE ANINAL KINGDON. 7

between the Mammalia and the rest of the vertebrates has scarcely been looked for anywhere, except among the birds, owing to the obviously high degree of mental development attained by certain members of this class, owing to the stronger and more perfect circulation of their-blood. But neither Buffon or any other later comparative anatomist has undertaken to give any specific proof of this link, because, as was said above, other circumstances pointed to a relationship with the Amphibians.

It will not be necessary to make other vain attempts to bridge over the gap between the Mammalia and the other vertebrates of the present day. It will even be shown that this difficulty is not at all or but little removed by our present knowledge of primeval times.

More striking still are the numerous isolated forms within the class of the Mammalia themselves. The best known example of this kind of an isolated form of mammal is the horse and its relatives, the genus Equns. The descriptive zoologist places it by the side of the two-hoofed animals. Yet the difference between the one-toed horse and the two-toed oxen and stags remains completely unexplained. Besides this, the more perfect dentition of the horse 
stands in sharp contrast with the reduced dentition of most of the ruminants, which lack the upper incisors; the only point of connection would seem to be the camel, which again has a much fuller dentition. Nevertheless, the horse remains a phenomenon so peculiar within itself, that descriptive zoology has always classed the genus Horse-which is limited to a few species-in the order of the twohoofed animals, which contains a number of different genera and several hundred species.

It is much the same with the perfectly untenable order of the many-hoofed or thick-skinned animals, for it is made to comprise entirely different members. What a peculiar form, for instance, we have in the elephant among the thick-skinned animals, or, indeed, among the whole class of Mammalia : a strict vegetarian, and yet in every respect an oddity among the plant-eaters. The caps of horn, somewhat like nails, which cover the points of his toes, can scarcely be called hoofs. 'The form of his skull, his teeth and his trunk, in like manner, separate him from all the other planteaters in whose society he has figured since the days of Linnæus. But even among the rest of the so-called many-hoofed animals there is no unity, even according to the interpretation of a later, 
post-Linnæan system; for the various genera differ more from one another in structure, feet and teeth, than do the members of other orders. That the pig shows more affinity with the rhinoceros or with the hippopotamus than with the ox, is anything but self-evident as soon as it is clearly perceived that the connecting link cannot be in the number of hoofs. We may mention as isolated genera also the camel, the giraffe, and the fingered-animals; and as isolated families all those animals which, on account of their defective dental arrangement, may be classed as animals poor in teeth (Edentata), such as sloths, girdled animals, ant-eaters, and scaled ant-eaters; for even as groups they show among one another a want of harmony similar to that of the heterogeneous divisions of the class of the many-hoofed animals. If, further, we draw attention to the contrast in which the Marsupials stand to all the other orders of mammals, while they differ very widely among themselves, we shall have pointed out a large number of phenomena that are wholly unintelligible by themselves.

In addition to this we meet with the many geographical difficulties; for instance, the geographical distribution of animals which, by itself, 
is inexplicable. ${ }^{1}$ Certainly all the phenomena here referred to are intelligible when the supposition of migration does not stumble upon contradictions and surmountable obstacles, and when the capacity of the organism to acclimatise itself-using the word in its widest sense-is taken into account as a long since established fact; but the question as to the origin of species in general is left as a point to be considered apart. Without doubt that which tends to the widest distribution of an animal form and to the intercourse between the most different species, is the sea. Since recent scientific investigations have made us as intimately acquainted with the ocean-currents as with the systems of rivers, with the range of cold currents and tongues of water in the southern seas and conversely, and has marked the different depths of the ocean currents, and given us charts of the bottom of the sea, with maps showing its elevations and depressions-it would seem that, with an account of the animals in the sea, the possibilities and causes of their occurrence would likewise be exhausted.

The state of the matter is very different as regards the distribution of animals on land, in

1 Wallace, The Geographical Distribution of Animals. 
THEIR POSITION IN THE ANIMAL KINGDOM. 11

lakes and rivers. Of a large number of inland lakes we know that it is only within a period scarcely separable from the present that they have become detached from the sea. A large portion of the inhabitants of these lakes is accounted for by this very fact. In regard to the rivers we have here specially to consider fishes and mussels. Now it is well known that a number of fishes-for instance, the salmon, smelt, eel, and certain kinds of plaice-spend their life partly in fresh and partly in salt water, according to the season of the year, for the sake of propagation ; and further, that they can be transferred from the one to the other kind of water without injury. Hence we may assume, in the case of all purely fresh-water fishes and mussels, that their progenitors could also at one time live in either kind of water: we have thus a perfectly satisfactory explanation of the occurrence of the same genera, partly also of the same species, in rivers situated very far apart. Examples of this kind in the group of mammals are not frequent, but instructive. The sea-cow, discovered by Vogel in the Benue, is the only species of the order of the Sirenia which, it would seem, has never attained a fuller development, and-to use an expression of Rütimeyer's-has completely taken 
leave of the sea. On the other hand, the American lamantin is still undergoing the transition, and feels as comfortable in the sca as it does in the lowest currents of large streams. The dugong of Eastern Africa has, however, remained perfectly faithful to its old, habitual element. An interesting example of the occurrence of a mammal in an inland lake is the dog-fish of the Caspian Sea. It was, in fact, simply left there. That this large sheet of water was at one time connected with the sea is a long since established fact.

By this remark, and a return to the geological past (even though it be to a most recent past), we have again entered the only path which leads to the understanding of all the geographical configurations of the present, more particularly to the distribution of the organisms, and above all to that of the land animals. The difficulty of meeting with closely related species, orders, and larger groups, in regions lying far apart and separated by high chains of mountains or impassable oceans, has, since Buffon's days, been quietly settled with the word 'vicariate,' which proves anything but a true understanding of the matter. When it is said that the Marsupials 'vicariate' in Australia for the other groups distributed on the other continents, 
this expression denotes nothing but the bare fact, nothing but the mere statement, that in America we do not meet with the camel but with the llama, which in a few main characteristics shows some affinity with it. The one 'vicariates' for the other. Why? we ask. What is the meaning of such 'vicariating'? We get no answer.

Now, in raising the study of zoology from the stage of a mere descriptive method to the height of a true science, we demand an explanation of connections and agreements. Every endeavour to comprehend the animal world, from a scientific point of view, makes modern geology the basis of its operations, and its testimony-which is of fifty years' standing-is that the present condition of the earth's surface, the distribution of land and water, has proceeded from the most gradual and primeval processes, except in cases of purely locally interrupted transformations. Scientific study must, secondly, accept the phenomenon of the power of adaptability in organisms, that versatility of the organs with which plants and animals meet the variability of their external circumstances, and adapt themselves to changes that are taking place, by habit and by the gradual changes of their own bodies which are connected 
with it. Whoever believes in the unity of the human race must be a decided advocate of this variability, even though it be but in the crude notion of regarding the negroes as sun-burnt white men, and the latter as bleached black men. Those, however, who feel convinced of the contrary maintain the variability to be the result of the undoubted mixing of the races and species.

If we look upon the dog as having been created, then the assumption of an extraordinary capacity of adaptation is unavoidable, but it is equally so to those who see in the domestic dog a number of different species of tamed jackals.

THE PHENOMENA OF CONVERGENCE.

Even Goethe early recognised the fact that external influences-' the four elements'-to which the animal has to submit and to adapt itself for the necessity of self-preservation, change the form and mode of life to so great an extent that resemblances have been produced between creatures wholly different at first. But Goethe did not give unequivocal expression to this thought till d'Alton had very clearly emphasised the transformation and development of organisms, as the result of 'elementary conditions.' A number of Goethe's 
remarks, which are continually being quoted since Haeckel's enthusiastic advocacy of Goethe as the precursor of Darwin, are mere transcriptions of passages from d'Alton. ${ }^{1}$ The phenomenon that different animals, very divergent in their structure, and hence not related to one another, can, when placed in the same circumstances, develop certain similarities, did not escape his thoughtful mind. He writes: "The Rodents in form show affinity with various orders; the rat resembles the beast of prey; and the hare in its mode of life and food, even in form 'and characteristics, resembles the Ruminants.' This sentence Goethe

1 Goethe's poem, the Metamorphosis of Animals, where we find the lines-

Hence, each form conditions the life and acts of the creature, And each fashion of life, with reflex forcible action, Works on the form ;

Also bestimmt die Gestalt die Lebensweise des Thieres, Und die Weise des Lebens, sie wirkt auf alle Gestalten IIIschtig zurück-

belongs to the year 1819. D'Alton, in his work on the Skeletons of the Rodents in 1823, says: "Thus it can no longer appear doubtful that the tendency of development in the organism is as dependent upon outward circumstances, as the mode of life of animals is determined by their organisation.' This thought, like others, is reproduced by Goethe when discussing this classical work in 1824. In this 'intellectual discourse' he may have found to his great satisfaction what he had himself long since perceived and pondered over. 
transcribes in his own way with a seemingly unimportant alteration, which, however, changes the matter itself essentially. He says: ' However much the form of the Rodent may vary to and fro, apparently knowing no boundary, still in the end it is found confined within the gencral animal type, and must approximate either the one or the other group of animals; and thus it inclines both to the beasts of prey as well as to Ruminants, to apes as well as to bats, and even to other intermediate groups.'

These similarities and parallelisms did not receive much attention until Darwin's day. Darwin himself speaks of convergence only casually, and by way of pointing out the great improbability of its occurrence as the cause of agreements in organisms not related by blood. But for the last ten years or more, zoologists have so often been forced to account for the existence of similarities and agreements-not as inherited peculiarities of race, but as transformations and assimilations, the result of outward circumstances upon the same or similar original forms-that this agency must be taken into consideration, and will be specially necessary in our present inquiry, for it seems to have played no small part in the group of the Mammalia. A 
few remarlis upon the origin of the idea of convergence will, therefore, not be out of place.

As soon as the idea has been grasped that mechanism governs an organism with the same regularity as it does an inorganic body, the question must naturally arise how far the living substratum can be influenced by outward circumstances, and how far the same results-independent of one another-may be attained under the same and similar conditions. The genius of Diderot comprehended the problem in its widest applicability. In a conversation with d'Alembert in 1769 , he makes the latter start the supposition that after the destruction of all life by the extinction of the sun, a repetition of the development of the plants and animals that formerly existed would recommence with the rekindling of the heavenly body which diffuses force and life. For, he adds, nothing else is conceivable but that the causes, once again set in motion, should produce the same effects as they had already done. According to the Linnæan and Cuvier's interpretation of species, this idea could scarcely expect to find acceptance, and it is self-evident that any agreement was made to rest upon the same origin of the individuals of the species, and further upon the same fundamental 
form, that is, upon the inexplicable sovereignty of the idea of type. Even though parallel groupssuch as the repetition of different orders of the Mammalia within the group of Marsupials, the repetition of the habitus of the Rodents in the Insectivora-were observed and discussed, still the contented zoologist did no more than enter these observations into his book; and remarks such as those made by Goethe and d'Alton remained without result. What position Darwin took as regards the idea of convergence, has already been stated. His school, too, endeavoured at first to account for the homologies exclusively by inheritance, and, on the other hand, regarded the effects of adaptation almost wholly as differentiation. Even that extremely interesting adaptation as a means of defence-mimicry-and, moreover, the ease where the species in danger finds immunity and protection in feigning a resemblance with the species not endangered, did not lead to any generalisation of the inquiry. Still, some striking phenomena of convergence were observed, and others that had long since been known, but not carefully considered, were inquired into more particularly. Among these is Fritz Müller's admirable analysis of the arrangements by which 
the land crabs of the most different families converge in their mode of life and physiology of breathing. The transition from life in water to life on land has commenced in the one and the other species, here and there, and they meet in the most different stages of capacity for life on land; no form is so far changed that its relation to some definite family is not unquestionably evident. The transition from a life in water to one on land has transformed both feet and gills, but has not gone so far as to show agreement or apparent homology. In this case of convergence the mode of life has remained the same as that in which the Rodents resemble the Insectivora and the Cetacea the Sirenia. They were judged differently without principle or consistency. The agreements in the Insectivora and the Rodents had always been considered as accidental and purely external, whereas the Cetacea and Sirenia were classed together in one order as close relatives.

We must here mention an attempt made by Kölliker,' an eminent German scientific man, to

' Kölliker's Alcyonarion in the Abhandlungen der Senckenbergischen naturforschenden Gesellschaft, vii., viii. Published separately under the title of Morphologie und Entwickelungsgeschichte des Pennatulidenstammes nebst allgemeinen Betrachtungen zur Descendenzlehre. Frankfurt a.M., 1872. 
prove the theory of descent as improbable and unnecessary, by assuming in its place a general law of development by which the different species originated side by side without blood-relationship. His fundamental idea, as he himself says, is that with the first origin of organic matter and of organisms a plan of development was also given, a whole series of possibilities (by whom? we ask), but that various outward influences acted determinatively upon individual development and produced a distinct character. That organic nature is the result of some grand plan of development and of universal laws, and that the explanation of the processes of development is nothing more than that they take place according to internal causes, according to laws by which the organisms are most distinctly forced to an ever higher form of development. In like manner eggs and germ cells are said to pass into new forms from internal causes: independent, living, youthful forms are said to begin a development different to the typical one, while outward influences affect the process in various modifying ways, and transformations ensue which, although contained in the general plan, did not all necessarily need to be fulfilled. Every different species is said to have originated in this way by it- 
self : further, that it would even seem probable that one and the same species appeared in different pedigrees; for, owing to the unavoidable assumption of universal laws of formation, it cannot be denied that the same primary forms might, under certain conditions, be able to lead to the same final form. Where individual species have been found in places widely separated, Kölliker even considers it more appropriate to assume an independent origin for them.

In the remarks just quoted there is clearly a question about development, even of a plan of development, but there is no mention whatever as to how we are to conceive those laws and effects which have produced the numerous branches of the animal kingdom; for what are these internal causes which so distinctly force things towards an ever higher form of development? Nothing is to be gained from this idea, which scarcely deserves the name of an hypothesis. It is a complete rehabilitation of dualism and teleology. Kölliker's supposition does certainly touch upon our present views of convergence, but it goes no further; for, in the first place, it takes for granted the existence of some plan which cannot be accurately defined, a tendency-i.e. a purpose; and, secondly, it does 
not consider the difficulties arising from the endless recurrence of the agreement of thousands of circumstances which are necessary for the production of a definite organism, but declares this highly improbable combination to be a law. That a seafeather of the southern ocean should 'originate' spontaneously without ancestors, and be precisely like an individual in the northern ocean, which owes its existence to the same unknown processes without ancestors, shows such a degree of improbability that it amounts to an impossibility. It is, in fact, as improbable as that Adam originated out of a clod of earth. The prophecy that the whole edifice of the Darwinians would collapse, while the theory of a universal law of development (which assumes a number of independent pedigrees as its basis) would rise up triumphantly instead, has not yet been fulfilled.

However, convergencies and repetitions have been observed in abundance since then. In my work on the Sponges, I have adduced special proofs of how a series of convergencies-the formation of water-channels, form and disposition of microscopic bits of skeleton and entire skeletons, root-like offshoots, tensions and other formations-which are defensive arrangements against the intrusion of 
foreign bodies, in short, characteristics which would seem to justify the conclusion of relationship, are merely the result of mechanical contrivances, of the effects of outward circumstances upon heterogeneous organisms.

That outward circumstances have co-operated helpfully and determinatively in the development of symmetrical animal forms, cannot be doubted by any except those who cling to their belief in the type theory. It follows from this that, to a certain extent, all organs appearing in pairs owe their origin to convergence. We should further have to weigh those circumstances where, in nearly related organisms, the same organs vary on one side; this, for instance, occurs frequently in the pincers of the Crustacea. It is only when starting from convergencies of this kind-which may be called homœogenetic, and, according to general supposition, are, as it were, self-evident-that we can pass on to those phenomena to which the idea of approximation is specially applied in our day, the heterogenetic cases of convergence. A shell-less tropical snail, Onchidium, has eyes on the numerous wartshaped protuberances on its back. Semper ${ }^{1}$ makes

1 Semper, Ueber Sehorgane vom Typus der Wirbelthieraugen auf den Rilcken von Schnecken. Wiesbaden, 1877. 
it appear extremely probable that these eyes - of different species and individuals-originated independently of one another. By connecting this development with the general characteristics of the cells of the upper skin and of the protoplasm, be shows that this repeated formation of eyes must be regarded as arising from a simple foundation. This is one form of convergence, repetition in the individual. The other is contained in the fact that the eye of the onchidium shows an advance towards the eye of the vertebrate, inasmuch as its structure and the retina differ essentially from the eye of the other molluses.

A few years ago a great fuss was made about a case of convergence which scarcely deserved this name, and when inquired into dwindled down to certain superficial resemblances, such as have becn observed times without number since we have had descriptions of natural objects. I refer to the resemblance of certain primeval reptiles to mammals, the so-called Theriodonta. The case was this. ${ }^{1}$ In the Trias formation of the southern extremity of Africa there were found, in addition to the colossal plant-eating reptiles of the group Dinosauria, a series of other animals, hitherto unknown, which,

' Owen, Fossil Reptilia of South Africa. London, 1876. 
upon the very first examination of the teeth, proved to be flesh-eaters. Now the teeth of the modern flesh-eaters are characterised by being definitely separated, and by the peculiar formation of the incisors, the canines, and the molars. The canines above and below and on either side of the jaw are powerful weapons, and admirable instruments for tearing off flesh and for the gnawing and the breaking up of bones. They separate the incisors from the molars in a distinctive manner.

In the case of the above-mentioned South African reptiles also, the teeth, which from their position we know to have been incisors, are separated from the molars by a large canine tooth. The lower one rises in front of the upper one, yet when the mouth is closed it lies close to the inside of the upper jaw. The molars are certainly small and cone-shaped; however, when drawing a comparison we can recall similar instances of this in seals. Owen, to whom we owe the description of these, in any case, very remarkable animals, also draws attention to the formation of the upper part of the arm, which, apart from the difference in the formation of the extremity of the upper joint, shows an approximation to the cat-type in the construction of the extremity of the lower joint, for the ulna 
and the second bone of the lower arm-the radius. Owen accordingly makes the names of the new genera remind us of the dog, wolf, tiger, \&c., Cynodracon, Lycosaurus, Tigrisuchus. He then speaks of the importance of the discovery and says: 'If the gap in the series of animals between the Mesozoic and Psychozoic air-breathers had not been filled up otherwise than by reptiles, the remnant of that class which has survived and reached our times would have testified to the total loss of such gains of organisation as had enriched the ancestors and predecessors of modern tortoises, lizards, and crocodiles.

'We know now that not one of these gains has been lost, but has been handed on, continued and advanced through a higher type of vertebrates, of which type we trace the dawn back to the period when reptiles were at their best-grandest in bulk, most numerous in individuals, most varied in species, best endowed with kinds and powers of locomotion, and with the instruments for obtaining and dealing with both animal and vegetable food.

'Has the transference of structures, it may be asked, from the reptilian to the mammalian type been a seeming one, delusive, due to accidental coincidence in animal species independently and 
thaumatogenously created? Or was the transference real, consequent on nomogeny, or the incoming of species by secondary law, the mode and way of operation of which we have still to learn? Certain it is that the lost reptilian structures specified, are now manifested by quadrupeds with a higher condition of cerebral, circulatory, respiratory, and legumentary systems-a condition the acquisition of which is unintelligible to the writer on either the Lamarkian or the Darwinian hypothesis.'

It is unintelligible to us also, for we do not in the slightest degree imagine that those coincidences, which are neither great nor astonishing, have to be understood by means of Darwin's hypothesis. There is, in fact, no question whatever about transferred conditions of organisation, for the coincidence is confined to mere adaptations, and, in part, very superficial ones; adaptations which, in some cases, are 'intelligible' without any difficulty. With the help of our present prototypes and the above fossil material, we can imagine all kinds of substitutes for our wolves and the other beasts of prey. It is extremely probable that many of the earlier, and to us unknown mammals, inherited a uniform set of teeth (perhaps somewhat like the dolphin's) direct from their ancestors of 
the amphibian or reptile species. Now the fact that direct descendants of reptiles, with a uniform set of teeth, should acquire distinctive corner teeth (canines) in consequence of their tearing their victims, as is the habit of beasts of prey, and that certain mammals have acquired these teeth also, owing to their having taken to flesh-eating, is a convergence that can be most satisfactorily explained as the result of the same activity upon similar or the same developments in the earlier forms of teeth. It is, as we have already said, a case of convergence of the most superficial kind. Among living reptiles-in the Hatteria, Uromastix spinipes, and also a species of agama-we meet with advances towards the dentition of the Carnivora. But even when the canine is followed at first by small pointed teeth, and then by broader ones, there is nothing, either here or in the case of the fossil African reptiles, that can be pointed out as 'peculiar molars with broad crowns' (Wiedersheim).

It is self-evident that given a like beginning and like circumstances, we will more readily meet with similar and the same phenomena than where there was inequality to start with. In other words homœogenetic convergencies occur most fre- 
quently. The Linnæan conception of things, together with the idea of type, and finally the more recent idea of homology as agreement by reason of derivation, have, however, been the cause that approximations in general, especially within the given ' nafural group,' were more or less neglected, or, at least, that merely surmised homologiessuch as the breathing apparatus of the lung-snails -turned out to be convergencies. Within the group of mammals we meet with a very evident series of convergencies which have already been spoken of above. Still, all circumstances considered, convergence can explain only the smallest portion of the phenomena. That the Marsupials should show agreements with certain orders of the higher mammals is, at least, in part approximation. That they form an unity among one another is another thing. Why are cats and dogs classed together as beasts of prey? Why are pigs, oxen, and deer classed as hoofed-animals? In short, setting aside the above instances, in the other cases of agreement convergence is improbable à priori, and the explanation of all the other, the main portion, must be looked for in the doctrine of descent. It contains the greater amount of probability, a probability which often borders upon certainty. 
And hence every class of the Mammalia of the present day can be understood only from its connection with its geological ancestors. But are we, by admitting true agreement in organisms and their parts, and by only allowing what is inherited to be real homologies, are we entering a domain wholly distinct from that of convergence? On the contrary. Inheritance is only a case of repetition under the same conditions, a case of universal law. The whole Darwinian principle of selection and progress finds its application also in the generalisation of the doctrine of repetitions.

\section{THE DISTINCTIVE CHARACTERISTICS OF THE}

\section{MAMMALIA.}

The earlier zoologists, with Linnæus, classed together as one species all those individuals ' that agree in essential points and have been descended unchanged from the same ancestors.' The later zoologists replace this supposed straight line of descent, which involves the miracle of creation and also the future invariability of organisms, by including the agency of variability dependent upon time and circumstances. As long as animal beings of a supposed or proved common descent agree in form and structure, we leave them together as one 
species : the idea is one of most uncertain limit, and differs according to the views of each investigator. We know of many species of such stability that the earlier definition would seem to find its application in their case; but there are others again whose variability, indefiniteness, and indefinability have baffled all attempts at a more accurate limitation.

Species of this kind, consisting of a mere succession of forms, are now met with principally among the lower orders of animals; for instance, the Sponges consist almost entirely of such a succession of forms which seem to merge one into the other. The Mammalia, on the other hand, have in the course of the later geological periods settled down more quietly. The days when they were undoubtedly much more varied in form than now, and-like the lower orders-developed almost entirely into varieties, are passed. In the grand sifting process of thousands of years, numerous forms have dropped off and vanished, and the majority of the mammals of the present day might lead one to assume the stability of species.

The Mammals of to-day are sharply separated from the other vertebrates by a series of peculiarities in structure and development. Even the 
entirely changed mode of life of the Cetacea has not obscured, or only superficially obscured, these characteristics; for even the loss of the hind limbs is of subordinate importance compared with other significant peculiarities of the class, and moreover the loss of limbs is met with in other classes, and only shows to what extent the members of one group may diverge.

We will mention one characteristic in the skeleton which distinguishes the whole group of existing mammals from all other vertebrates : their lower jaw is directly attached to the skull, and not by means of the so-called 'quadrate bone.' This bone is met with from the fish to the bird, mostly as one of considerable size. Indications of it occur also among mammals. The substance, however, does not harden into bone and become the stalk of the lower jaw so easily recognised in the heads of birds, but is employed in forming one of the small bones of the ear. Further, in all of the Mammalia the chest and abdomen are separated by the diaphragm or midriff, a muscle which is exceedingly important for the mechanism of breathing. All the Mammalia have lacteal glands, and in the case of most mammals the fœtus is attached to the mother by a placenta, so that the 
nutrition and growth of the embryo do not require to be restricted to the comparatively small amount of yolk in the egg, but, as a rule, are derived directly from the blood of the mother.

We know of the 'quadrate bone'-which in the Mammalia has to a certain extent become displaced and slipped into the skull-from the Fishes; we see the beginnings of a diaphragm in the Amphibians; we find various kinds of slin-glands (to which the lacteal glands belong) in all of the Vertebrates; there is but one step from the distribution of the embryonal blood-vessels on the socalled allantois of reptiles and birds, up to the formation of the placenta: these characteristics of the Mammalia are all prepared or begun in the lower classes of animals. But the placenta came into existence only with the actual mammals, and is an acquisition towards a higher degree of progress. But although these characteristics are obviously inheritances-apart from the last-named arrangement, which was acquired only subsequently-still we are absolutely without any transition forms. It can only be said that the Mammalia must have developed from one stock, where the characteristics of the present Amphibians (for instance, the two occipital condyles at the back of the head) were 
allied with those of the present reptiles (e.g. the allantois). The earliest traces of mammals from the Triassic rocks lead us to suppose a long series of predecessors, and direct our thoughts to further unfathomed depths of the earth's development.

It is a different matter as regards those characteristics which the systematic zoologist makes use of, first of all in distinguishing the subdivisions of the group, the differences of the instruments of locomotion, more especially of the outer limbs, hands and feet, and also of the dentition. The function of propagation exercises universally a more subordinate influence upon the outward appearance and the general habitus of the animal, than does nutrition. The manner in which its food is acquired gives the organism its peculiar stamp, apart from the outer covering that acts as a protection against its enemies and climatic changes, and varies accordingly; and this stamp is expressed chiefly in the formation of the limbs and the dentition of the mammal. Cuvier's words, 'Give me a tooth, and from it I will build up the whole animal,' are to be taken seriously; they may be applied to almost every other individual part of the skeleton, and above all to the extremities of the limbs. The last portion of a finger will 
often suffice to determine the order. A whole toe will give a complete iclea of the mode of life and of the appearance of the primeval or still living animal. In order, therefore, to obtain an insight into the relationship and social position of a mammal form, we must first of all become acquainted with the foot of the vertebrate in its simplest accessible form, and then examine the different variations of the mammal foot under the supposition of direct transformation. This study was undertaken for the first time with perspicuity and success by Gegenbauer; and thus later modifi cations-which became specially necessary, owing to the primeval form of fin of the Australian Ceratodus-could perfectly well be explained in connection with Gegenbauer's conclusions both by himself and others.

The simplest form of hand and foot is met with in the four-fingered and five-toed Amphibians and various reptiles, e.g. the tortoises. Among the former the rudiments of a sixth, sometimes even of a seventh, toe are met with; but with the exception of these few indications, and the sixth finger of some amphibian-like primeval animals, there are no fossils relating to the early history of hand and foot, or their transformation from the fish's fin. 
On the other hand, the five-toed limb extends from the salamander to man. Together with this we

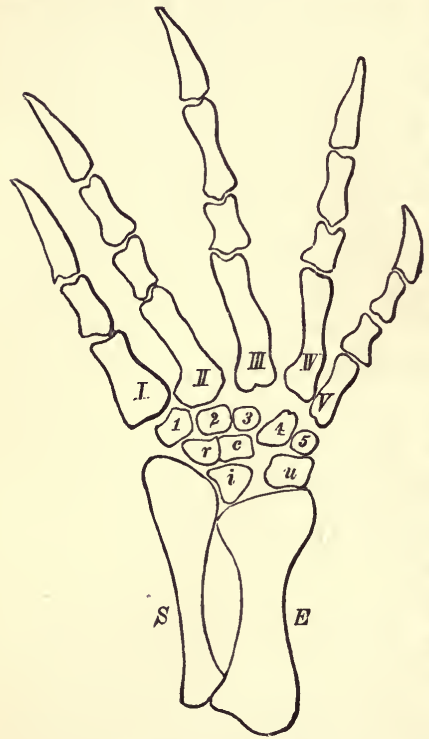

Fra. 1.-Right hand of a river tortoise. number of toes. Nat. size. various kinds of disappearances and coalescings till we reach the one-toed foot of the horse, and find, in fact, that a diminution in the number of fingers and toes takes place; never do we meet with a restoration after the decrease, and never with an addition to the have the most In order to illustrate the fundamental form, which we shall follow in its most varied and interesting changes, let us take the right hand of a fresh-water tortoise 
(Chelys fimbriata) in its connection with the lower arm (fig. 1). The two hollow bones of the forearm running parallel with each other are the radius (s) on the thumb-side, and the ulna (E). Then comes the root of the hand, consisting of nine separate little bones, to know which in detail is part and parcel of the A B C of the study of the Mammalia. The first, $r$ (radiale), lies close to the radius, a second, $u$ (ulnare), stands in the same relation to the ulna. Between the two is a connecting bit $i$ (intermedium), and in the curve formed by the three is the little central bone $c$ (centrale). The five other parts of the root of the hand, 1, 2, 3, 4, 5 (carpalia), belong each to one of the fingers, or rather to the five parts belonging to the middle hand (metacarpus), $\mathrm{I}, \mathrm{II}, \mathrm{III}, \mathrm{IV}, \mathrm{v}$, before the actual fingers. The foot with the shank shows precisely the same construction in number and position of the parts. ${ }^{1}$ There would be no need to give these names in the example chosen, had not the inquiry and naming proceeded from the anatomy

\begin{tabular}{cl}
\multicolumn{1}{c}{ Hand } & \multicolumn{1}{c}{ Foot } \\
Radius, Spoke & Tibia, Shinbone \\
Ulna, Ell & Perone, Fibula \\
Carpus, Root of the hand & Tarsus, Root of the foot \\
Metacarpus, Middle of & Metatarsus, Middle of the \\
the hand & Foot \\
Digits, Fingers & Toes.
\end{tabular}


of the human subject, where the contrast between hand and foot has advanced in a very striking manner. Our foot has remained an organ of support, our hand has become the organ for grasping. The fibula, whiclı corresponds to the ulna, is reduced, the tibia is the principal bone. The parts of the fore limb called the radiale and intermedium $(r, i)$ have generally coalesced into the springbone (astragalus), and the bone of the root of the foot attached to the fibula-the ulnare of the hand -becomes the heel-lone (calcaneus), and is distinguished by a strongly-developed continuation at the back; the centrale exists as the skiff-bone (naviculare). The first three bones of the middle foot are called the wedge-shaped bones $(1,2,3$, cuneiforme), the fourth and fifth bones of the middle foot have united and form the cube-bone (cuboideum).

In accordance with this scheme we shall find that the different mammals show a similar contrast in hand and foot-less in the fingers and toes than in the roots of the hand and foot. It will be our endeavour to bring this subject prominently forward in the course of our discussion.

It will also be shown that the dentition stands in as close a relation with the whole organisation 
as regards form as well as the mode of life. The study of the teeth has acquired an entirely new interest since Gegenbauer has proved that the teeth of sharks and rays are perfectly identical with the scale and plate formations of their outer skin; and thus in the case of these fishes we can at once see the transition of the outer body-skin into the mucous membrane of the mouth-cavity, also the direct transition of the hard formation of the skin into movable teeth. Oscar Hertwig has given us a supplement to and a further application of these fundamental inquiries. Accordingly, teeth have originated from skin developments having been used for the purpose of seizing and crushing food. In the higher vertebrates we are no longer reminded of this first origin of the teeth. We there find the adaptation to the new activity completed, the organ has long since come to stand in a closer relation to the skeleton as a whole. In the case of every mammal the tooth, in its development, can be traced to have proceeded from the membranous covering of the mouth. And while the capacious mouth and gullet of fishes has been able in almost every case to cover itself with teeth, the Amphibians and Reptiles show a reduction in the number of teeth and of the bony supports, and finally in the 
mammals we find only the actual jaw-bones furnished with teeth.

By this a concentration of the tooth-material has been accomplished, and connected with it we find that concentration of force by which the mammal more readily and surely overpowers its living prey, and prepares it for use in the intestines, by mastication. In the dentition of the mammal we have not a retrogression but an advance in the organisation, and a further diminution in two directions may be expected. What has taken place with numerous fishes has also happened in the case of some of the Mammalia : under certain conditions of nutrition teeth have become useless. and have disappeared; and, secondly, the fuller number of teeth of the geologically older species has given place to a dentition less numerous but more specialised in form and action, and therefore more advantageous. As an instance of the one direction, we may take the jaw of a Ruminant, which shows a want of the upper incisors; of the other direction the jaw of the Cat species.

In order to understand the manifold forms of teeth, we must have some knowledge of the development of the various substances that form the tooth, the origin of the hard bright enamel (ebur), of the 
tooth-bone (dentine), which constitutes the principal portion of the tooth, and of the somewhat softer cement (cementum), which serves in various ways as material for covering and filling. A general account will suffice for our purpose. The membranous covering of the mouth-cavity-like that of the outer skin-consists of two layers, the epithelium (the upper skin), formed of several layers of cells, and the membrane of the cutis (leather skin), consisting partly of cells and partly of fibres. The first sign of a tooth is a knotty protuberance of the cells of the epithelium rising into the cutis. Again, into this protuberance upwards there rises from the cutis a cone-shaped elevation, upon which there then appears the first formation in the shape of a cap; this is the enamel-germ or the enamelmembrane which produces the enamel. The other portion belonging to the cutis-i.e. the membranous tissue of cells which rises up into the epithelium and is termed the dentine-germ-becomes calcinated into tooth-bone. But, in addition, the membranous tissue of cells directly connected with the dentine-germ produces-in virious measures and extent-the fewer-celled and softer cement round about all the immediate surroundings of the tooth. ${ }^{1}$

' Baume, Odontologische Forschungen, I. Th.; published also 
The first indications of teeth are met with at a very early stage of the embryo in the gums that are still in the process of forming, and these beginnings of teeth are then gradually enclosed by the gums. In man and most of the other Mammalia during the first years of life we do not find the whole set of teeth of their later years, of their mature age, nor indeed any such teeth as are to serve them throughout life; there is at first a temporary set of teeth, the so-called milk tecth. These teeth are very like those that replace them subsequently, the permanent teeth, but are smaller and weaker. It was an extremely interesting and important discovery when Rütimeyer proved in detail that the milk teeth of many of the Mammalia show a greater agreement with their historical-i.e. their geological ancestors-than do the permanent teeth. As a rule, for instance, in man the first set of incisors, canine teeth, and front cheekteeth are replaced by a second set, and thus constitute the milk teeth. The teeth which replace the milk cheek-teeth are called premolars, and these

under the title of Versuch einer Entwickelungsgeschichte des Gebisses (Leipzig, 1882). This work may be recommended as an excellent one on the subject and full of suggestive thoughts, even though we may, at times, feel disposed to dispute some of the views put forward. 
are accompanied by the other back cheek-tceth, the molars. But apart from the fact that in several groups of mammals - the whales and armadilloesmilk teeth do not occur at all (Owen's Monophyodonta), there are among those which do show a change of teeth (Diphyodonta), so many deviations and exccptions to the rule that, as Baume has proved, the prevailing idea of cliange of teeth as a succession of two distinctly different sats, can scarcely hold good. The origin of the so-called milk teeth can be traced back to the fact that with the shortening of the facial portion of the skull, the place for the incoming of the tooth-germ naturally became smaller as well, and the germs, in place of lying side by side, came to lie one above the other. Hence those placed uppermost had to be used first, before the lower ones had developed and could uproot and finally expel their predecessors by pressure. The weakening of an individual milk tooth or of the whole set of milk teeth will, accordingly, in general be a question of time, and depend upon the delay in the development of their successors. The milk teeth are at a disadvantage, owing to the inevitably hostile position which their successors must sooner or later assume towards them; and they have to face a certain 
defeat, even though, in most cases, this takes place with the utmost slowness. Instances of the loss of milk teeth are met with among the Marsupials and seals. The whole phenomenon belongs to the .chapter of 'abbreviated development.' It was our intention here merely to point out this view of the subject, in order to make use, in what follows, of the designations given to different parts of the jaw, according to position and time, since Cuvier's and Owen's classical investigations. ${ }^{1}$

Let me here repeat that the specialisation of the dentition frequently runs parallel with a specialisation of the limbs. Thus, in comparison with its geological ancestors, the dentition of the horse is very specialised, and this is equally evident as regards its foot, the transformation of which, from a five-toed member-not specially suited either for running, grasping, or climbing-into a one-hoofed member, so admirably adapted for running, has

1 Example.-In man the milk teeth, the dentes decidui, consist of the cutting teeth (incisors), the canine or eye teeth, and the two front cheek-teeth. In addition to these there are the three back cheek-teeth that have no predecessors. The teeth of the full-grown man are indicated thus: $-i \frac{2}{2} c \frac{1}{3} p \frac{2}{2} m \frac{3}{3}$, i.e. on either side above and below two incisors, one canine, two premolars and three molars. Although Cuvier of course knew the dents de lait and the dents de remplacement, still Owen was the first rigorously to carry out the designation 
been accomplished step by step. Thus we very often, and justly, hear of generalised and specialised animal forms, which show their characteristic and contrasting peculiarities chiefly in those organs, the extremities and the dentition. These differences were perceived even by the earlier observers, and were compared with the embryonal conditions, with the development from the general state of the early indications through all the details of the ripening offspring. The significance of this point must be borne in mind when we term the geological and earlier forms as general and embryonal forms, and the later ones as the specialised forms.

\section{THE EXTENSTON OF PALÆONTOLOGICAL SCIENCE} SINCE CUVIER.

The fact that the theory of descent appears less prominent during the first half of our century, and is so frequently and justly connected with Cuvier's opposition to it, makes it necessary for us to allude to his position in regard to this great question. Cuvier's almost autodidactic manner of working and viewing things comprised, as is well known, the whole animal kingdom, with the exception of some groups of microscopic and other lower animals. But he was a specialist, above all things, in 
the osteology of the living and fossil Mammalia, and thus stands as the founder of palæontology and its comparative method. It was no small advantage to Cuvier that in his immediate neighbourhood were to be found deposits of the Paris Eocene, lime and gypsum, containing the remains of the earliest forms of mammals. It is astonishing what he accomplished in his 'Recherches sur les ossements fossiles,' where his principle of correlation is so brilliantly proved. The imperfectly observed geological facts and the imperfect discoveries led him, nevertheless, to the conviction that from time to time sudden convulsions, catastrophes, had transformed the earth's crust, and destroyed the living creatures, either completely or with the exception of a small remainder; he further thought that those which survived were obliged often to seek a new home far from their original abodes. The question as to whence came the new inhabitants of the succeeding peaceful period, after each of the great murderous catastrophes, Cuvier settles in a somewhat cursory manner. ' I do not maintain that a new creation was required to produce the present species; I say only that they did not live in the same regions, and that they must have come from elsewhere." This

' The quotation is from Cuvier's book referred to above-his Recherches sur les ossements fossiles (1821). 
vagueness remains in spite of his admitting the fact that at one time life began on earth. For, according to Cuvier, the varieties that are dependent upon time, climate and domestication, remain within a given boundary, while the species show certain clraracteristics which resist every kind of influence, and are as little affected by time as by climate and domestication. Hence lie directly opposes Lamarck's theory of descent, i.e. that the fossil forms are the ancestors of those of the present day. His main argument is the want of fossil intermediate forms, 'for,' he adds, 'if the species had changed gradually, we should find traces of these gradual transformations; we should find some transition-forms between the Palæotherium and the species of the present day, and these have meanwhile not been met with.'

Cuvier therefore did not, as many have supposed, hold fast to the belief in a supernatural creation from any preconceived opinion; he was more disposed to leave the problem as to the origin of animal forms in uncertainty, as facts did not seem to admit, meanwhile, of any safe conclusion. It is therefore very intelligible that one of Cuvier's last and still living pupils-the eminent palæontologist and zoologist, Richard Owen-should straightway have accepted the theory of natural descent (under 
a special Divine direction, it is true), after having satisfied himself personally as to the existence of intermediate forms between the Palæotherium and Horse. Cuvier, his teacher, had, however, not the desired knowledge of these forms.'

Since Cuvier's day, i.e. within the last fifty years, and more especially within the last twenty and twenty-five years, our palæontological knowledge as a whole, and particularly as regards the Mammalia, has been so immensely extended, that

1 Owen, in his Anatomy of Vertebrates, General Conclusions, says: "With this additional knowledge, the question whether actual races may not be modifications of those ancient races which are exemplified by fossil remains, presents itself under very different conditions from those under which it passed before the minds of Cuvier and the Academicians of 1830. If the alternative-species by miracle or by law-be applied to palæotherium, paloplotherium, hipparion, equus, I accept the latter without misgiving, and recognise such law as continuously operative throughout tertiary time.' By law (natural law or secondary cause), however, we understand nothing but a regular and recurring phenomenon where the acting cause is not touched upon. This, according to Owen, is the Will of the Creator; for he adds : 'I believe the horse to have been predestined and prepared for man.' Hence natural law is in this case not opposed to miracle, but denotes merely the manifestation of an Almighty Will working towards a definite purpose. The same view is expressed also by Gaudry in his Considerations sur les Mammiferes (Paris, 1877), where he says: 'A mesure que j'ai cherché à comprendre l'histoire des étres fossiles, il m'a paru de plus en plus probable que l'Auteur du monde n'a pas créé isolément les espèces successives des âges géologiques, mais qu'il les a tirées les unes des sutres.' 
had Cuvier been able to make use of our present material his conclusions would have been entirely different. I have no doubt also, that our great German teacher and master, Johannes Müller, would likewise have set aside his mystic ideas of the origin of animals and of creation, in view of the rising sun of Darwinism.

We have, of course, no intention here of giving an account of the gradual extension of palæontological science itself. Our object is rather to explain how palæontology and zoology inter-penetrate and correlate with each other. And it is self-evident that in doing this the newer period stands prominently forward, since the revival of the theory of transformations. One of the conditions of this theory of development is the overthrow of Cuvier's theory of catastrophes, and indeed it was finally overthrown for all time to come when Lyell, in 1832, published his famous 'Principles of Geology.' Lyell there proved that the earth's crust does not condense and change suddenly, and that the geological periods of peaceful life have not been separated from each other by general convulsions extending over whole continents, but that the continuity of lands and seas has never been entirely interrupted, even though they have 
often been disturbed by mighty upheavings and sinkings.

The connection of the oceans must, in fact, never be altered to account for the migration and distribution of the animals. For instance, it is now an established fact-from deep-sea investigations-that, since the chalk period at least the bottom of the sea has experienced only unimportant changes, changes that are almost imperceptible in their slowness and their effect upon the animal world; its petrography has, in fact, undergone such small changes that it may be said that we are still in the chalk period, and that the formation of ehalk is still proceeding. And further, we may assume the process to have been the same with all the other and earlier geological periods. This theory may, moreover, with certain limitations, be applied to the main land. Larger accumulations of land of some consistency are probably first perceived in the Coal formation, and there can be no question of continents, in our present sense of the word, till the Jura and Chalk periods. At all events, however, temporary connections of large Jura islands-probably also the accumulations of land belonging to the Trias-must have also existed. For, not merely have we to date the individual 
origin of the Mammalia as far back as the Trias at least, and probably even further back, but we have to assume that the class was one of pretty considerable extent. And, with the beginning of the Tertiary period we already stand on the threshold of the presient. Whether or not there was ever a Sahara ocean, ${ }^{1}$ or Europe ever half under water or encrusted with ice, or England torn away from the mainland by an inroad of the sea, or again whether or not North Africa could exchange land animals with South Europe by means of two isthmuses-these and other incidents on a grand scale would in no way affect the truth of an uninterrupted development. There remain, it is true, a series of animo-geographical problems unsolved, problems which are geological as well; for instance, the case of Madagascar, the distribution of wingless birds, the Edentata, the isolated cases of the Australian fauna, \&c. These difficulties must simply be accepted as such. They do not hinder our recognising the natural connection of the living world which is forced upon us by other facts, and they do not oppose our present conception of the universe, which is already a very old

1. This conjecture may be said to be altogether refuted by the latest investigations. 
one, although in its modern form it has the new name of monism.

However, our intention was to speak of some of the work that had been accomplished in our day in the domain of palæontology, which is intimately connected with that of zoology. In the first place, then, we must mention Rütimeyer's works, and can, in fact, mention only some of his most eminent and comprehensive publications. When Darwin's grand work on the origin of species, the derivation of domestic animals, and the influence of domestication on the transformation of the original species first appeared, and was being universally talked about, as much interest was simultaneously aroused by the discoveries of the Swiss lake-dwellings. They gave the greatest impetus to the study of modern anthropology, and also called forth Rütimeyer's work on the fauna of the lake-dwellings, ${ }^{1}$ a masterly performance, and one precisely such as was required by the new theory with its very imperfect evidence. The manner in which he explains the prehistoric discoveries by the races of the present day in connection with the diluvial forms, pointing out certain primary forms as the ancestors

1 Rütimejer, Die Fauna der Pfahlbauten in der Schweiz. Basel, 1861. 
of our domestic animals, more especially of the oxen, the accurateness of his account of the actual facts, the subtlety and carefulness of his combinations-everything, in fact, makes Rütimeyer's work appear as if it had been ordered for a given purpose. Soon after this, in 1863, he published a work on fossil horses. ${ }^{1}$ This work, which was undertaken by way of explaining the relation of the genus Horse to its primeval ancestors, is, in reality, a treatise on comparative odontography, or the study of the teeth of the whole class of hoofedanimals. The precision with which he points out the significance of the characters of the teeth, the relation of the milk teeth to the permanent teeth, the transitions in the geological successions of the genera and species, and traces them back to universal principles and laws, can be compared only to the sagacity of a Cuvier. I must confess that I have never felt my interest so thoroughly aroused in a subject, wholly distinct from my own special study, as it has been by these two works of the Basle zoologist.

Unfortunately, our greatest authority on domesticated animals, Herman von Nathusius, who died a few years since, and was always vehemently

- Beiträge zur Kenntniss der fossilen Pferde 
opposed to the doctrine of descent, has left us a fuller report only of the Pig family as regards what he had to say in opposition to Rütimeyer. He never published a full account of his valuable comparative investigations respecting the domestic ox. But Rütimeyer has published a later and admirable paper on this very subject, his object being to show the connection between the living. oxen and all those belonging to the Diluvial and Tertiary periods. ${ }^{1}$ We shall presently have to quote from Rütimeyer, and may here supplement our remarks on his works by mentioning his treatise on the genus Deer, ${ }^{2}$ which is carried out in the same spirit. All of these contributions are masterpieces as regards method, for although starting from a limited horizon, they extend over the whole earth, according to space and time, and the claims of a practical speculation are set forward in opposition to a system of philosophy, according to which our investigations in natural science would not have advanced beyond the scheme of Plato's Ideas and Aristotle's Entelechiæ.

Rütimeyer's investigations are not confined

' Rütimeyer, 'Versuch einer natürlichen Geschichte des Rindes' in the Reports of the Swiss Falcontological Society, xxii. 1877.

2 Die natirliche Geschichte der Hirsche l.c. 1880. 
merely to the objects found in the lake-dwellings, the pea-ore and molasse strata of his native country, for in his monographs, referred to above, he generally makes use of all the available material in the European collections. ${ }^{1}$ We would mention together with Rütimeyer two French naturalists, Albert Gaudry and Filhol, both of whom have, as it were, been forced by their important discoveries to come forward with imposing proofs for the theory of descent. It is more than twenty years since the publication of Gandry's work on the fossils of Pikermi. ${ }^{2}$ Pikermi is the name of a hamlet on the road between Athens and Marathon, near which, in the deposits of a mountain stream which at one time rushed along there, are found an incredible accumulation of vertebrates, more especially of mammals belonging to the upper Tertiary period. In summing up the results of his investigations Gaudry gives his readers a picture of a tertiary landscape and its forms of life, which we cannot resist quoting word for word, as an example of how our imagination should, in all cases, weave single

1 We must also mention here his extremely instructive paper on Die Herkunft unserer Thierwelt (1867), although for us nowadays it certainly presents considerable gaps.

2 Animaux fossiles et géologie de l'Attique (1862). 
dry observations into a picture full of colour and life.

- The province of Attica has undergone great changes since the far off times when these animals existed, the remains of which are accumulated round about Pikermi. At the present day it is a strip of hilly country twenty miles (lieues) long and ten broad. That this locality should have been considered the abode of the gods, and should have witnessed the glory of the most eminent minds of antiquity, is quite intelligible. But the numerous and gigantic four-footed creatures of primeval times required a wider area, and they are, moreover, too like the present species from the interior of Africa for it to be possible that they could have lived in Greece under the same conditions as exist at present. Without doubt at one time Europe was connected with Asia by uninterrupted plains that are now covered by sea. We must also imagine these plains to have been provided with a more luxurious vegetation. The marble hills of Pentelicus, Hymettus, and Laurium produce now only small plants upon which the bees find their food. At one time valleys with a rich vegetation must have run along by the side of those barren hills, and grassy meadows 
alternated with splendid forests. For an abundance of animal life demands a corresponding fulness of vegetation.

- Those landscapes were enlivened by the most varied forms of mammals, by the two-horned rhinoceros and the gigantic boar; also by monkeys leaping from rock to rock; carnivora-from the families of the civet-cats, martens and cats-all on the hunt for prey ; the caves of the Pentelicon hills were inhabited by hyænas. In the same way as quaggas and zebras now inhabit Africa in enormous numbers, immense herds of Hipparion must have there careered across the plains. Not less fleet in their movements, and of an even lighter build, were the antelopes, also in great numbers. Every troup of a distinct species would be distinguished by the form of their horns: those of the Palæoreas had a spiral twist like those of the eland of the Cape; the horns of the Antidorcas were curved in the form of a lyre; in the Palæoryx they were long and bent. The horns of the antelopes resembled those of the gazelles, those of the Tragoceras were placed like those of goats. Palæotragus was distinguished by a slighter build and a narrower skull, with horns situated immediately above the eyes. But Helladotherium and another species somewhat akin to 
the giraffe towered above all of the Ruminants. And Ancylotherium also-one of the Edentatawas a creature of considerable size with bent toes. The most gigantic of all the animals, however, was the Dinotherium. What a magnificent sight it must have been to see it marching about, accompanied by two species of mastodon! In those plains was heard the roaring of the frightful Machairodus with its sabre-shaped canine teeth; and many other species associated with those named above. Their cries were intermingled with the songs of birds, and in the concert raised by all these creatures the voice of man alone was wanting.

' Nowhere does the earth now present a similar scene, as we may be convinced by a glance at our present fauna. In the virgin primeval forests of America, where plant life is met with in the full majesty of development, we might expect to find an equally full development of animal life. But the four-footed animals are less powerfully developed there than in the Old World, and are even less so in Australia. In Europe and Central Asia they have decreased in numbers by having been hemmed in between the civilisation of the temperate zones and the ice of the north. The largest mammals of the 
present day are found in India and more particularly in Africa. Delegorgue, in his account of his explorations in Africa, describes a lake which was inhabited by a hundred hippopotamuses, and within a space of 3,000 (?) he found more than six hundred elephants. On one occasion he met with from three to four hundred hyæna-dogs, and again with troups of from four to five hundred quaggas. Livingstone relates that he frequently saw herds of more than four thousand antelopes passing. One of his descriptions of this wild part of the earth runs somewhat thus: "hundreds of zebras and buffaloes were seen crossing the plains; numbers of elephants were seen feeding, and their trunks alone showed any signs of movement. I should have liked to have photographed the picture, for scenes like this will ranish when firearms are brought into use, and will then be forgotten. It is perfectly marvellous what immense numbers of animals are to be seen crossing the country. I could fancy myself transported back to the days when the giant sloth roamed about the primeval forests.",

Gaudry goes on to say: 'However splendid such pictures may be, old Greece could offer even grander scenes. In fact, while the whole of Africa is the home of but one species of elephant, Pikermi 
had two different forms of Mastodon and the Dinotherium, the principal giants among the four-footed animals. Africa has only one kind of giraffe. Attica possessed a giraffe surpassing all the living antelopes in size, and the Helladotherium, an animal with short legs, it is true, but larger than the giraffes in bulk. Among the living Ruminants there are none that can be compared with the Helladotherium; the camel is much inferior in size. Africa has but one species of rhinoceros, distinguished by its rudimentary incisors, whereas in Pikermi are found a rhinoceros of the African type, another of the Asiatic species, and in the Acerotherium, probably also a genus related to the rhinoceros. The huge thickskinned animal, the Chalicotherium, which is said to have been discovered in Greece, is unequalled by any in our day. The skull of the Erymanthian boar exceeds that of the wild boar by one third; and among the latter are some larger than the wart-hog and the masked boar of South Africa. The earth-hog (Orycteropus), the largest of the Edentata in the Old World, is a miserable creature compared with the Ancylotherium of Attica. Lastly, the lion is surpassed by one of the Carnivora of Attica, the panther by another. 
' It is unjustifiable to dispute the existence in the Greece of that period, of aquatic animals-such as the river-horse, sea-cow, crocodile, which are of frequent occurrence in Africa-simply because their remains have not yet been discovered there. For the stratum of Pikermi is essentially the result of a mere landslip, inasmuch as the layer of mud which surrounded the bones was washed down from the heights, where there could be no waters inhabited by those gigantic animals. As little does the absence of anthropomorphous apes prove that they never existed among the fauna of Southern Europe ; the gorilla, for instance, inhabits silent forests where scarcely any other four-footed animals are met with.

'In Attica, therefore, more species of large mammals are met with than in any other part of the present world. I have no means of determining the number of the individuals of the different species, but there is no reason to suppose that this number was smaller than those of the present species. Notwithstanding the great number of animals observed in different parts of Africa, nowhere could a greater quantity of individuals be found, on a space of the same size, as where I made my excavations. This space-only a small portion 
of the entire stratum containing the bones-was 300 paces in length and sixty in breadth. The quantity of bones all mixed up together, which a fortunate excavation at times brought to light, presented a remarkable sight. When I remind my readers of the fact that I brought back with me 1,900 pieces of Hipparion, more than 700 pieces of Rhinoceros, 500 of Tragoceras, \&c., it will readily be understood that I was obliged to leave behind me on my last journey the remains of the commoner species of animals, to collect which would only have delayed my examination of the rarer pieces.'

Gaudry was able in every direction to determine the position of the different species which had lived together on the ancient ground of Pikermi, midway between the Miocene and Pliocene deposits. One main result of his comparisons was the proof that almost all belonged to that sort of intermediate form of which Cuvier had so greatly felt the want. 'If,' says Gaudry, 'with all the eminent palæontologists of to-day, we add all the other known fossils and living species to those found at Pikermi, we feel convinced that the gaps would disappear in the same proportion as new discoveries are made.' Thus he found himself obliged 
to set up pedigrees-those systems of the probable geological connection-which are ridiculed only by persons who lack the preliminary knowledge for forming a judgment.

Yet Gaudry, like other of his countrymen who maintain the incontestability of the theory of descent, is not a disciple of Darwinism-i.e. of finding a proof for the theory of descent in the hypothesis of natural selection in the struggle for existence. He, like $\mathrm{R}$. Owen, remains within the realm of miracles, and supposes a personal Creator to have directed the countless forms of development towards definite and pre-ordained purposes. With this conception of things-which at a certain point sets sober inquiry aside-the assumption of accident has to be met, and accident, in the opinion of Darwin's opponents, is raised to the rank of principle. We do not, of course, intend here to enter into any further polemies while speaking of the great achievements of a man who admits his belief in such things, but still we must again remark that even that which is called accident is not beyond the pale of legitimate occurrence. We leave it to the reader to decide whether it appears more reasonable to assume that the absolute intelligence of a personal Creator should 
break off, for no result, millions of commenced series, than that so-called accident should prevail within the absolute laws of Nature.

Gaudry, in a very admirable work,' has given an account of the main substance and the results of all the palæontologico-zoological inquiries.

Of even greater importance to the question of transition- and intermediate forms are the works of Filhol, a young compatriot of Gaudry's. We refer to his papers on the 'Phosphorites of Quercy,' ${ }^{2}$ which appeared in 1876 and 1877 ; also his article on the 'Fossil Mammals of St. Gérard le Puy,' and his comprehensive treatise on the 'Fossil Mammals of Ronzon,' which appeared in $\mathbf{1 8 8 2 .}$

Phosphorite belongs to the Upper Eocene formation of South-western France, deposits of noncrystallised phosphated lime. It is found in cracks and hollows which have been filled up from above. The deposit, Filhol says, was no doubt the result of warm springs, which from time to time caused extensive inundations, and drowned or suffocated

'Gaudry, Les enchainements du monde animal dans les temps géologiques. Mammifères tcrtiaires (1878).

2 Filhol, Recherches sur les Phosphorites du Quercy. Études sur les fossiles qu'on a rencontrés, et spécialement les mammiferes. Annales des sciences géologiques, vii., viii.; Mammiféres fossiles de St.-Gerard le Puy, Ibid. x.; Mammifères de Ronzon, xii. 
all living things. Pachyderms, Ruminants, Rodents, Carnivora, all met with a rapid death together; frequently the animals were buried while their skeletons were still intact. The deposits at Quercy have furnished the most important facts that have yet been discovered for the study of the fossil Mammalia in Europe. They are as important as the more recent discoveries in America. The characteristics of the animals met with in France are perhaps less remarkable and conclusive; they are not striking at first sight, and it is only by a very careful study of them that we perceive their true value. The transitions are extremely delicate; we have there to do with shades of difference, not with differences clearly expressed. Hence the period of Phosphorite witnessed great changes, and the types now existing were giving signs of appearing. The influence of natural circumstances, which we are not able to define more narrowly, but the traces of which have been discovered, changed the species in various ways and gave rise to varieties which became fixed, and thus passed over into a new species. Thus far Filhol.

Of the incredible wealth of forms among the higher classes of animals in the South-western Europe of those days, we have proofs in the fact 
that Filhol distinguishes, among the beasts of prey alone, some forty-two species. In this abundance of forms, in the occurrence of these most varied kinds of flesh- and plant-eaters-which cannot be imagined without a struggle for existence-we can, as it were, quietly watch the gradual, very gradual, process of transformation, the origin of species. The inestimable value of Filhol's researches, like those of Gaudry, is that they could extend over thousands of objects. His investigations are peculiarly valuable, owing to the fact that three of the most important deposits of France and of Europe (Quercy, Ronzon, and Gérard le Puy-the rich outcome of which he was able to work upon), belong to three closely connected geological horizons. And Filhol has compared-in a way that scarcely any other palæontologist has done-the changes and advances of the animal world from one of these periods to the other, in their specialisations, and has placed these in the foreground as the general result of his most careful and detailed accounts.

Another investigator of great enterprise, Woldemar Kowalewsky, ${ }^{1}$ has unfortunately died at

'W. Kowalewsky, Sur l'Anchitherium Aurelianense Cuv. (Acad. de St. Petersbourg, 1873) : Osteology of the Hyopotamida (Philoso. Transact. 1873); Versuch einer natïlichen Classifica- 
too early an age. His works also belong to the seventh decade and treat more especially of the Hoofed animals; they contain the most important supplements to Rütimeyer's works, for he, at times, takes up entirely new standpoints for determining the connection between the present and the remote periods. He has not done so much in bringing to light new forms, as in carefully comparing those long since known. Certain opinions about primary and fundamental forms, such as Palæotherium, Anoplotherium, Dichobune, and others, which had become traditional since Cuvier's day, he has finally corrected, and has in a masterly way clearly defined the essential differences between odd-hoofed and pair-hoofed animals; he has also endeavoured to explain the disappearances of forms, and the continuance and transformation of others by very careful examinations, more particularly of the hand and foot. Accordingly he has set up pedigrees which do not indeed differ in many points from the results given by Rütimeyer, but they are certainly proofs of the extremely suggestive and ingenious manner in which he contemplates the primeval world, in its continuity with

tion der fossilen Hufthiere. Monographie der Gattung Anthracotherium (Palæontographica, 1876). 
the earth as it is nowadays. Specially ingenious I consider his distinction between the adaptive and inadaptive reduction of the limbs, which we shall have to consider more in detail when discussing this point.

Having now pointed out the direction in which these investigators have worked, and their conception of things in general as distinguished from those of their numerous fellow-workers in the domain of the higher animals, and having further referred to the stimulus which their studies have given to the theory of descent, I may now confine myself to mentioning them only in so far as they concern the palæontology of the Old World.

Within the last fifteen years a series of surprising discoveries have been made concerning the palæontology of America; these discoveries have almost subverted, at all events completely modified, the opinions that had hitherto prevailed as to the distribution and derivation of animals, in so far as they concern the exchange and succession between the Old and New World. We have a summary of the zoo-geographical inquiries into those primary periods in a work of Rütimeyer's, ${ }^{1}$ not very comprehensive but rich in substance. He there says:

' Ucber die Herkunft unserer Thierwelt, 1863. 
'The whole surface of the earth of the Old World during the Tertiary, as far as is known, formed one single natural domain for the mammal fauna; it was more extensive, but the same as that which had previously sustained the animal world of the Eocene formation.' From here the primeval Mammalia proceeded not only southward into Africa, but had also, as it seems, found their way into the New World by an isthmus of land connecting Europe with North America; partly also-as is shown by the fossil elephants of Japan-from Northern Asia in the direction of the Aleutian Islands. The fauna of North America, the principal portion of which, to all appearances, was not indigenous to the country; then wandered southwards, following the course of the principal mountain ranges, where they met members of a foreign fauna coming northwards from the south, and which in the more recent periods even crossed the isthmus. At all events, the Mammalian fauna of North America appeared as inferior and dependent upon that of the East, and immigration from the New to the Old World seems a doubtful matter and even a question of secondary importance. As Rütimeyer goes on to say: "The Miocene fauna of Nebraska is the offspring of the Eocene formation of the Old World. The 
Pliocene fauna of Niobrara, which lie buried in the same ground as Nebraska, but in a later stratum of sandstone, prove this in an even greater measure. Elephants, tapirs, and various species of horses differ scarcely at all from those of the Old World: the boars, to judge from their dentition, are descendants of the Palæochoerus, \&c., of the European miocene deposits.'

Even when these remarks of Rütimeyer were written, we possessed an eminent work on the Tertiary fauna of North America by Leidy. ${ }^{1}$ But since those days the discoveries made have been so extraordinarily numerous, and the immense variety of animals that lived there has proved so much more varied than the European fauna, that American investigators, headed by Cope and Marsh, have come to the conclusion that America was not colonised with Mammalia from the Old World, but that the former gave Europe some of its original superfluity; even the theory accepted by Rütimeyer, that the Tertiary strata of America were in part somewhat more recent than ours, is proved to have been the reverse. Marsh writes in 1877: "These natural divisions (of the American Tertiary) are not the exact

3 The Ancient Fauna of Nebraska, 1853. 
equivalents of the Eocene, Miocene, and Pliocene of Europe, although usually so considered and known by the same names; but, in general, the fauna of each appears to be older than that of its corresponding representative in the other hemisphere-an important fact not hitherto recognised.'

The area of the life which extended throughout the Tertiary period, and showed, in part, a closer connection than can be proved in the case of Europe, lies along both sides of the Rocky Mountains. To the west-more especially in the region of the Green River-it extends up to the height of the Great Salt Lake. It is more extensive still to the east, where the so-called Bad Lands (Mauvaises terres) in the state of Dakota are the most productive centre.

Leidy's work on the ancient fauna of Nebraska, which marks an epoch in the palæontology of the United States, has been completed by his investigations on the extinct vertebrates of the Western Territories. ${ }^{1}$ Since then not a year has passed without Cope, and Marsh especially, bringing to light new branches of this rich tree of knowledge. ${ }^{2}$

1 Leidy, 'Contributions to the Extinct Vertebrate Fauna of the Western Territories,' United States Geographical Society. Washington, 1873.

2 We do not yet possess any detailed account of this incom 
No less magnificent than these discoveries relating to the Tertiary mammals, are the disclosures concerning the Diluvial mammals that have been made since Cuvier's day. But it is chiefly South America that attracts our attention as regards these. Most remarkable of all are the discoveries of fauna from the Upper Tertiary and Diluvial, which were found mainly in the caves of the Brazilian province of Minas Geraes, and also in the deposits of Argentinium and Bolivia. Fossil remains from the Eocene are very rare, and of these remains those of the Palæotherium and Anoplotherium from Europe, point to connections of which geology has as yet been unable to give any explanation. Testimonies from the Miocene are altogether wanting. On the other hand, the later deposits show an extremely peculiar character, owing to numerous, and in part colossal forms of Edentata. Whether some of their most wonderful representatives, such as the giant sloth, were

parably valuable material. We have to refer to the short papers contributed to the American Naturalist, Stillman's Journal, also to the Proceedings of the Amer. Philos. Society. Marsh gives a survey in the paper on the Introduction and Succession of Vertebrate Life in America, 1877; also Cope's article, 'Mammalia Bunotheria,' in the Report upon United States Geographical Survey West of the One Hundredth Meridian, vol. iv. Palreontology, 1877. . 
driven northwards when the isthmus was restored, or whether, according to Marsh, the north was the original home of this animal likewise, does not seem to be a settled point. This Megatherium was already known to Cuvier. But most of the Edentata were not discovered till later, and Lund's discoveries ${ }^{1}$ in the cave-deposits of Brazil may be said to mark an epoch; in more recent times, Burmeister, ${ }^{2}$ a veteran in zoological research, has in a masterly way described the gigantic Argentine armadilloes and other animals.

A comparison of our present fauna, both of Europe and Asia-as well as of the two Americas -with that of the Diluvial period in these same regions, will show the present at a very great disadvantage; Wallace might well say that we live in a world which is zoologically very impoverished, and from which the hugest, wildest, and strangest forms have now disappeared. This disappearance of numerous races of animals, in the eastern and western hemispheres, almost makes the impression as if it had been the result of some such catastrophe as we have declared ourselves

' Lund, Brasiliens Dyrverden. Copenhagen, 1841-45.

${ }^{2}$ Burmeister, Annales del Museo priblico de Buenos Aires, 1864, p. 9. 
unable to admit. At all events, the period within which the European mammoths and their associates, the American mastodons, the giant sloths and giant armadilloes, rapidly died out, must have been very short in a geological sense of the word. But there was no general destruction or dying out, only a portion of the species became altogether extinct, e.g. the horses of America: one portion found means of differentiating, to adapt themselves to a new locality, or returned at a later period to their old home when the hindrances to their existence no longer prevailed. Among those inhabitants of the earth able to cope with the existing difficulties was Man, who may, with positive certainty, be seen struggling through the whole Diluvial period. All these signs of life succumbed, or had partially to withdraw, before the great ice formations which took place during the subdivisions of the Diluvial age. The cloak of iceevidently of many thousand years' duration-which still persistently envelops Greenland, while Norway and Sweden, in the same latitudes, enjoy the most splendid green summers, gives us a vivid picture as to how we have to conceive the enormous glacial formations in Europe and America during the Diluvial period. 
An extremely interesting question in palæontology, and one which is at present engaging the attention of geologists, is, whether North Germany was under water or encrusted with ice during one division of the Diluvial. Nehring ${ }^{1}$ has come forward in support of the latter hypothesis. He adduces weighty arguments against the drift theory, i.e. against the generally accepted supposition that, during one subdivision of the Diluvial, North Germany was under water, and that the Scandinavian blocks of granite scattered over the land were deposited by icebergs from the north. His chief argument against this theory is the utter want of any remains of marine animals, the want of every trace of shore fauna. Some few discoveries in East and West Prussia, in Holstein and about Hamburg, which have been examined by Berendt and Jentzsch, 'prove only,' says Nehring, 'that certain limited portions of North Germany were, during the ice period, covered by the sea permanently, or perhaps only for a time.' For, he adds, it was not sea but glaciers which covered the lowlying plains of Germany, as far as the Hartz and the other mountain ranges to the south. Where

' Nehring, 'Faunistische Beweise für die ehemalige Vergletscherung von Norddeutschland,' Kosmos, vii. 1883. 
the glaciers themselves lay there are absolutely no remains of animals, but remains are found in those localities where the edges of the former glaciers must have been situated. And all of these remains belong to an Arctic Alpine fauna, such as now live round about the North Pole-the reindeer, musk ox, arctic hare, lemming, arctic fox, arctic hen, arctic owl. The occurrence of all these animals is carefully pointed out by Nehring, for instance, at Tiede in Brunswick, and at Westeregeln. The nature of the bones, and the discovery of young specimens by the side of the older animals, shows that the conclusion must be that the animals lived there. It is still uncertain whether there was only one, or two, or even several ice periods. The Glacial period with its fauna was followed by one with an improved climate, which, however, did not as yet permit the growth of forests. A new fauna appears corresponding with that of the steppes of South-western Siberia-jerboa, suslik, lagomys, saiga-antelopes. Gaudry, too, has shown that the latter were also very widely distributed in France. If Northern Europe had only one Glacial age, then the period of the steppe fauna marks the retreat of the glaciers in the very different configuration of the land. If, however, there were two Glacial periods-as seems very probable at least in the case 
of Switzerland-then those periods during which the steppe fauna might have dispersed must have been the intermediate epochs. However, we still require much enlightenment on this point, and much also remains to be explained as regards the causes of all these ice formations.

It is not known how far back Man extends into the Tertiary period. In the central and northern latitudes of the Old World as well as of America he could, of course, not gather into communities, or rise above his origin, till the Glacial period (as may be assumed) gave way to incalculably long ages of assured order in the later geological period. And Man's distribution over the earth is accompanied by a diminution of the animals.

THE STRATA OF THE TERTIARY FORIATION.

Air-breathing animals are met with first in the Coal formation. Thereupon we have in succession the Dyas formation (in Germany, Kupferschiefer and Rothliegendes), the Trias (bunter Sandstein, Muschelkalk, Keuper), the Jura with its numerous divisions, and the Chalk. We possess a few fossil remains of Mammalia even from the Trias and Jura formations. Nothing is preserved in the Chalk. On the other hand, the subdivisions of the Tertiary are unusually rich in fossil remains of 
mammals. By way of pointing out the position and succession of the formations, we will here add a tabular view of the more important strata ; first those of the Old World, where Central Europe is, of course, the part that has been longest and best known, and then a comparison of the divisions of the Tertiary of North America. At the same time the names of the more important species are given by the side of the different strata in which they are found. All that lies above the Tertiary formations is considered as Diluvium, the lowest strata of which are frequently also called Quartary or Quarternary. It need scarcely be stated that there is no sharp boundary between the uppermost Tertiary strata and the lower Diluvial, and that the separation of the upper Diluvial from the later Alluvium is equally indefinite. Owing to this difficulty in distinguishing the different formations, most palæontologists prefer speaking merely of a lower or an upper stratum of the Tertiary, in place of subdividing it into Lower, Middle, and Upper Tertiary, Miocene or Pliocene. The following arrangement is partly taken from a tabular view given by Gaudry $;^{1}$ in the case of America we have followed Marsh.

1 Gaudry, Considerations sur les Mammifères qui ont vécu en Europe da la fin de l'époque miocène. Paris, 1873. 


\section{A. TERTIARY FORMATIONS OF THE OLD WORLD.}

Pliocene.

19. Perrier. Crag of Norwich. Val d'Arno.-Numerous deer. Antelopes rare. Elephants. Mastodon.

18. Marl of Montpellier. Lignite of Casino. -Both deer and antelopes. Hyaenarctos.

\section{VIENNA BASIN II.}

UpPer Miocene.

17. Pikermi. Baltavar. Mont-Léberon. - Helladotherium. Ictitherium. Hyæna.

16. Siwalik Fills.

15. Eppelsheim. Oeningen.-Hipparion. Sus. Doreatherium. Tapir. Dinotherium. Simocyon.

\section{MiddLe Miocene.}

14. Sansan. Georgsmünde and Günzberg. Eibiswald.-Antelopes. Mastodon.

\section{VIENNA BASIN I.}

13. Limestone of Montabuzard. Sand of Orleans. Lignite of Monte-Bamboli.-Palæochoerus. Cainotherium. Dremotherium. Dicroceras. Dinotherium. Mastodon.

\section{LoWer Miocene.}

12. St. Gerard le Puy (on the Allier).-Anchitherium. Dremotherium.

11. Sand of Fontainebleau. Lignite of Cadicona.-Rhinoceros.

10. Lime rocks of Ronzon.-Gelocus.

\section{UPPER EOCENE.}

9. Phosphorite of Quercy.

8. Lignite of Debruge.

7. Paris Gypsum. Hampshire.

6. Sands of Beauchamp. 
5. Paris Coarse Limestone.-Characteristic are entelodon, hyænodon, pterodon, dichobune, palæotherium, anoplotherium, siphodon. In the upper strata are found also among others anthracotherium, cainotherium.

\section{Middle Eocene.}

4. Mauremont. Pea-ore. Egerkingen.

Lower Eocene.

3. London clay.-Hyracotherium. Pliolophus.

2. Lignite of Soissonnais.-Coryphodon. Palæonictis.

1. Sandstone of La Fere.-Arctocyon. 
STRATA OF THE TERTIARY FORMATION.

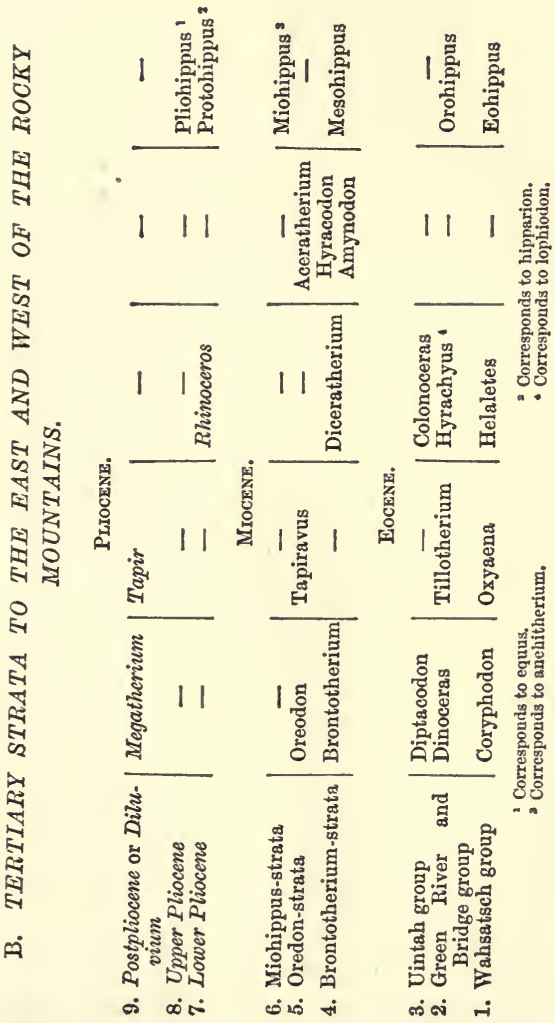




\section{II.}

SPECIAL COMPARISON OF THE LIVING MAMMALIA AND THEIR ANCESTORS.

Is entering now upon an examination of the different groups of the living Mammalia according to their historical or palæontological past-an explanation of that which has come to be out of that which has been - the method to be followed is selfevident: a systematic arrangement, proceeding from the lowest to the highest forms, comprising the result of anatomical as well as of palæontological considerations. The lower groups of Mam. mals are, of course, those which have retained the inherited qualities of their ancestors most distinctly, and have changed least. This does not necessarily include the certainty that they inhabited the earth at an earlier period than all those whose skeleton, brain, and fœtal development show a pre-existence of the lower forms, but end with a higher result. The lower Mammals may have remained as a remnant of a group whose nearest relatives-at first, 
LIVING MAMMALIA AND THEIR ANCESTORS. 83

by scarcely noticeable deviations - raised themselves above their cousins by making use of the advantageous changes and adaptations in their organisations. And yet the probability is that the lowest animal forms were, in general, also the oldest geologically.

Although even Cuvier had prepared the downfall of Buffon's indefinite idea of arranging the animal kingdom into one series, still it was not till our own day that it became generally admitted that the conception of a figurative expression for the system could only take the form of an immense tree, with hundreds of branches and thousands of twigs. The animals we see living to-day are the tips of the twigs and shoots; those that preceded them must be looked for down towards the branches, and from these again down towards the trunk. The comparison of a tree, however, serves only as a means of arrangement. On our grand tree of life, the branchings are all unlike one another, and show resemblances only where they are in close proximity; the farther they have branched off from the tree the more different do they become.

From another point also the figure of a tree will give us a distinct idea of the actual state of things. The farther we go back into the history 
of the existing animal forms the nearer we come to their origin. In cases where to-day no connections seem to exist except the characteristics of the class and order, in going back we find more definite and ever clearer resemblances, till finally the common original forms are discovered. These have often been called 'mixed forms,' which term, however, does not properly indicate the nature of the matter. For in most cases the question is much less about a combination of marked characteristics which, in earlier times were, and at present are distributed over different branches, than about a still undifferentiated basis that has in various directions proved itself transformable. For instance, the Hoofed Animals, which when first met with are unfortunately already very marked in character, possess the full number of toes and a good supply of teeth. Of the teeth it might indeed be said that they show a 'mixed character,' inasmuch as the front ones are more adapted for attack and defence, while the rest are specially adapted for munching vegetable substances. But if the earliest forms of Hoofed Animals and the earliest forms of Carnivora point to animals resembling the Insectivora in structure and form, as their common ancestors, and these again point to the Marsupials, we can assuredly 
LIVING MAMMALIA AND THEIR ANCESTORS. 85

not call these mixed forms, but forms bearing the impress of different circumstances.

But when brought into this connection with the primeval world, the systematic arrangement of the Mammalia-made in accordance with their present state-must above all things appear altogether unsatisfactory. The Mammals, as the most highly developed animals, not only, of course, stand farthest from the beginnings of animal life, but they have also-at all events the Vertebrates -diverged more from one another than any other class. For even the Reptiles, whose day is, in every respect, long since past, are behind them in this. However adaptable their limbs were to circumstances (their teeth were less so), their brain remained stationary. It was only with the characteristic advance in the organisation of the Mammalia that scope was given to a progressive brain. The attempts which have repeatedly been made to make use of this point also for a systematic arrangement of the Mammalia, have either been too onesided, or could not show any satisfactory result, owing to the large gaps in our palæontological knowledge. It is reserved for the future to make the systematic classification of the Mammalia a really 'natural' one, and one which shall attain the 
goal towards which Cuvier and Lamarck paved the way with their grand beginnings, although starting from such different points of view. Meanwhile we must content ourselves with following the old tracks.

\section{THE MONOTREMA, CLOACAL OR FORKED ANIMALS.}

An example as to how the animal form should not be conceived is given by Giebel, a man of vast knowledge but yet opposed to the theory of descent. He says of the two well-known species of this group, the Ant-eaters (Echidna), and the Duck-moles (Ornithorhyncha): 'If there is anything marvellous about any series of animal forms, the Cloacal animals appear the strangest of all; for the irregularities and wondrous shapes in the variously formed organisations of the Edentata are far surpassed by those met with in the Cloacal animals.' Brehm also does not carry us much farther; he says: 'The Ant-eater and the Duck-mole are still classed sometimes with the Marsupials and sometimes with the Edentata. And, in fact, they combine not only the peculiarities of the one and of the other class, but also the most varied and opposite characteristics of the whole first-named class (the Mammals); indeed, they seem, to a certain extent, 
THE MONOTREMA, OR CLOACAL ANIMALS. 87

to be the connecting links between the Mammals, Birds, and Reptiles.' That he should regard them as connecting links is certainly somewhat to the point, only the Birds must be left out of the question. A direct connection between Bird and Mammal there is not; they are allied through their ancestors, and the latter stand widely separated, although within the extremely comprehensive order of Amphibio-reptiles.

Their beak-shaped jaws do not possess any teeth; only in the case of the Duck-mole do we find a few horny plates. This want of teeth has perhaps been inherited from reptile-like ancestors, and must have been distinct from the ancestors of the toothed mammals; hence it would be a case of convergence. The possible case of the common origin of Duck-moles and of Toothed mammals from primary forms of toothless animals, and of the acquisition of teeth by Mammals independent of toothed ancestors, is in the highest degree improbable; or else the loss of the teeth may have occurred only at a later period, after a common origin on the line of duck-moles, as in the case of Birds and various Edentates, partially also in the upper jaw of the Hoofed Animals, and in all cases of the reduction in the number of teeth. We take 
all these possibilities into consideration without gaining anything for the point in question.

It is, however, a different matter with the following characteristics. The Cloacal animals are the only Mammals where the collar-bones have become united into one piece by means of the breast-bone, as in the case of the well-known forkbone in birds. In all other Mammals, including Man, we find, in place of this free os coracoideum, a short hook, the crow-beak bone. This circumstance, in and of itself, might lead to the supposition that the Duck-moles were more fully developed than the other Mammals. However, from the course of the development as a whole, it is obvious that this portion of the shoulder of the higher Mammals must be regarded as a case of reversion. Another peculiarity of the skeleton of the Monotrema is a couple of bones which, turned towards the front, rise above the pubic bones at the abdomen side of the pelvis. These bones exist also in the Marsupials. As, however, we are uncertain about their origin and significance even in the case of the Marsupials, nothing much can be made out of the agreement. Still, the occurrence of these bones in the two classes points to a close relationship. 
THE MONOTREMA, OR CLOACAL ANIMALS.

All the more characteristic is another peculiarity of the Monotrema: the urinary and genital apparatus have no separate openings, but one opening in common with the intestinal canal, called the cloaca. This stage of development at which the Monotrema, like the lower Vertebrates, ${ }^{1}$ remain all their life, is an embryonal stage in the case of all the other Mammals, and not, as Giebel says, an irregularity or singularity, but a perfectly normal inheritance. In the other Mammals the peculiarity exists normally as a transition form, but after the embryonal life it is a condition that has been overeome.

That the Monotrema possess actual lacteal glands is a long-established fact. There are a number of separate glands from which the milk issues, not, however, from a teat or nipple, but from flat, perforated patches of skin. These were formerly held to be mucus- or perspiration glands, but are now recognised as an actual proof for the irrefutable supposition that the secretion of milk was acquired only gradually. Those of our readers who may consider this idea-of the common skinglands of the reptile-like animals having in the course of time developed into the important

: In most Fishes these arrangements are different. 
mammary glands-as very strange and but little pleasant one, we would remind of the case of the pigeons. Pigeons do not indeed possess glands on the outer skin, but have glands developed in their crops which provide the young with food; whereas in the other birds we find at most only secretions for softening the food and preparing it for digestion.

Owing to the fundamental importance of the mammary glands, we must enter somewhat more fully upon the subject here, while discussing the lowest known forms of Mammals. The simplest arrangement is that of the Duck-mole, such as was perhaps inherited from unknown ancestors, but which probably also represent a stage of reversion. It is different with the Echidnas, porcupine anteaters. We here find the perforated glandular patch lying somewhat deeper and surrounded by a circular wall of skin. In this so-called mammary pouch the immaturely-born offspring finds admission and protection, and by sucking forms for itself probably a temporary pointed teat. The most important matter is that the formation of the teat or nipple begins in all the other Mammals and in Man with the indications of this kind of mammary pouch. The form and more delicate structure of 
the outer milk apparatus does not appear to have been directly transmitted only to the Marsupials; thus the various formations of teats, which can be traced, from those first beginnings, amid all sorts of modifications, through the whole series of the higher Mammals, also corroborate the inductive proof of the relationship of the whole mammal world including Man. ${ }^{1}$ And even in this case the history of the development of the living representative of an animal group, supplements the want of observations on conditions and processes that have played a part in the remote period of the earth's history.

A separate origin for the Monotrema cannot be unconditionally rejected, but is exceedingly improbable, if only on account of the perfect agreement of the embryonal mammary apparatus of the Marsupials and of the other orders, with the marsupial pouch of the Echidnas. The suppositions favouring the possible independence of the Monotrema do not, of course, possess any actual foundation as long as we do not know the amphibio-reptile forms where the mammal character shows the first signs of incoming and of

' Klaatsch, 'Zur Morphologie der Säugethierzitzen' (Morpholog. Jahrbuch, ix. 1883). 
becoming established. On the other hand, to take a very obvious case, when competent authorities emphasize the possibility that birds of the ostrich species (the Ratitæ) are of a different reptile origin to the other birds - e.g. those with a keel-shaped breast-bone-the supposition of a convergence would, in fact, be established; for birdlike peculiarities are met with in the skeleton of several fossil groups of reptiles, hence the transformation to the real bird would in various respects be absolutely no wonder at all.

The geographical distribution of the Monotrema is confined to South Australia and Tasmania. But a few years ago a new species of Ornithoryncha was described from a perfect skull found in New Guinea. This does not really make the range of their distribution any larger, as New Guinea was clearly at one time connected with the continent of Australia, and consequently belonged to the same zoological province. Not a trace of any fossil discovery leads us from the present living Monotrema back to the primeval world, to which nevertheless they stand in such palpable relation. They are, moreover, widely different from the other groups of living Mammals. Even admitting the debatable supposition that they were directly allied 
THE MARSUPIALS, OR POUCHED ANIMALS. 93

to the Marsupials-hence derived from common primary forms-their separation from these must have taken place before the Trias period. ${ }^{1}$

\section{THE MARSUPIALS, OR POUCHED ANIMALS.}

The Marsupials stand in a remarkable position between the Prototheria (the Monotrema) and the Eutheria (the 'higher Mammals'), but obviously their relation to the latter is more direct, whereas the gap between the Monotrema and the Marsupials is left to the free play of the imagination. It is not readily intelligible how the marsupial pouch of the Echidna-which serves to protect the helpless offspring-could have originated by natural selection. Here the two bones rising from the pelvis, the ossa epipubica, transmitted to them by their ancestors of the monotreme species, have been brought into connection. The openings of the urinary and genital organs have remained at a low stage and show resemblance to the

1 For the sake of clearness and simplicity we intend in the following pages, with Huxley, to call the Monotrema, as the lowest Mammal form, Prototheria. They are followed by the Marsupials as Metatheria; and all the other orders comprised as the "higher Mammalia' then follow as Eutheria. Zoologists will know that the two last designations stand for the more general terms Didelphia and Monodelphia, which, however, require a special explanation. 
arrangement in the Monotrema. The young leave the maternal womb in a very immature state, i.e. the nourishment, the renewal of blood in the uterus which, in the case of the Eutheria (the high Mammals) is regulated by means of the placenta for the advantage of the offspring, must, owing to the absence of this fotal organ, be accomplished at an early stage by mammary glands. The further development of teats, in accordance with a beginning corresponding to the marsupial pouch of the Echidna, has already been mentioned.

A fresh feature by which the Marsupials are brought into direct connection with the higher Mammals is their dentition. And, moreover, with their dentition they extend back beyond the Monotrema to primary amphibian forms, and at the same time the great variety of the forms prove, in a most obvious way, that they have differentiated from the simpler beginnings of their ancestors, in so far as they were obliged to do so owing to the generally more uniform surface of the earth. One peculiarity affecting the whole group of Marsupials is this, that only one pair of teeth in either jaw is changed during the lifetime. The succession of the teeth with the incoming of the one 
THE MaRSUPIALS, OR POUCHED ANIMALS. 95

deciduous tooth, is not a safe starting point for making a satisfactory comparison of their dentition with that of the Eutheria (the higher Mammals).

In an interesting paper on the classification of the Mammalia, Huxley' says: 'As Professor Flowers has pointed out, the question arises whether we have here a primary dentition with only one secondary tooth, or a secondary dentition with only one tooth of the primary set left. I have no doubt that the answer given to this question by Prof. Flowers is correct, and that it is the milk dentition of which only a vestige is left in Marsupialia. Among existing Rodents, in fact, all conditions of the milk dentition exist from a number equal to that of the permanent incisors and premolars (as in the rabbit) to none at all. The same thing is observed in the Insectivora, where the Hedgehog, and probably Centetes, have a full set of milk teeth while none have yet been found in the Shrews. In these cases it is obvious that the milk dentition has gradually been suppressed in the more modified forms; and I think that there

1 ' On the Application of the Laws of Evolution to the Arrangement of the Vertebrata, and more particularly of the Mammalia, (Kosmos, ix. 1881). 
can be no reasonable doubt that the existing Marsupials have undergone a like suppression of the deciduous teeth in the course of their development from ancestors which possessed a full set.' If this is the right explanation, the suppression of the milk teeth in Marsupials must be transferred to a comparatively more recent period when the branching off of the Eutheria, which still possess the milk teeth, had not yet taken place. A proof of this is that some groups of Mammals do not show this succession of milk teeth and permanent teeth, or rather that they have lost it notwithstanding a relationship marked by a change of teeth.

As regards teeth and limbs, the Marsupials of to-day bear testimony to no small amount of adaptability. It may be compared with that adaptability which is evident in the whole class of the higher Mammals, if we are not to admit that the Eutheria have originated separately in groups from the already modified Metatheria. True, the most useful and docile Hoofed Animals are looked for in vain among the Marsupials, and notwithstanding the great diversity in the formation of their teeth-which goes hand in hand with their mode of life-the types of the insect-, flesh-, grass- 
THE MaRSUPIALS, OR POUCHED ANIMALS. 97

and root-eating Marsupials are far more alike in structure than are the Eutheria among one another. The largest numbers of teeth-fifty-is found in the opossum, Didelphys. The marsupial pouchthe characteristic feature of the class-has, it is true, become reduced to a few unimportant folds on the abdominal skin. Still, because of the number of their teeth, and because the earlier fossil Mammalia show most affinity to them, they must be regarded as the least modified members of the family.

The Didelphidæ, or Marsupial Rats, are now confined to southern and central America. Neither geology nor palæontology gives us any clue as to how this has happened: whether and when this branch separated from the main group confined to Australia : whether the agreement of the Didelphidæ with the other Marsupials is a matter of convergence: or whether the Australian Marsupials are of American origin. However, we shall have to return to this latter supposition owing to an anatomical peculiarity. The dentition of the Marsupial Rat shows most resemblance to our Insectivora, and they also agree with them in many ways as regards mode of life and food. Even Cuvier discovered their fossil remains in the Eocene strata of Paris. It was only 
at a much later date that $R$. Owen ${ }^{1}$ traced similar animals back to the Trias formation.

In the so-called Rhætic beds, one of the sections of the Trias, a few minute teeth were found which probably belonged to an Insectivorous Marsupial; these teeth have given rise to the genus Microlestes. Again, in the Lower Lias (of the Jura formation), fragments of lower jaws have been found that must be regarded as belonging to small Insectivorous Marsupials. Phascolotherium is most frequently mentioned. Similar remains are found in the strata directly below the Chalk formations, and among these we have Plagiaulax, very remarkable on account of the reduction and specialisation of its dentition. In Fig. 2 we have the lower jaw of $P l$. minor (A) in natural size. Hence it was an animal of the size of a mouse. In the enlarged jaw of another species (Fig. 2, в) the premolar (?), marked by number 4 , and followed by two molar-shaped teeth, shows the very marked character of the genus, which is less distinct on the preceding teeth-i.e. the deep diagonal grooves.

Owen looks upon all these imperfect remains as 'generalised forms,' whereas Huxley asks, what are

' Owen, 'Monography of the Fossil Mammalia of the Mesozoic Formation' (Palcoontological Society, 1871). 
THE MARSUPIALS, OR POUCHED ANIMALS. 99

the peculiarities of the more embryonal or less specialised type of the Phascolotherium as compared with the Opossum of to-day. Upon the whole Owen seems to us to be right, as regards the dentition, in coming to the eonclusion that from Phasco lotherium to Didelphys we have an advance from the generalised to the specialised form. This supposition cannot, however, be extended to Plagiaulax.

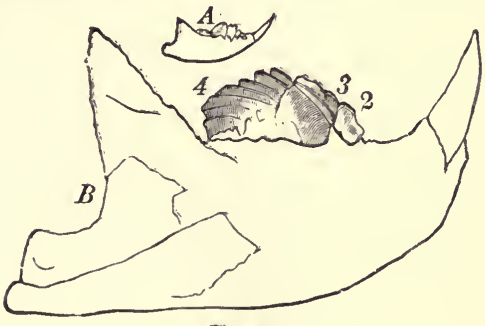

Fra. 2.

A. Lower Jaw of Plagiaulax minor. Natural size. $B$. Lower Jaw of Pl. medius. Four times eularged.

This animal appears rather to be already so far specialised that it advanced but little farther in subsequent times; nay, if the line were carried down to the aetual present, it might even be said to have become effaced.

The remains found of Plagiaulax show the following connection with the living Marsupials. 
An animal allied to the European Plagiaulax is described by Marsh from the Jura of WyomingCtenacodon - without the above-mentioned deep grooves on the premolars, but they are jagged on the upper edge. ${ }^{1}$ In addition to this, in 1883 a discovery of great interest was made, by which the connection between the primary and the existing Marsupials has been almost directly restored. In the Lower Eocene, in the neighbourhood of Rheims, Lemoine found the jaw of an animal which shows a remarkably grooved tooth as the only premolar, and behind it two low tuberculate molars (Fig. 3, $\Delta$ ). Owing to its close resemblance Lemoine called it Neoplagiaulax, and classes it by the side of the existing dwarf-kangaroo of Australia, the Bettongia penicillata (Fig. 3, B). This latter also has a grooved tooth, even though somewhat less deeply marked.

As the Eocene animal has two, and Bettongia three teeth behind the grooved tooth, we cannot, of course, speak of any direct relationship, but we may assume a lateral connection between the two.

1 We shall here use the words premolars and molars (as most palæontologists do), although according to the conditions of the living Marsupials, we are not absolutely certain whether we are right in distinguishing the teeth of the fossil forms as milk and permanent teeth, premolars and molars. 
Lemoine also finds agreements between Plagiaulax and Microlestes, and has thus lengthened the series from the Present to the Trias formation. The French zoologist further discovers in the upper cheek-teeth of the Brown Rat similarities with teeth which, found isolated, probably belong to
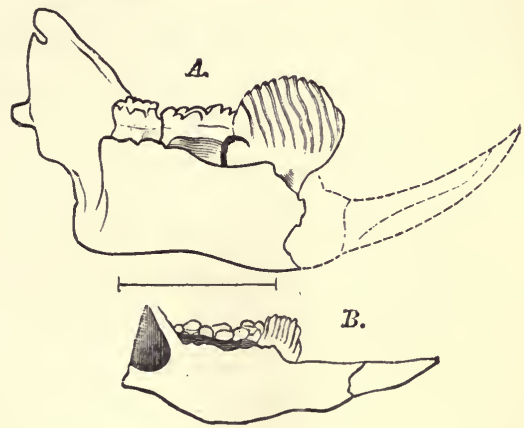

Fig. 3.

A. Lower Jaw of Neoplagiaulax.

B. Lower Jaw of Bettongia penicillata. After Lemoine.

Plagiaulax. All this points to the primeval stock where Marsupials, Insectivora, and Rodents meet. But we cannot imagine that Plagiaulax was an insect-eater; I should be inclined rather to assume that Bettongia lived upon vegetable food.

The scientific dispute regarding the mode of 
life of Plagiaulax - as expressed by its dentitionwhich has been carried on with much animation, more particularly by English enquirers, also affects a Marsupial of the Diluvium; and Owen has expressed his conviction as to the carnivorous habits of the animal (which is almost the size of a lion) by the name he gives to it, i.e. Thylacoleo carnifex. Its skull, like that of many of the Marsupials, shows the peculiarity of strongly developed middle incisors. The canines and front cheek-teeth are very insignificant. But both above and below follows a huge, compressed premolar which involuntarily reminds us of the canine of the large cats of our day. The rest of the back teeth, also, do not oppose the supposition of its being carnivorous, hence here again we do not understand Owen's learned opponent who would characterise Thylacoleo as a plant-eater. We agree with Owen's opinion that none of the existing Carnivorous Marsupials show a similar concentration of the dentition-such a good or serviceable set of teeth-as Thylacoleo, in whose case this direction of development has exhausted itself. But does our Marsupial Lion show affinity with Plagiaulax, as Cope would have us believe? Quite apart from the question of food, we consider a transition from the dentition of 
THE MARSUPIALS, OR POUCHED ANIMALS. 103

Plagiaulax to that of Thylacoleo as exceedingly improbable; besides this, the discovery of the Neoplagiaulax leads us to an entirely different track from Plagiaulax.

The Marsupial Lion of the Australian Pleistocene takes us back to the time when the group had

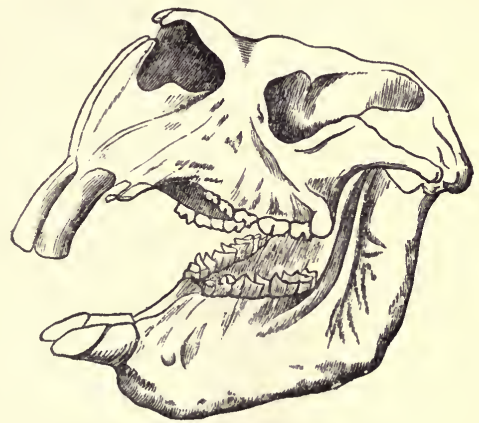

Frg. 4. - Skull of Diprodon Australis. One-tenth natural size. After Owen.

reached its fullest development (followed by a somewhat rapid decline), and which presupposes a similar and contemporaneous abundance of plant-eaters necessary for the sustenance of the huge flesheaters. And there exists at least one species of those theoretically required-the colossal Dipro. 
todon australis, whose skull is one metre in length. It was obviously a plant-eater with a specialised dentition, as is proved by the peculiar incisors and the compressed cheek-teeth, which are separated from the incisors by a considerable gap. According to Owen's masterly comparisons, in Cuvier's style, Diprotodon was a gigantic kangaroo, but without the power of leaping. Like most of the primeval species which attained an unusual development of strength and a certain monstrosity of form, it has not left any direct descendants, but together with it there lived, in those days, powerful creatures closely related to the kangaroos, such as Palorchestes, with a skull $40 \mathrm{~cm}$. in length.

Wombats also (Phascolomys), of which there exist only a few species, find their fossil completion in numerous species of this genus, and partly corresponded with them as regards size, and partly far surpassed them. They appear all to have been root-eaters, and, as is well known, the habitus of the Rodents is repeated in a remarkable manner within the group of Marsupials. The one that can most readily be compared with them is the Nototherium, which again is a creature that far exceeds the living species in size, with a skull of the most ugly description imaginable. While the 
THE MARSUPIALS, OR POUCHED ANIMALS. 105

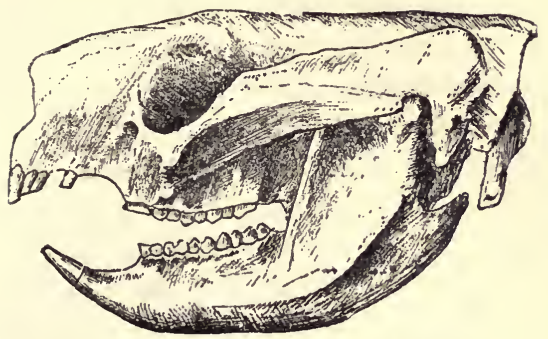

Fig. 5.- Skull of the Wombat (Phascolarctus fuscus). One-half natural size. After Owen.

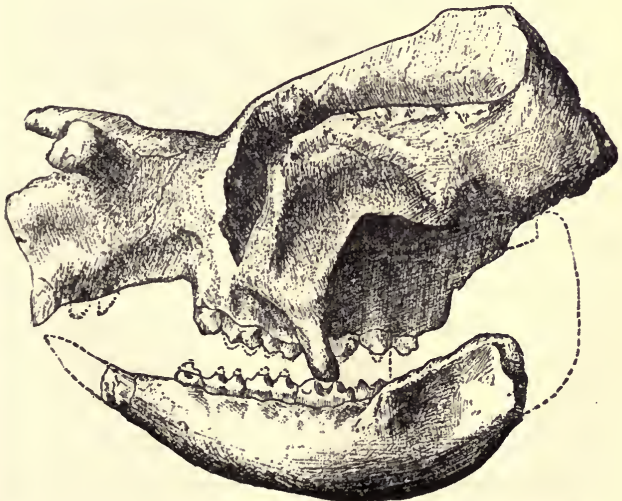

FIG. 6. - Skull of Nototherium, from the side. One-sixth natura] size. After Owen. 
Phascolarctus fuscus of the present day (Fig. 5) shows a skull of $19 \mathrm{~cm}$., the skull of Nototherium Mitchelli (Figs. 6 and 7) is $46 \frac{1}{2} \mathrm{~cm}$. long, to $40 \frac{1}{2} \mathrm{~cm}$. broad. The breadth is caused by the enormous arch of the cheek-bone. The cheek-teeth

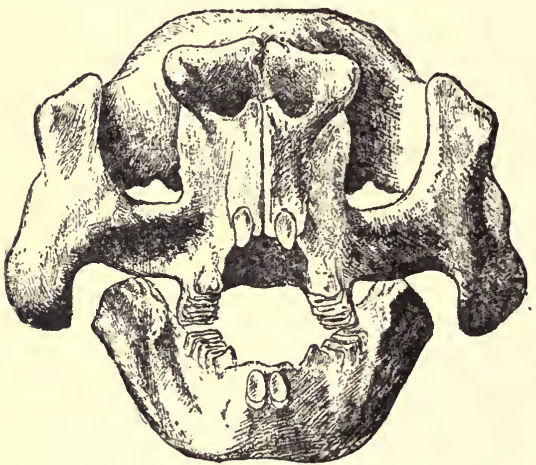

Fir. 7.-Skull of Nototherium, front view. One-sixth natural size. After Owen.

are very like those of Diprotodon, and are likewise furnished with transverse ridges, the whole dental formula being the same: $i \frac{3}{1} c \frac{0}{0} m \frac{5}{5}$. The structure and form of the teeth point to a plant-eater, and not to the habits of a wombat that grubs for roots. 
THE MARSUPIALS, OR POUCHED ANIMALS. 107

All of the above-mentioned fossil Marsupials, which have been described by Owen in his masterly work, ${ }^{1}$ belong to the most recent geological past. They are found principally in Eastern and South-eastern Australia, partly in river-bedsas for instance in that of the Condamine and its tributaries-and in the dried-up deposits of fresh waters, partly also in caves. The so-called Darling Downs, not far from the Condamine, have yielded a great number of these fossils. It was here that Leichhard, among others, collected at the commencement of his journey the remains of the Diprotodon, and considered them so little like fossils, that he expressed the hope that he would meet with living specimens of the same animals in the interior of the continent.

In conclusion, we come again to the question as to the relation between the American and the Australian Marsupials, with regard to which, as has already been said, the primitive earth gives us no clue. Several peculiarities, more particularly the completeness of the dentition, point to the Didelphidæ as the earlier branch. But there is also another circumstance. According to Bar-

Owen, Extinct Mammals of Australia (London, 1877), with 131 plates. 
deleben's recent observations on the structure of the tarsus or root of the foot in mammals and in Man, ${ }^{1}$ the Didelphidæ herein show most agreement with the Lower Vertebrates. All the American Marsupials (the number of which has been considerably increased by the researches of Hensel, who died at too early an age) possess the determining bones which, it is true, are not altogether wanting in the Australian species, but are very much modified, and thus point to a later differentiation. All of the American species, says Bardeleben, are fivetoed. The larger forms, also those without the isolated bony intermedium, and finally those with a reduced metatarsus, are all found in Australia. For this reason Bardeleben thinks himself justified in maintaining it to be probable that America, and not Australia, was the primeval home of the Marsupials. Hence, that the Australian Marsupials differentiated after the continent became separated from the rest of the earth, and that they there became to a certain extent fixed forms.

If the enormous area of the Australian continent-of which Tasmania, New Zealand, and New

'Bardeleben, 'Ueber das intermedium tarsi' (Sitzungsberichte der Jenaischen Gesellschaft für Medicin und Naturwissenschaft, 1883). 
THE MARSUPIALS, OR POUCHED ANIMALS. 109

Guinea form a part, and which is so poor in Mammals-be compared with any other corresponding latitudes, the contrast in the fauna will appear most striking. The eminent German naturalist Carl Ritter, in his lectures on Australia, ${ }^{1}$ was, if I am not mistaken, the first to describe this continent-not, as is usually done, as the 'latest,' but as the 'stationary' continent, and as old-fashioned both as regards fauna and flora. This uniformity resulted in an entire absence of the most important outward inducement to the formation of varieties: with a moderate struggle for existence, a consequently smaller progress in the functions of the organisms. No Marsupial has shown itself suitable as a domestic animal; neither work, nor protection, nor milk has been obtained from them. Their flesh only, which is unpalatable to a refined taste, was made use of by the nomadic primeval inhabitants; the latter were a very low race of men who, in fact, could not advance beyond the threshold of civilisation, because neither the necessity for settling in certain localities (which goes hand in hand with the taming and training of animals), nor any inducement to cultivate the land, was ever brought before them.

1 Which lectures I had the good fortune to attend. 
3. THE EDENTATA, OR ANIMALS POOR IN TEETH.

Gaudry tells us that the famous brain-anatomist, Gratiolet, compared the Sloths to old men crawling along heavily, with hands that had become immovable, and as having lost their teeth all but a few pieces of cheek-teeth. Now if we take these sloths in connection with the Ant-eaters, Armadilloes, and scaly ant-eaters (which call forth similar comparisons), and then endeavour to determine the common character of the strange company from a scientific point of view, we shall find it easier to ask the question than to give a reply. It is true that, as their systematic name indicates, all are poor in teeth-i.e. have an impoverished set of teeth, some even no teeth at all, and in most cases only pointed, regularly formed cheek-teeth without enamel; again, all possess limbs with large elaws; further, the brain is in all cases of very moderate size, the surface of the larger hemisphere being flat. However, this latter peculiarity is met with in other of the lower orders of the Mammalia, and upon a closer examination not much importance can be attached to the certain amount of uniformity of the toes mentioned above. One sloth has three, another two, the Giant Sloths 
three and four toes, the Ant-eaters and Armadilloes mostly five on the front limbs; some are burrowers, some climbers, some walk upon the soles of their feet, others on the outer sides of their feet; the Sloths and Ant-bears have hairy coverings, whereas the Armadilloes and Scaly Ant-eaters are covered by an armour of bone, horn, or scales. The armadilloes and ant-eaters live on worms and insects, the sloths are decided plant-eaters.

Even from a superficial consideration like this, it is evident-and a careful study of the question only corroborates the remark - that the living Edentata stand in a wholly different relation among one another from that of the members of other orders of animals, with the exception, perhaps, of the Marsupials and Semi-apes. The certain something by which they are connected, but which our system of arrangement cannot specify in a few brief or clear words, could not be definitely stated unless we were acquainted with the early history of the group.

Unfortunately, we do not know their early history. Even the geographical distribution of the few existing species points to a very remote period. Were we to assume that the ancestors of the Asiatic and African Armadilloes, the African 
Ground-pig, and the American Ant-bears, Sloths, and Girdled-animals were at one time allied, we shoulc also have to assume a connection between the three continents. There has been no lack of very bold combinations to bridge over the gap to our undiscoverable friends-who, it is to be hoped, were better equipped for a wandering life than they are nowadays, and have been since the Tertiary, at least-and also to the ostriches, which, owing to a similar geographical distribution, are equally enigmatical. But geology has, as yet, not been able to say her yea to this. America alone shows a rich past for the Edentata of the earth's most remote periods. In Europe traces, at least, have been found which justify the conclusion that where single individuals of the modified forms lived, others also of the same group must have existed contemporaneously or in the preceding periods.

The comparatively large variety of Edentates in South America is accounted for by the still larger number of Diluvial species, some of which were of gigantic size. Many inhabited the same tracts of land which are at present the abode of their evident successors, if not descendants. Others we find pushed farther northwards, but we cannot with certainty determine whe.her their 
THE EDENTATA, OR ANIMALS POOR IN TEETH. 113

nearest relatives, in those days, lived in the southern centre of distribution-where they continue to live up to the present time-or whether the migration

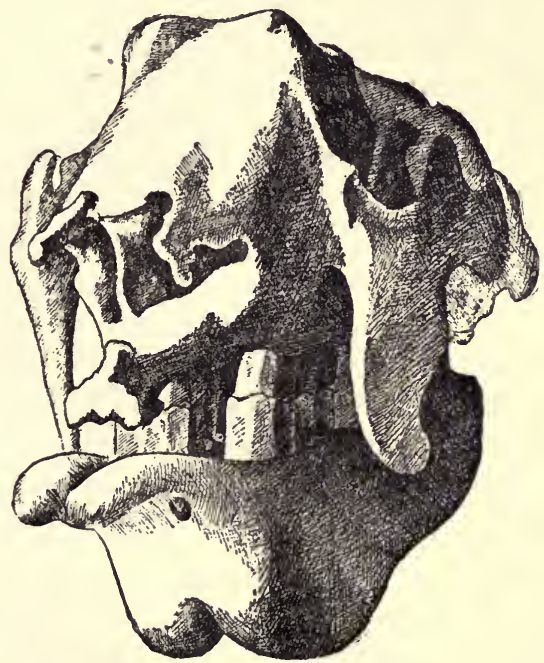

FiG. 8.-Skull of the Giant Sloth. One-tenth nat. size. After d'Alton.

from the north southwards was the origin of the present distribution.

The limbs of our present leaf-eating Sloths are most perfectly adapted for clutching hold of the 
branches of trees, and the animals are, by a peculiar arrangement in the circulation of their blood, enabled to remain hours and days in the most uncomfortable positions; hence they have almost completely lost the faculty of moving along level ground. The nearest relatives of the Sloth-i.e. of the genera Bradypus and Cholopus-are the colossal Megatherium and Mylodon, found in the Diluvial deposits of North and South America. Of the former we have an account, with illustrations, in E. d'Alton's 'Classic Monographies,' where it is called 'the giant sloth.' He there says, that, compared with its skeleton of fourteen feet in length and seren feet high, that of the rhinoceros appears graceful, the elephant light and slim, and the hippopotamus of good proportions. Its unusually broad and bulky body has a very small skull (Fig. 8), and is remarkably like that of our present Sloth. True, the cheek-bone, which in the case of the Giant Sloth is firmly attached to the temporal bone, is not thus joined in our present Sloth (Fig. 9), but in the case of both the cheek-bone shows a strongly dereloped continuation that points downwards. The teeth of the fossil animal, sixteen in number, are compressed within the actual region of the cheek; in the existing species they stand more apart; but in 
both they bear witness to the peaceful habits of a plant-eater, and the unmistakable agreement in the type of skull leaves but little space for a brain, even in the Giant Sloth.

But what a difference in the limbs! Of the character of these limbs in the two species, Mega-

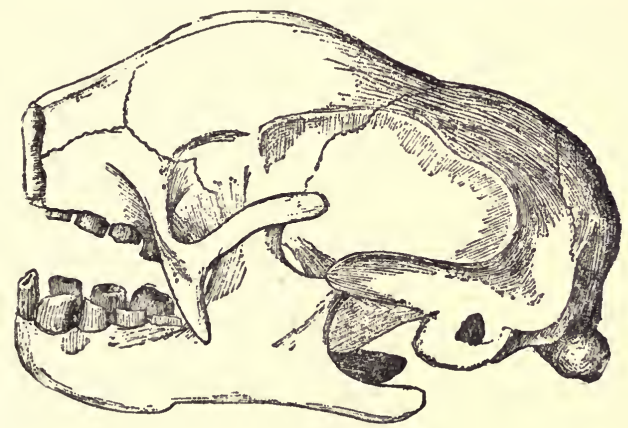

Fra. 9.-Skull of the Three-toed Sloth. Nat. size.

therium and Mylodon, and of the mode of life of these animals as it has to be imagined from the limbs, Owen gives an admirable account. We will here quote his description of the Primeval Sloths which supplements our knowledge of the nature and habits of the living species, even though it may not give any direct explanation of them. 
After a detailed account of tne various parts of the limbs, he says: "The principle of viewing structures and instruments, in reference to the work that they do, is shown to be good in gaining insight into the mode of life of extinct animals, in a striking degree through its application to the skeletons of the Megatheriods (Giant Sloths). The teeth of these conform so closely in all characters with those of the Sloths as to suggest leaves rather than roots to have been their food. In the light, slender Sloths the modifications of structure for climbing, clinging, and living altogether in trees are carried out to an extreme. In the colossal extinct kinds, the foliage was obtained in a different way. The huge, single claw on the hind foot ${ }^{1}$ would be applicable as a pickaxe to clear away the soil from between the ramifications of the roots: a second claw ${ }^{2}$ would have interfered with such work. The foot is organised to give great strength to that claw; dislocation of its toe is specially guarded against; the rest of the tarso-metatarsal structure relates to the power of the foot to sustain superincumbent pressure, with a position of the claw bringing its

1 This is the claw of the middle toe. The other toes appear to have been furnished with a kind of hoof.

2 The reader who finds this explanation somewhat too odd must not forget that 0 wen is a decided teleologist. 
THE EDENTATA, OR ANIMALS POOR IN TEETH. 117

side instead of its point in contact with the ground. The bones of the thigh and leg are remarkable for their massive proportions, for their thickness, and especially their breadth in proportion to their length: the femur in both Mylodon and Megatherium would rank rather with the "flat" than with the "long" bones. These osseous columns were needed to support the huge, heavy, expanded pelvis. The iliac expansions are the chief conditions of the other characteristics of this part; and they are unintelligible save in relation to adequate extent of powerful muscles, especially those arising from the crista ilii, the chief of which muscles concentrate their force upon the fore limbs. This indicates that these limbs were put to some unusual work; and the inferences from the teeth and the hind claw lead to its recognition as the pulling down trees and wrenching off their branches; but for these operations the pelvis must have adequate fixity, and to the weight and strength of itself and its supporting limbs there is added a tail so developed as to serve as a third support and give the pelvis the basis of a tripod. Without this view of the function of the hind parts of the skeleton, we can only see that the pelvis is so great and, with its caudal appendage, so weighty as to 
require the massive proportions and structure of the hind limbs, and, reciprocally, that these bespeak a proportionate size and weight of the parts to be sustained; but why such development of sustaining limbs and parts to be supported in reference to any other action and way of life is inconceivable. The excess of bone in the hind part of the skeleton once recognised as relating to the fixed point of attachment of muscular forces working the fore limbs-to the exertion of power adequate to prostrate a tree-and the rest of the bony organisation becomes intelligible. That of the hind foot has been explained : the concomitant extent of the muscular origin afforded by the broad scapular plate, with its many ridges, crests, and processes, is thereby accounted for. The necessity of the firmness imparted to the shoulder joints by the perfect clavicles abutting at one end against a large "manubrium," at the other end against the conjoined acromion and coracoid, becomes obvious. The fore foot retained three huge claws to effect an adequate grasp of the trunk or bough: for their due and varied application the fore arm enjoys all the variety and freedom of movements which an arm terminated by a hand possesses. A tree being prostrated and its foliage thus brought within 
THE EDENTATA, OR ANIMALS POOR IN TEETH. 119

reach, every indication in the skull of the size, strength, flexibility, and prehensile power of the tongue harmonises with the foregoing teleological conclusions. The Megatherioids, like the giraffe, thus plucked off the foliage on which they fed. In the ridged crowns of the grinders of the Giant Ground-Sloth we discern the power of crushing coarser parts-a greater proportion of twigs and stems, e.g. of the foliage, than the diminutive TreeSloths take. It needed only evidence of the occasional occurrence of what might happen to a beast in the fall of a tree which it had uprooted, to seal the foregoing physiological inferences with the stamp of truth: and the skeleton of the Mylodon in the Hunterian Museum shows that evidence above the right orbit and at the back part of the cranium.'

Those who can agree with Owen's whole deduction as to the tearing down of trees will also accept his ingenious explanation of the cracks in the skull of the famous specimen in the Hunterian Collection of the College of Surgeons.

But although this account and our observations concerning the existing Bradypodæ throw light on the structure and habits of the fossil group, they do not tell us anything about the real an- 
cestors of the living Brazilian Sloths. The expression so frequently used in illustrating the relation, that the sloths of the present day are the pygmean remains of the family which attained a colossal development in the Diluvium, would be wholly misunderstood were we to regard the Bradypodæ as crippled Megatherioids which had taken refuge in trees. In both cases the limbs have attained extreme formations which exclude every thought of their having been transmitted the one to the other; and we are again referred to a primary form that lies beyond all the palæontological discoveries yet made.

The existing Girdled-animals and the Diluvial Glyptodons resemble one another less in structure than in size. But also in the group of the burrowing and grubbing Armadilloes (which live on worms and insects) one is tempted to set too little value upon the length of time necessary for their origin than a careful consideration of the divergences would warrant. Thus the Girdled-mouse, Chlamydophorus, a native of La Plata, differs so much from the girdled-animal proper, the Dasypus, in spite of the most obvious relationship, that there must be between them a whole series of transitions; and hence probably one or two geological periods 
THE EDENTATA, OR ANIMALS POOR IN TEETH. 121

between them are necessary for the development of these transitions.

In order to arrive at a right estimation of this and of all the other similar cases which we shall have "to allude to later, it will be well to explain our views by a graphic example. Let us suppose that there existed by the side of our present one-toed horse, a three-toed form-like that of Hipparion-which possessed, in addition to the middle toe (corresponding with the horse's toe), other two toes, smaller, withdrawn from the ground and which had reached a stage of entire disuse. This is by no means a capricious idea. For, in the same way as 'circumstances' led to the disappearance of the one-toed horse in America, circumstances might have preserved the three-toed form in Asia or Europe, somewhere by the side of the races that were being transformed into a onetoed family. But even granting the existence of a three-toed animal, a non-scientific person would scarcely realise the length of time necessary for the deviation and for the formation of the existing form of horse. Hipparion disappeared from the scenes as early as the Upper Miocene, and yet our horse was not what he now is, immediately before our present geological formation, as is proved by the order for- 
merly considered identical with it, and described under the name of Equus Stenonis. This matter we shall have to enter upon more fully in a subsequent chapter. Although not extending farther back than to the Miocene, the period necessary for this reduction of the two toes and of the metatarsals to last rudiments (splint bones), was one of enormous length. And yet the modifications that took place during that period in the horse's foot, and the transformation of the dentition that accompanied the modifications of the foot, were but trifling compared with the differentiations in the group we are at present discussing (the Edentata). There is one other point to consider as regards the approximate length of the period. In the case of the horse, the question was less about a new formation than about parts that lapsed into disuse; now such parts are transmitted with incredible tenacity through long periods of the earth's history. It is evident that more rapidity is shown in transformations where adaptation does not create entirely new organs, but merely modifies those already existing; thus, for instance, where it changes running feet into climbing feet, and insignificant skin-ossifications into huge shields and plates. 
THE EDENTATA, OR ANIMALS POOR IN TEETH. 123

If, accordingly, we require a very considerable length of time-one certainly extending back into the Tertiary - for bringing the Armadillo and Girdled-mouse back to one family, we shall require at least as long a period for the development of the branch of Glyptodons from the common stock. Almost precisely the same latitudes in South America where the existing Girdled-animals find a home, gave shelter during the Diluvial period to the various species of the gigantic Glyptodons. Buenos Ayres possesses the richest collection of these very perfect fossils. They have been admirably described by Professor Burmeister, ${ }^{1}$ formerly of Halle, who some thirty years ago went to reside in South America; and the descriptions could be made as complete as if he had been describing the skeletons of some common existing animal.

Glyptodon clavipes measures $2.80 \mathrm{~m}$. from the snout to the end of the tail. Of these 1.50 go to the huge shield which covers its back and sides, forming one piece. The skull shows an unmistakable resemblance to that of the Sloths, not only as regards dentition, but also in the pecu-

' Burmeister, Annales del Museo publico de Buenos Aires. 1864. 
liar formation of the cheek-bone; however, as regards the structure of its limbs it keeps wholly within the limit of the Armadillo group. The animal obtained its food by burrowing and scraping, probably hid in caves, and protected itself from the attacks of the not very powerful Carnivora, by drawing its head under its breast like the armadillo, its back being protected by a shield similar

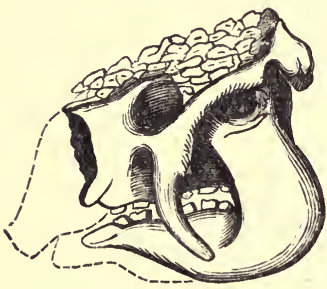

FIG. 10.-Head of Glyptodon clavipes. One-tenth natural size. After Burmeister. to that of a gigantic tortoise, its head by a helmet of bony plates, while the bony rings of its tail were anchylosed, and formed a kind of tunnel or arched bridge of bone.

The Ant-bears of South America have an ancestor in the Glossotherium. Another giant of Diluvial South America-but without any living representatives -is Toxodon, known to us by its skull, which measures 0.60 metre; it possessed a more complete dentition, but nevertheless shows affinity to the Edentate type. Toxodon, owing to its isolation, does not account for the existence of 
THE EDENTATA, OR ANIMALS POOR IN TEETH. 125

any of its contemporaries or any portion of the living animals, and only asks us to imagine round about him, and back to his own day, a wealth of forms that cannot be conceived in too great a variety.

From the Tertiary strata of South Americaour knowledge of which, however, is very meagre -we have no Edentates. In North America a few forms, such as the Moropus (of the size of a tapir) have been traced back to the Miocene. This fact, and the frequent occurrence in Nebraska of the remains of Giant Sloths from the transition period of the New Tertiary to the Diluvium, induces Marsh to dispute the prevailing idea that the Diluvial Edentata spread from the area of their distribution in the south, northwards; he maintains that it is more probable that they migrated from the north, southwards.

Fossil remains of Edentata have only rarely been discovered in Europe. We have the Macrotherium from the Middle Miocene of Sansan (France) with its peculiar retractile claws. To judge from the character of its limbs, it might have been a climber, but can scarcely have been this, for, as Gaudry says, it cannot often have come across trees strong enough for such exercises. The inexhaustible beds of Pikermi (Upper Miocene) 
have furnished one huge Edentate, Ancylotherium. Finally a few remains from the Upper Eocene of Quercy corroborate what is demanded by our theory and common sense. With this division of the living world, we may be said, upon the whole, to stand utterly helpless as regards geological antiquity, in so far as the question refers to a special proof for the origin of species, and the perfectly justifiable proof of a general deduction is not accepted.

\section{THE UNGULATA, OR HOOFED AÑmaLS.}

The usual classification of the living mammals furnished with hoofs into many-hoofed, doublehoofed, and single-hoofed animals appears as natural and self-evident as convenient. However, it becomes utterly inapplicable and proves altogether incorrect when tested by our present scientific principles, and when we further consider the palæontological material that has gradually been acquired. Of no other group have such numerous fossil remains been found, and in no other have so many lines been evolved from the earliest Tertiary periods, partly up to the present; hence the remark of a recent writer, that "the genus Horse is the true "show horse" of the theory 
THE UNGULATA, OR HOOFED ANIMALS. 127

of evolution,' may truly be applied to the whole order. All the animals of the present age have become what they are, but in scarcely any other case is the process of becoming so obvious, or the transition more perfect : the transition, that is, from the less specialised dentition of the Omnivora to the peculiar jaw of our horses and ruminants, the disappearance of the toes of the five-fingered primary-hoofed animals down to our two-toed ruminants and one-toed horse.

The basis of the correct classification has long since been given by Owen, who divided all the Hoofed animals into odd-hoofed and pair-hoofed. It is not the number of toes that is the characteristic feature, but the distribution of the weight of the body upon the outer parts of the legs, or, what is the same thing, the relation of the lengthened axis of the leg to the middle toe. The Odd-hoofed animals (Perissodactyla) are those with either five, four, or one toe, but where the lengthening of the axis of the upper and lower arm, and upper and lower leg, passes through the middle toe, whereby the middle toe has to bear the main weight even where we have a three, four, or five-toed animal. And Paired-hoofed animals (Artiodactyla) are those where the axis passes between the middle and the 
fourth toe; hence these two toes are more active than the side toes, and have an almost equal amount to do in bearing the weight. They acquire strength by this function, while the less active toes gradually become useless and finally disappear. We have already referred to the importance of the specialisation of the teeth, and to the simplification of the limbs produced by the reduction and disappearance of the toes, as an adrance for certain functions. And it is self-evident that the disappearance of the toes must, in a lesser or greater degree, affect the middle part of the hand and foot, the roots of the hand and foot, the bones of the lower arm and leg, and also the muscles and other soft parts of the limbs.

Kowalewsky has pointed out an exceedingly interesting circumstance connected with the bones of the hand and foot, and distinguishes inadaptive and adaptive forms among the Hoofed animals, where the toes are either partly rudimentary or have completely disappeared. This explanation of Kowalewsky's throws some light upon the question why so many lateral branches of the Mammalia have died out, whereas previously we had to be satisfied with the general supposition that these were the very branches that had not survived in 
the struggle for existence. The case is this: the original five-toed extremity (compare above Fig. 1, p. 36) has, in the second row of tarsals, one bone for every toe. If the side toes become reduced, one of two eases may then happen to the bones of the second row : either they become reduced with the toe, or they are retained for the remaining toe; i.e. they adapt themselves to the circumstances of the limb which changes with the toes and add to its strength and agility. The examples adduced by Kowalewsky are, in fact, very instructive. In the case of the

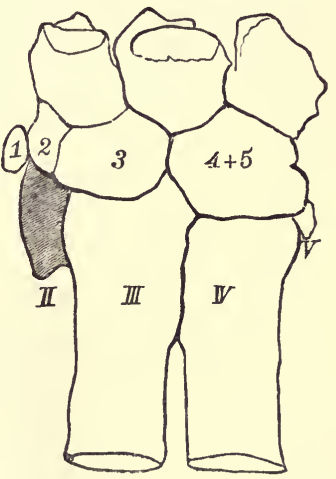

Fig. 11.-Left Fore-foot of the Anoplotherium. After Kowalewsky.

Eocene Anoplotherium (Fig. 11), the first digit is wanting up to the carpals, but the carpal bone (1) belonging to it exists, only it is reduced and is of no further use. Of the second digit the shortened metacarpal (II) exists, as also the carpal (2), but both are useless. 
Now if we compare the same part of the foot of the Peccary (Fig. 12), the first carpal has vanished with the first toe. The second toe, of which our illustration shows the metacarpal (II), is withdrawn from the ground as the lateral

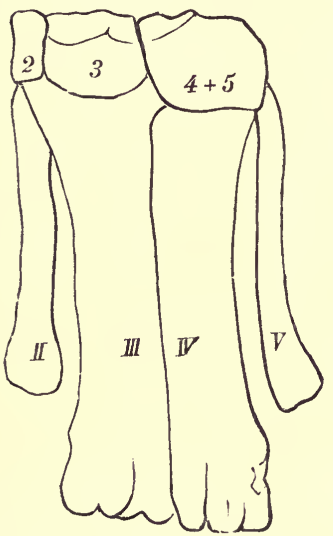

Frg. 12.- Left F'ore-foot of the

Peccary. After Kowalewsky. toe, hence becoming reduced, but its carpal (2) has not become a superfluous appendage, as in the case of Anoplotherium, it has entered the service of the third, one of the two principal toes (III, Iv); it has adapted itself to the new conditions of its organisation that have gradually been acquired.

The illustration

shows that both animals are essentially the same as regards the fourth and fifth carpals. In the peccary the fifth toe is still attached to the fifth metacarpal, as in the case of the second reduced toe of the Anoplotherium, which has dwindled 
THE UNGULATA, OR HOOFED ANIMALS. 131

down to a mere remnant of the fifth metacarpal. But it is of use almost exclusively to the fourth toe, and has grown into one piece with its neighbour, 4. Kowalewsky thinks that he may safely affirm that the inadaptive forms like the Anoplotherium had, as a rule, a very short term of existence, and differentiated within narrower limits; and that the adaptive forms possessed the more advantageous predisposition of being further developed, as is shown by their preservation and transformation up to the present time. ${ }^{1}$

The first incomings of the Hoofed animals are as yet lost in the same obscurity as those of the other orders; they are found variously developed as early as the Lowest Eocene strata. A single genus, indigenous both to the Old and the New World, possesses five toes on the fore and hind limbs, but already showing an inclination to oddhoofedism, if we may use the rather strange ex-

' Filhol has uttered a decided protest against the genus Anoplotherium. It is said to be plentifully represented in the Upper Eocene by a number of sub-genera and species. Filhol asks us to consider that the sudden disappearance of the Anoplotheridæ, without leaving identifiable descendants, may as well be the result of emigration as of a general dying out. Still Kowalewsky's opinion has the advantage of being not merely a supposition, but one based upon a very plausible scientific deduction. 

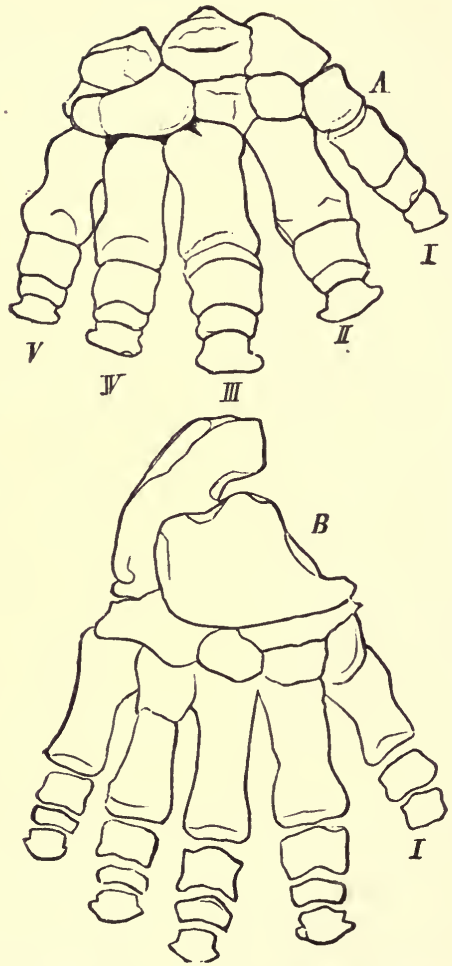

Fig. 13.-Coryphodon. Right Fore and Hind-foot. One-sixth natural size. After Cope. 
pression. The animal is called Coryphodon, and is somewhat the size of a rhinoceros. The toes are all complete (Fig. 13); but I and IV are strikingly weaker, and III decidedly the strongest, corresponding with the lengthening of the axis of the shank. The form of the skull of this earliest known Hoofed animal does not make any strange impression, any more than do the limbs. The full dentition (forty-four teeth) leads to the conclusion of its having lived upon different kinds of food. But the brain - the circumference of which can be gathered from well-preserved impressionsshows an inferior type of organisation, owing to its insignificant size and the smallness and the flat surface of the larger part of the brain. It is, in fact, the lowest and most reptile-like brain known to us. The diameter of the larger portion scarcely exceeds that of the spinal marrow, the middle brain being the broadest section. Further, the form and position of the olfactory lobes remind one of the lower vertebrates. The length of the hemispheres measures one fifteenth of the skull, their volume one twenty-seventh of that of a tapir of the same size. Hence the brain of the Coryphodon has more the appearance of that of a lizard than of any existing mammal. But, nevertheless, this and similar 
forms leave us very far from a proper knowledge of the primary Hoofed animal. And the connection between Coryphodon and the colossal Dinocerata

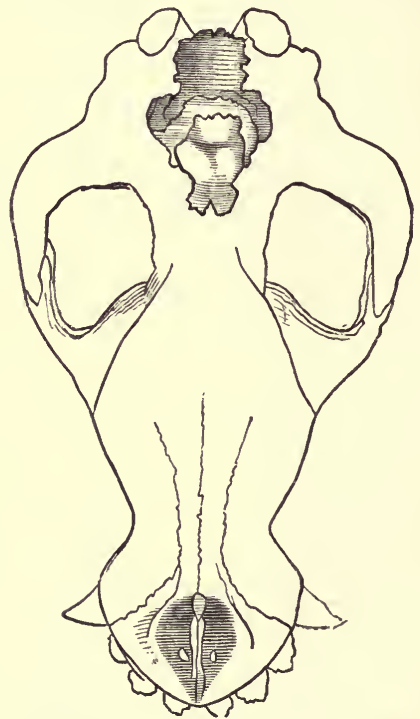

FIG. 14.-Coryphodon. Skull with Brain. One-fifth nat. size. After Marsh.

(which are confined to the west of the Rocky Mountains) also appears very indefinite. We shall again have to return to the Dinocerata. 
The palæontologist, therefore, meets with Oddhoofed animals (Perissodactyla) as early as in the Lower Eocene strata, and distinct from the Pairhoofed animals (Artiodactyla). He can, in both groups, follow a few lines up to the present, and can thus construct the pedigrees of the existing families, at all events in very probable outlines. In addition to the above-mentioned general form of specialisation-which received its fullest expression in the ruminants and horses-we have a very marked change as regards the predominance and the variations of the group in the New Tertiary as compared with the Post Tertiary periods. The tapir-shaped and pig-shaped Thick-skinned animals, which at one time swarmed among the moist forests and marshy banks, decrease in number, while deer, antelopes, and oxen become more and more the inhabitants of the newer formations of forest lands and of the grassy plains-or at least the drier steppe-lands-which became possible with the greater consistency of the newer continents. Deer, antelopes, and oxen have, since the Pliocene up to the Present, steadily and very strikingly increased in number of species, whereas the Odd-hoofed animals have as steadily decreased. As late as 1869 Rütimeyer-in special reference 
to the Hoofed animals-was able to maintain, therefore, that, 'in spite of our as yet knowing with certainty only a very small portion of the fossil animals, still it has come to seem at least probable that not only the variety and very marked character of the forms, but that the number of the species also has continuously increased.' However, this opinion requires modification since the discoveries made in America during the last fifteen years, which discoveries may, to a certain extent, be classed with Filhol's discoveries in France. The Hoofed animals teach us above all things, as has already been said, that we live in a world zoologically very impoverished.

The fossil species which have not left any living representative of their former existence will receive only our second consideration; but as this very class contains most of the genera that must be the primary forms of the present species, we shall best attain our object by showing the links which connect the mammals we have around us with those of the primordial world, by starting in a general way from the known Hoofed animals-as a few of the highest and still blossoming off-shoots of a mighty tree-and thence take a survey back towards the roots. 
Artiodactyla, or Pair-hoofed Animals.

The two main groups of the living Pair-hoofed animals are the Pigs and the Ruminants. We have an approxination to the pigs (above all in the form of the molars) in the hippopotamus, which constitutes a side group. The characteristic feature, which is met with even in the earliest known forms, is the peculiar formation of the crowns of the molar teeth; and we shall accordingly designate the Pigs as tuberculate-toothed animals or Bunodonta; the Ruminants as crescentic-toothed animals or Selenodonta. In animals of the pig species the enamel of the surface of the crowns shows elevations. The almost four-cornered crown (Fig. 15, to the left) shows a front and a back wall $(v, h)$, an outer and inner side, an outer and an inner front tubercle (AI), and an outer and an inner back tubercle $(a i)$. The tooth varies in accordance with this scheme. Elevations of the enamel are met with also in the ruminant type, but present the form of a crescent (Fig. 5, on the right), and much deeper folds.

1. THE SUIDE, OR PIGS.

The Pigs are represented in Europe by the widely distributed genus Sus, and a few others of 
lesser importance, in America simply by the Peccary, Dicotyles. From Sus we can most directly follow the series in its earlier forms, whereas the hog-deer of Celebes (Babirussa) and the African warthog (Phacochœrus) show peculiarities of dentition which, in the Babirussa, have proceeded from new and special adaptations; and the Phacochœrus seems to owe its existence to an unknown lateral branch.
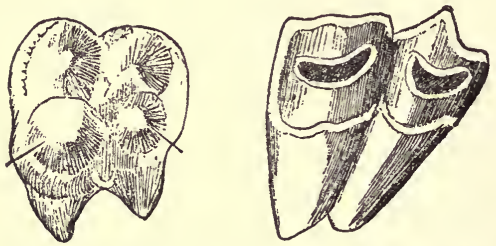

Fra. 15.-Representation of a Tuberculate Tooth and of a Crescentic Tooth.

The head of the Pig is remarkably long. Its mode of life has played a great part in forming this elongated shape. This is evident from a comparison of the Wild Boar with the Domestic Pig, or of an animal kept in a sty with an individual-even of the same litter-that has had to seek its food in meadows. The more the pig has to work with its head, by burrowing, the more it stretches the 
muscles of the neck attached to the back of its head, and the more is the plastic part, which is specially soft in the young animal, affected by the mechanical influence and becomes elongated. Further, the shape and length of the snout is the result of the pressure experienced while the pig is obtaining its food, but is especially connected with the larger number and full series of teeth. The dental formula ${ }^{1}$ is: $i \frac{3}{3} c{ }_{1}^{1} p m{ }_{3}^{3} m \frac{3}{3}$. The lower incisors stand out almost horizontally, as in the case of some of the plant-eaters, and are adapted for cropping grasses in which the tongue takes no part. The canines of the male animal de. velop into fearful weapons, especially in the case of the wild boar. The premolars are of an indefinite character and of subordinate importance, both as regards taking food and for chewing it. The molars, on the other hand, both in form and action, occupy a middle position between the cheek teeth of the Carnivora and those of the decided grass-eaters; yet in structure, in spite of their affinity to the latter, they show a closer resem-

1 The milk-teeth of the Pig consist of fonr cheek-teeth. The first one is not replaced, but remains in its position for some length of time, till after the three permanent premolars have appeared. 
blance to those of the Carnivora. They are adapted

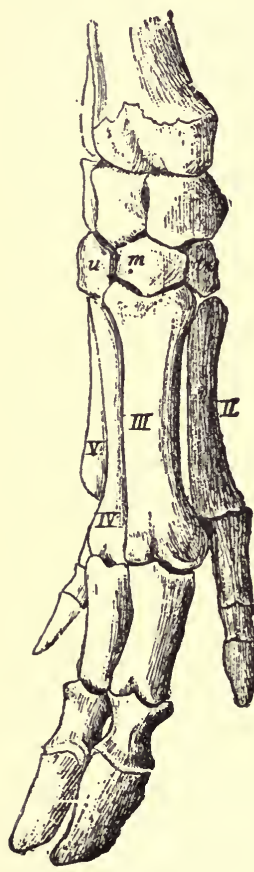

Frg. 16.-Right Fore-foot of the Pig. not only for chewing but for crunching food. Their dentition is, in fact, that of an animal living upon a mixed form of food-one of the Omnivora.

In the structure of its foot the Pig is very closely allied to the Peccary, which we have already mentioned as an example of the socalled adaptive animal form. However, the Peccary has advanced farther in the adaptation of its tarsal bones to the two principal toes than the Pig, in whose case both the second and the fifth toe still almost wholly claim the support of the carpals, without thereby accomplishing anything particular in the way of standing and running. From the relation between the carpals and metacarpals it is evident 
that the Peccary (Dicotyles), by the simplification of its limbs-which is advantageous for running-has advanced farther than Sus; it is, in fact, a better runner than the Pig, and we are fully justified in supposing that both animals will make still further progress in this direction. They are, without doubt, swifter runners than were their ancestors with their less reduced feet, and a further advantageous reduction will depend only upon circumstances. The inward disposition towards this exists, but I must beg the reader not to confound the simple word 'disposition' with the dangerous word 'tendency,' the play-word of philosophers and one apt to lead over to the idea of purpose. If, after many thousands of years, the foot of the American Peccary and the European Sus should have lost every vestige of its second and fifth toes, this would be a perfectly intelligible, nay, a most obvious case of homœogenetic convergence. If, however, our Pig and Peccary should no longer exist for the zoologists of the future, they would most probably regard the anticipated and distinctly two-toed feet of both animals as having been inherited.

This consideration may now lead us to the question as to the primary forms of our living Suide. The genus Sus is found only in the Old World, eren 
as fossils, and extends back as far as into the Middle Miocene. A powerful Boar is one of the numerous fauna found in Pikermi. Its discoverer, Gaudry, has given it the name of S. Erymanthius. The line is continued through the strata of the Eocene by the genus Palcochorus and Chorotherium, still with, or rather already with, a dentition of the Pig species, but still with less reduced, or, more correctly speaking, still with a full number of toes. Even Palcochœrus typus from the Lower Miocene of southern France shows the characteristic teeth of the genus Pig (Fig. 17) : on either side three incisors, a grod-sized canine $(c)$, four premolars and three molars. A still earlier form of the tuberculatetoothed animal is Chorotherium, which still has four toes almost equally developed. The 'ancestral line' of Primeval Pigs is thus evident enough for those who choose to follow it, and is more distinct than many a human pedigree.

Among the cousins of this family who could not maintain an existence, and whose position is, in fact, somewhat doubtful, are Choropotamus, and also the colossal animal Anthracotherium, from the Coal formation, which attained the size of a rhinoceros.

America likewise possessed a line of pig-shaped animals which may be traced from the Eocene up 
to the present living Peccary, and, with the exception of a few species, is one different from that of the primordial world. In this series we find repeated the transformations and reductions which we have just followed. Marsh makes out the line from the Eocene thus: Eohyus, Helohyus, Perchœrus, Tinohyus, Dicotyles. Hence we still stand before the unanswered questions, whether, to what extent,

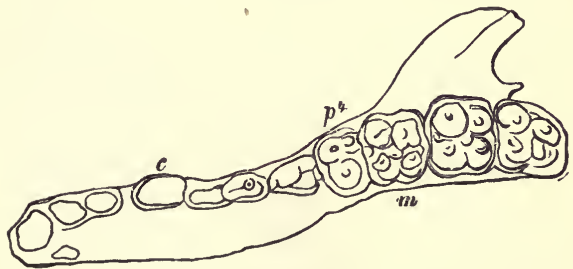

Fig. 17.-Palæochœrus typus, Left Upper Jaw. Nat. size. After Gaudry.

and in which direction (from Europe westwards? from Asia? or from America?) the exchange took place, as affecting the formation of the differences of the species? or whether the development was a parallel one; Chœropotamus to the Pig, Eohyus to the Peccary? Geologists are pretty well agreed that during the Earlier Tertiary period, up to the Lower Miocene, the Old and New World were connected by 
land, and during the Later Tertiary as well. An exchange, therefore, may have taken place, and certainly must have taken place up to the Eocene period, as is proved by the occurrence of Coryphodon in Europe and America, and of Palæotherium and Anoplotherium in Europe and South America. But for a long period, during the Miocene, there was no connection either between North and South America or between America and the Old World. Hence during this period there must, in any case, have been a further parallel development upon the same basis, a parallel development of Pair-hoofed animals with tuberculate teeth, where the reduction of the toes, discussed above, was an advantage; and the supposition of an even wider case of convergence is perfectly admissible from a scientific point of view.

\section{THE HIPPOPOTAMUS, OR RIVER-HORSE.}

The Hippopotamus has to be traced back to a similar primary form, for it is the only living representative of the Hoofed animals with tuberculate teeth which has preserved the old structure of the limbs pretty well unchanged. The still uncut, rootless cheek-tooth (Fig. 18) somewhat resembles a double mitre with a basal setting, which in front and at the back passes over into a three- 
sided shield, and has a wart-shaped protaberance between the two halves both out and inside. Each half consists of two almost three-sided tubercles, which lie flat against the inner sides that are turned toriards one another. From this it is evident that the enamel outline of the used tooth

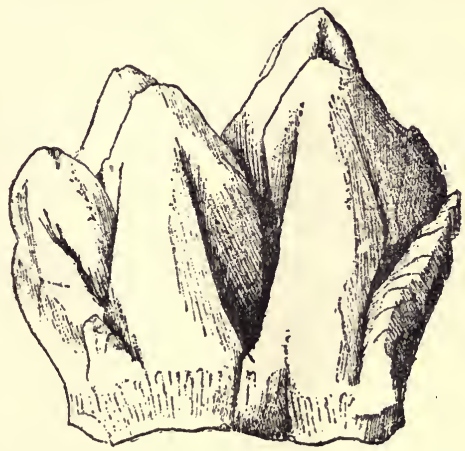

Fro. 18.-Second Lower Molar of the River-horse, to the right. Nat. size.

(Fig. 19) consists originally of two pairs, with the basal line of the three corners turned towards one another, and which do not coalesce till they have been used for a long time.

The Hippopotamus has become almost an amphibian in its mode of life; its skull and 
dentition show very little modification, and the formation of its foot has remained very faithful to the primary type from the Eocene, the lineal descendants of which, unfortunately, cannot be pointed out singly. The Eocene animals with tuberculate teeth, and likewise the Early Tertiary ancestors of the Ruminants, had to dwell prin-

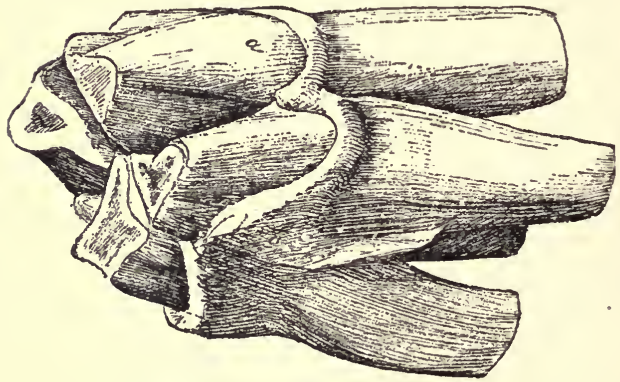

FIa. 19.-First Upper Molar of the Hippopotamus, to the right. But little worn off.

cipally in waters and on marshy ground. Their descendants adapted themselves gradually to life on dry ground, and this is connected with the advantageous reduction of the toes. The Hippopotamus family has taken an opposite course, from being an animal that liked the marshy soil of the primeval forests, it has become almost an 
aquatic creature, and accordingly has preserved the completeness of hand and foot, the four toes almost fully developed. In Fig. 20 we have the root and middle portion of the right fore-foot, and we will here use the terms generally given to this part of the skeleton in Man and the higher

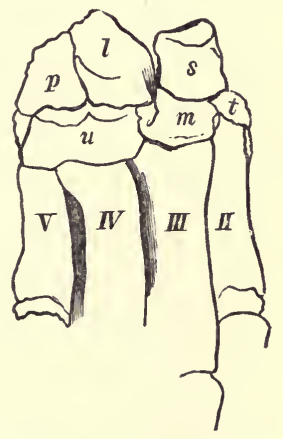

Fir. 20.-Hippopotamus, Right Fore-foot. After Kowalewsky.

vertebrates: $s$ (scaphoideum $)=$ radiale $; l$ (lunatum $)$ $=$ intermedium $; p($ pyramidale $)=$ ulnare $;$ (trape zoideum $)=$ carpale $2 ; m$ (magnum or capitatum $)=$ carpale $3 ; u$ (uncinatum $)=$ carpalia $4+5$.

A one-toed hippopotamus in the natural course of development is an impossibility. The gradual reduction of the toes, as already said, can be con- 
nected oily with the drying up of marshy lands. And if, by some extravagant flight of the imagination, we could conceive the existence of a one-toed leviathan, the very fact of its possessing a one-toed foot would be the cause of its speedy extinction. As regards dentition also the hippopotamus shows signs of being geologically very old. The skull of the unwieldy creature reminds one of a clumsilyformed box. The breadth and height of the muzzle are produced by the enormous development of the middle incisors and of the canines. All of these teeth are furnished with roots that are not closed, but open wide apart. It is certainly not impossible that these teeth assumed this form first among the nearer ancestors of the river-horse. But it is more probable still that the disposition to assume this form was a remote inheritance, and that it was only by accommodating itself to feed on aquatic plants that, as regards position and size, the teeth have grown into such ugly but useful tusks.

It has been already stated that the river-horse is the only representative of its family. This remark requires some explanation; for we have not only the well-known and so-called Nile-horse, which is distributed over a large portion of central Africa, but there is a second species, only 5 feet 
in length, which, among other things, is distinguished by the remarkable shortness of the face as compared with the total length of the skull. This animal, which is met with in Siberia, has been classed apart from the hippopotamus as a distinct species under the name of Choropsis. As, moreover, the dentition is not quite the same, this separation may be allowed to pass; but both species are and remain 'river-horses,' and all that has been said above applies to the smaller species as well.

It is only quite recently that we have become more intimately acquainted with a third species, ${ }^{1}$ the Hippopotamus madagascariensis, which, as regards size-it became some 7 feet long while the Nile horse attains 11 feet-fills the gap between the two African species, and as regards skull and dentition approaches very close to the Hippopotamus amphibius. Its occurrence is extremely interesting, inasmuch as it leads from Africa over to Madagascar, where its remains were found in marshy deposits together with those of the colossal bird Epyornis. Its having been found in company

1 Goldberg, 'Undersōgelser over en subfossil flodhest fra Madagascar,' Christiania Videnskabs selskabs Forhandlingar, 1883 , No. 6. 
with this bird, and the nature of the locality where it was discovered, justify the expression of 'subfossil ' which is given to the species. It lived on the threshold between the Diluvium and the Present. And even granting that Madagascar and Africa were at one time connected by land, their separation must, nevertheless, have taken place early in the Tertiary, and accordingly the stability of the genus Hippopotamus is also proved from a geological point of view. It is not only the formation of the foot that points to very ancient primary forms to be looked for beyond the Tertiary period; but the dentition also-which had specialised even before the separation of the family into the African and the Madagascar species-has varied only to a very small extent.

\section{THE RUMinaNtia, OR CUD-CHEWING ANIMALs.}

After setting aside the, at present, very subordinate group of pig-shaped Pair-hoofed animals, and the Hippopotamus, all the remaining forms of this division belong to the Ruminants. As all are, for the most part, lively and nimble animals, they do not, while grazing, take proper time to masticate their food sufficiently, but hurriedly stuff their paunch full of provision and then retire to 
some safe retreat, where they assist the digestive process by giving the grasses and leaves consumed a subsequent crunching and chewing. The Ruminants do not bite off the plants, but tear them off, in doing which the tongue plays an important part as an organ for grasping, especially when long grasses and branches have to be dealt with. In this mere tearing off of grasses, \&c., the incisors of the upper jaw can be dispensed with; it may be said that with the development of meadow plants and pastures, these teeth have in course of time become superfluous. Only animals of the Camel species show rudiments of the upper incisors, and in addition to this case, canines have been preserved by the musk-deer. The crowns of the molars, as a rule, show two transverse ridges, and, moreover, the upper and lower molars fit in such a manner that they can glide over one another from right to left and also in a horizontal manner, as may be seen in any ox or sheep 'chewing the cud.' This movement of chewing is rendered possible by the condyle of the lower jaw not being sunk into a transverse socket of the temporal bone, as in the case of the Carnivora, or into a furrow running parallel with the axis of the skull so as to move backwards and forwards, as in the Rodents, but by 
being allowed free play upon an almost level, or even a somewhat raised surface.

All Ruminants possess the above-mentioned typical molars with the enamel crescents running in the direction of the longitudinal axis of the skull, which, of course, present a very different appearance-within the boundaries of the generic characteristics-according to age and wear. Fig. 21 shows an, as yet, uncut fourth right molar of a calf as seen from the front and the inner side. It seems to consist of two almost quadrilateral prisms, both terminating on the outer and inner side, in two curved flaps (A-I and $a-i$ ). All the surfaces, which pass over into various curves and folds, one within the other, and are lost in the interior of the tooth, consist of the, as yet, imperfect and still somewhat soft layer of enamel. Below it is the dentine, which is likewise just beginning to develop, and round about in the depressions, between A and I and $a-i$, we find the incomings of the cement which is still a membraneous formation. Now, if we take this embryo tooth and compare it with the polished edge of one of the already cut front teeth (Fig. 21, I), we shall at once obtain a clear idea of the relation of the enamel folds and edges of the molar of a full-grown animal. The 
transverse ridges, which fit into the depressions or transverse valleys of the opposite row of teeth, remain throughout life, even though, at a later age, they may become more and more rubbed off and level. The crescents, which become filled with cement and are encased on the outside by enamel, on the inside by dentine (tooth-bone), $\mathrm{A}, \mathrm{I}, a, i$, are
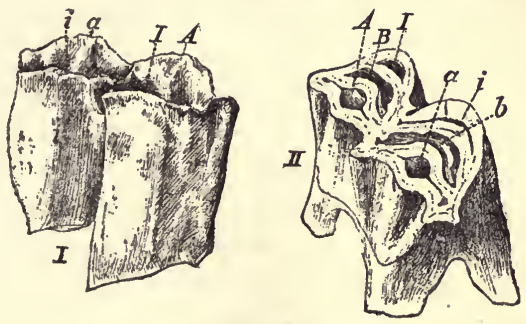

Fro. 21.

I. Right upper molar of a calf before it has cut the gums; $i$, inner side; $A, a$, the outer lobes of enamel; $I, i$, the inner lobes.

II. The right molar of a calf that has cut the gums, artificially ground; from behind and the outer side.

the transverse sections of the flaps of the same name; $\mathrm{B}$ and $b$ are the arched-shaped spaces which likewise become filled with cement, and were obviously larger in the thin-walled, uncut tooth. If we weigh the different possibilities of the folds of the outer walls, the form of the crescent, the development of the side folds and pillar-shaped processes, 
we come to understand the great variety which distinguishes the Selenodonts among one another, and which becomes all the more marked, the more obstinately the characteristic form is preserved.

But since Kowalewsky's classic works there can be no question that the peculiarities, connected with the reduction of the limbs, are testimonies at least as distinctive and trustworthy for the Present and the Past.

The majority of the living Ruminants are divided into the large families of the Deer, the Antelopes, and the Oxen. The last two, as horned animals, are more closely allied to one another than to the deer. The goats and sheep are closely allied to the antelopes. Apart from all these we have the Camels, to which we shall first direct our attention, for, at least as regards dentition, they have preserved a higher geological antiquity than the others.

\section{THE CAMELIDE, OR CAMELS.}

When Rütimeyer calls the llama 'a late offshoot of the Eocene Anoplotheriæ, and as originating first in America,' he gives a proof of the utter uncertainty which prevailed about ten years ago as to the position and historical development of the two species which, since Buffon's day, had been regarded 
as belonging to one another. Of the two species of camels the one with two humps is assigned to Central Asia; the other has been distributed over a large portion of Africa by Asiatic nomads, and represents a peculiar mode of life. The llama 'vicariates' for them. The hoofs are small, but the foot has a broad horny sole; the skeleton of the foot is that of a true Ruminant. The camels differ from all the living Ruminants by the total absence of horns and by a fuller dentition; for they not only possess strong sharp canines, but an incisor in the mid jaw-bone, somewhat to the side. All the other Ruminants, without exception, have lost their upper incisors. On this account, and because of the superficial resemblance in the form of the skull with that of the horse, camels were formerly classed as a group standing midway between the horses and the two-hoofed animals; this, however, is an unwarrantable conjecture. American investigators have, on the other hand, now made us acquainted with a whole series of primeval forms, according to which the camel appears to be a very old branch of the Selenodonts.

Marsh gives us the result of his own and of Leidy's observations thus: 'A most interesting line, that leading to the camels and llamas, sepa- 
rates from the primitive selenodont branch in the Eocene probably through the genus Parameryx. In the Miocene, we find in Pœbrotherium and some nearly allied forms, unmistakable indications that the cameloid type of Ruminant had already become partially specialised, although there is a complete series of incisor teeth, and the metapodial bones are distinct. In the Pliocene the camel tribe (in America) was, next to the horses, the most abundant of the larger mammals. The line is continued through the genus Procamelus, and perhaps others, and in this formation the incisors first begin to diminish and the metapodials to unite. In PostTertiary we have a true Auchenia represented by several species, and others in South America, where the alpacas and llamas still survive. From the Eocene almost to the present time North America has been the home of vast numbers of the Camelidæ, and there can be little doubt that they originated there and migrated to the Old World.'

' Cope, in 1877, gave a fuller account of these opinions. The Miocene Pcbrotherium possesses of grinders $p .4, m$. 3. The two elongated metapodials have not coalesced; seven tarsals. Then comes Protolabos still with $p .4, m .3$; the last molar is more prismatic. The incisors also are still there in full number, but fall out readily. Procamelus is the first to show incisors like our present camel, yet still $p .4, m$. 3. The side rudiments of the metatarsals of Pcbrotherium have disappeared, hence the 
Nothing can well be said in opposition to this. Our illustration below (Fig. 22), gives the upper

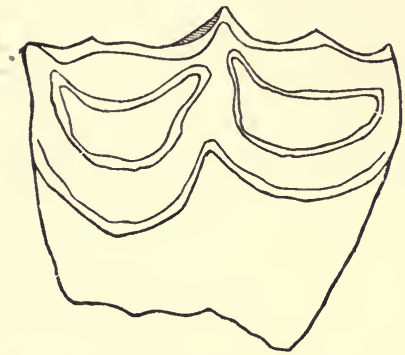

Fro. 22.-Auchenia hesterna. Second Molar of the Left Upper Jaw. Nat. size (after Leidy).

molar of one of those Diluvial llamas, the Auchenia hesterna, in the natural size.

trapezoid. The metatarsals have coalesced and become the 'canon-bone.' Then comes Pliauchenia with $\frac{4 \text { ?-3 }}{3-3}$ cheek-teeth, Camelus, $\begin{aligned} & 3-3 \\ & 2-3\end{aligned}$, Auchenia $\frac{2-3}{1-3}$. A more and more con. tinuous debay in the formation of the teeth is observed; the teeth eventually no longer cut the gum, and finally disappear completely, a process which is repeated in many other lines. The occurrence of the llama in South America shows that the causes which led to its extinction in North America did not exist in the southern continent. 
5. THE CERVIDE.-DEER AND THEIR KINDRED FOTMS.

Rütimeyer, in his ' Natural History of the Deer,' when speaking of the characteristic features that distinguish the various forms of deer, maintains that the antlers are periodical, and that they are attributes confined to the males of the species. In looking for the relationship between the formsprincipally in the female skull, as in the case of the Ruminants-he finds the character of the deer (as compared with the antelopes and oxen) to consist in the very elongated, almost cylindrical shape of the skull. This is caused by the great length of the olfactory tube with a lesser height of the toothed portion of the upper jaw. The skull is elongated and, as compared with the facial part, is less voluminous than in the case of the horned animals; the brow is less of an abrupt incline, the axis of the skull straight. The character of the head of the deer may, of course, be thus described, and Rütimeyer has endeavoured also to characterise the antelopes and oxen. Still, it cannot be denied that the antlers, nevertheless, play a very great part, and that their existence is of decided importance in the classification of the deer.

The common Roe and Red Deer furnish us with 
two examples of very different degrees of development in the antlers of single species; and by observing the annual changes of the antlers we can, with almost certainty, trace the different stages attained by the various species with less fully developed antlers. The first sign of the coming of th 3 antlers in the calf, is a thickening and protruding of the frontal bone, the incomings of the permanent base of the horn. Between it and the upper layer of skin are then formed the beginnings of the actual antlers-ossifications of the skin-which soon coalesce with the frontal process, dry up after completing their growth, and fall off after pairing time. The antlers of the first year-the stem or beam-consist of a pair of simple stumps with the circular ridge of bone called the burr. The following years furnish the branches or tynes.

This development of the antlers in the individual case of the red deer, Rütimeyer compares with the antlers in the historical and geological succession of stag-shaped animals, which in the Lower Miocene are still without antlers. In the Middle Miocene of Sansan and Günzburg, and in the Upper Miocene of Eppelsheim, we first meet with an animal that is almost, but still not completely, 
a stag. Frontal protuberances very elongated,

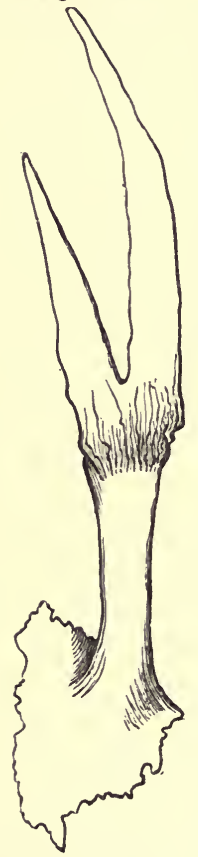

Fig. 23.-Proz furcatus. Left antler. One-half nat. size. beams with single branches are there, but no burr (Fig. 23). The genus has been described under various names, as Dicrocerus, Prox, Procervulus. The tynes are often found broken off, and it cannot be said with certainty where accident ends, and the regular periodical casting off has begun. It would seem as if the casting had become established from the irregular occurrence-partly the drying up of the skin and the brittleness connected with this.

Rütimeyer observes that it is difficult to distinguish the primary stags from the primary antelopes, and that perhaps the North American prong-horned antelope which, curiously enough, casts its horns annually, must be traced back to those indefinite primary forms. Cope had made the same observation in 1877 when he wrote: 'The 
genus Antilocapra is related to the Dicrocerus by its pronged horns and the hairy covering of skin which constitutes the immature stage of the hornsheath.' The Procervulus mentioned above was a widely distributed genus in the Miocene period, as is proved by the discoveries in New Mexico and Nebraska. The genus Cervulus, which is distributed over both the Old and the New World in about eleven different species. inust be regarded as a diluvial remnant of the genus Procervulus, by the side of the more modern family of the Deer, which show a further advance in the development of their antlers. The best known representative of the genus is the Muntjak (Cervulus muntjac) in India and the Sunda Islands.

In the Deer, as in the case of most of the living pair-toed animals, the two metatarsals which support the two fully developed toes have coalesced into the so-called cannon-bone. Their limit is indicated by a more or less distinct longitudinal furrow on the front side, frequently also by a deeper indentation in the lower joint. We never meet with complete metatarsal bones for the two outer toes that are removed from the ground. The modifications which prevail in this respect, within the group, appear of very little importance and 
interest when considered by themselves, but when taken in connection with the geographical distribution of the animals, are of great significance. As
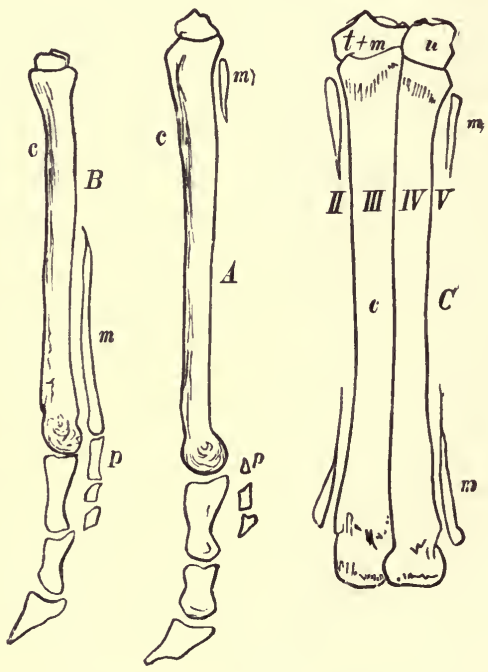

Fia. 24.

A. Left fore-foot of the Red Deer. B. Left fore-foot of the common Roe. $c$, Cannon-bone; $m$, metacarpals; $p$, upper phalange. $C$. Second row of tarsal and metatarsal bones of the Gelocus. After Kowalewsky.

examples of this we may take the red deer and the common roe (Fig. 24). The rudimentary toes in both cases consist of three phalanges. In the red 
deer the first of these is smaller than the other two, whereas in the roe the first one is of the proportionate size. Now this arises from the fact that the rudimentary digits of the deer have become entirely detached from the metacarpals, and that only the rudimentary upper end of it remains $(A, m)$. The roe still possesses the lower portion of this bone $(\mathrm{B}, m)$ and, moreover, in connection with the first phalange. The red deer is a 'plesiometacarpal' cervide, the common roe a 'tele-metacarpal' cervide. All the thirty-nine known species of Cervidæ, confined to the Old World, are constituted like the deer with the exception of the two species of roe and the hornless Hydropotes in China, with which we have only recently become more intimately acquainted. These three latter species, however, as regards the construction of foot, are allied to the American deer. Of the twenty American species with tele-metacarpals, one, however, the Wapiti (Cervus canadensi3), is not related to the others, but to the Europe-Asiatic group.

From the formation of the foot, therefore, wc find an almost perfect means for distinguishing the species. And this leads to the very natural supposi. tion that the American deer developed in the New 
World, and the Europe-Asiatic species in the Old. It is only the ancestors of the Roe and the Hydropotes that must not be looked for in the Old World; they are scattered members of the group from the other side of the ocean, like the Canadian species which, in the days when the two continents were connected by land, separated entirely from their Europe-Asiatic cousins. It is found in the Quaternary strata of Europe, e.g. in those of Louverné, near Le Mans, where it lived as a separate family by the side of the red deer, but soon afterwards, for some unknown causes, vanished from this locality and reappeared in the New World.

The reduction of the side toes and the disappearance of the one or the other ends of the metacarpals took place after the still four-toed and geologically older stag-shaped animals had acquired antlers. This may have been the course taken by their development, unless we are to assume that the antlers appeared in different localities as a parallel formation, yet not till after the separation of the older hornless Ruminants, which likewise showed a reduction of the limbs spoken of above. The latter case is very probable, and must be drawn into the circle of combinations, for in Gelocus we have become acquainted with a very ancient 
Ruminant of this kind, out of which both plesiometacarpals as well as tele-metacarpals forms might have developed. Gelocus is an adaptive species of Ruminant from the Eocene. The skull as yet scarcely shows the character of the ruminant, but the molars are already reduced to ${ }_{6}^{6}$, whereas other genera of the same age show $\frac{7}{7}$. The two principal metatarsals (Fig. 24, c, III, Iv) have coalesced along almost their entire length; the metatarsals of the side toes have, however, disappeared in the centre (Fig. 24, II, v), and only the lower and upper ends remain $(m)$. Animals of this kind might have descendants with feet of the Deer species, another with feet like the Roe. At all events, deer and roe, both of these well-known denizens of our forests, have been strangers to one another from very remote times, strangers as complete as the Canadian stag (the Wapiti) is to all the other American Cervidæ.

An intermediate position between them is occupied by the Elk and Reindeer. Both are circumpolar species, and both, as regards construction of the foot-as tele-metacarpal species-are allied to the deer of the New World, the reindeer, moreover, by the form of the nasal cavity. Our material is at present too fragmentary to enable us clearly to 
survey both sides. But all of these observations, which we owe principally to Sir Victor Brooke,' confirm Rütimeyer's remark that the form and derelopment of the antlers can only rery cautiously be made use of as a means for a strict classification of the Cerridx.

Even though animals with antlers are met with as early as the Miocene, still the more complete development of true Deer belongs to very recent periods, and this explains their geographical distribution in the main. In addition to the circumpolar reindeer and elk, Rütimeyer, agreeing with Brooke, reckons twenty species to America and thirty-nine to the old World, many of which are certainly doubtful. An exchange between East and West seems evident, and yet, as we have seen, it was extremely limited. The remarkable want of deer in Africa beyond the desert, would have to be explained, with Wallace, by the fact that there must have existed obstacles almost insurmountable to the animals when they first began to distribute; on the other hand, antelopes and eren giraffes had either already passed the open road southwards, or, owing to their organisation, had gra-

'Brooke, 'On the Classification of the Cervidæ,' Proc. Zool. Soc. 1 sio. 
dually overcome the difficulties presented by the desert.

Zoologists have always classed the Musk Deer and the Dwarf Musk Deer (Tragulida) with the true stags, although they are hornless animals. In doing this they have allowed themselves to be led by the general impression that the possession of antlers is not determinative of the relationship; this had already been affirmed by Alphonse MilneEdwards in 1864, and has been proved by their connection to the fossil forms that have now been brought to light. From these annexed groups the Hyamoschus aquaticus, which lives on the west coast of Africa, is of great importance as the connecting link between the present and the remote past. Our Figure 25, $\mathrm{s}$, gives the left fore-foot of this animal. Hyæmoschus is also a decided twohoofed animal, although the two middle metacarpals (III, Iv) are entirely separate, and although the two outer metacarpals (II, v) are perfectly complete and the two lateral toes are developed and connected. Hyстовсhиs thus proves itself an adaptive form, inasmuch as the two toes that are no longer of use have ceded their right to the tarsals, to the principal toes, and thus increased the strength of the latter. The skeleton of the fore- 
foot of the IIycmoschus appears a slight modification of that of the Miocene Hyopotamus (Fig.
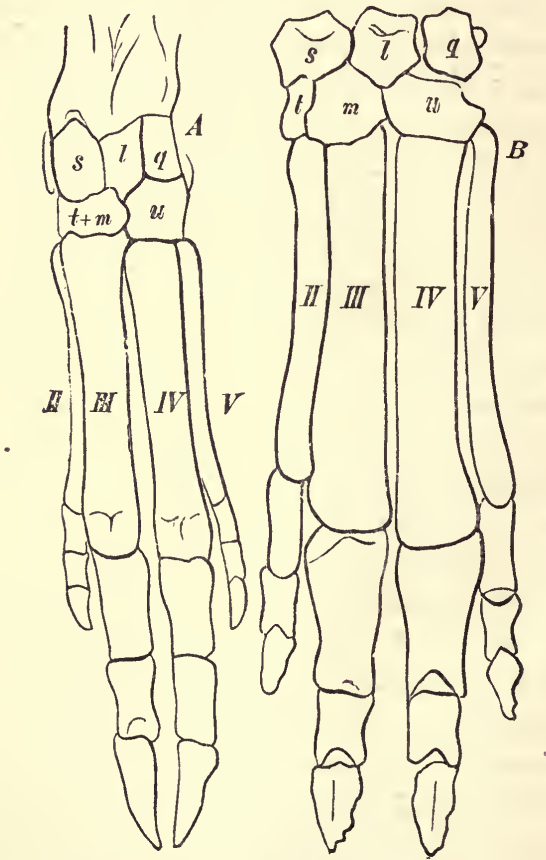

Fra. 25

A. Ieft fore-foot of Hyæmoschus aquatious.

$B$. Same foot of Hyopotamus. After Kowaleweky. 
25, в). There both outer toes are still somewhat longer and stronger. Trapezoid and os magnum have not yet coalesced; the metacarpals II and $\mathrm{v}$ are still connected with the carpals. Upon the whole, however, the differences between the living and the Niocene representatives of the pair-hoofed group are so slight that Hyamoschus may be called a surviving form of primary ruminant.

The hind limbs of the IIyamoschus are more changed than the front limbs, owing to the two principal metatarsals having almost completely coalesced. A greater reduction of the hind limbs is often met with: for instance, the peccary has only one rudimentary toe on its back foot, whereas there are two on the fore-foot. This difference in the construction of the front and back limbs is, we think, to be explained by the greater amount of work which the hind legs have to accomplish; for, as was said above, we look upon a reduction of this kind as an advance in the power of the adaptation. But, while we are naturally led back from our present Deer and Tragulidæ to those early fourtoed Hyopotamidæ, we do not in any way mean to affirm that up to the Middle Tertiary all animals of the Ruminant group without horns or antlers possessed the full number of four toes. On the 
contrary, it is found that the Anoplotherium from the Eocene of the Paris limestone, which has left no descendants, shows scarcely any traces of the second and fifth toes; and by the side of the Hyopotamus, with four-toed feet, there existed the distinctly two-toed Gelocus, ${ }^{1}$ whose extremities are almost as much reduced as the Deer; and the same is the case with Diplopus. It would be rash to attempt to determine, among all these varied forms, which was the actual and definite primary form for the Deer or any other living group of the Ruminants; still, any attempt to explain the striking relation between the past and present forms, otherwise than by means of the theory of descent and in accordance with Darwin's principle, cannot be expected from us. The share which homøogenetic approximation may have taken in this connection has already been discussed.

The same result is obtained by the condition of the teeth; and, as in the case of the limbs, the teeth must not be examined in the Deer by themselves, the whole group of Ruminants must, first of all, be compared with the fossil forms.

Among our living Hoofed animals the Giraffe

'Filhol, 'Mammifères fossiles de Ronzon, 1882,' Gelocus, Ancodus, and others; their Relation to Hyopotamus. 
occupies a perfectly isolated position. Apart from its strange shape - the result of a lengthening of the vertebræ of the neck-and of the different lengths of its fore and hind limbs, descriptive zoology has very rightly laid stress upon the frontal decorations which adorn both sexes, and which have been said to be neither horns nor antlers. The two horn-like unbranched protuberances are covered with a hairy skin which never dries up as in the case of the deer, and hence they do not fall off periodically. These skin-covered bony protuberances cannot, however, be compared to the bony protuberances of the Oxen, as might be supposed, that is, to the processes of the frontal bone covered by the horn sheath. On the contrary, like the antlers proper, they begin as ossifications of the skin, and grow precisely in the same manner as antlers, but never become perfectly attached to the frontal bone. In order briefly to distinguish the character of the formations it may be said that-

Hollow-horned animals have frontal processes without antlers,

The Deer processes with antlers,

The Giraffes antlers without processes.

Hence Rütimeyer calls the giraffes ' a most fantastic form of deer.' 
Like the lions and gazelles, the giraffes of Africa are probably immigrants from the South of Europe. Among the Mammalia buried at Pikermi is a species, Camelopardalis attica, almost the same size as the African variety. Unfortunately its skull is not known. The disproportion between the hind and fore limbs seems to have been even greater in the fossil species. Further traces lead us to the Siwalik hills in India. Numerous remains have enabled Gaudry to restore the complete skeleton of a genus closely allied to the giraffe-the Helladotherium-which lived in herds in Miocene Attica, and owing to their great size must have been characteristic figures in the landscape of the primeval world.

It was customary to class with the above the colossal Indian Sivatherium, which possessed a pair of simple horns in front, and a second branched pair. And yet our conjectures with regard to its affinity with the Giraffe are uncertain, and Rütimeyer thinks that the Sivatherium points as much to the Antelopes, as the Giraffes to the Deer. Our knowledge of two other Indian species, the Bramatherium and Hydaspitherium, is as yet so fragmentary that it is wiser not to make any conjecture as to their relationship. 
The Giraffes stand close to the Deer, not because they have branched off from the deer, but because the unknown ancestors on both sides showed a disposition to certain reductions and convergences of a similair kind.

6. CAVICORNiA, hOLLOW HORNED ANiMALS.-ANTELOPES AND OXEN.

The horned Ruminants, which are grouped round the Chamois, Sheep, and Oxen-and hence furnished with horn-cores rising from the frontal bones, and a horn sheath-would appear to anyone to form a natural group. And even those who have not studied the subject would undertake to distinguish a Gazelle, as the representative of the Antelopes, from an Ox. The gracefulness of its whole appearance, more particularly of the horns, the smallness of the head, the slender shape of the legs, sharply distinguish the Antelopes from the Oxen, whose horns stand at the outermost point of the brow, whose skull is unwieldy in form, and whose legs (in keeping with the rest of the skeleton) are anything but graceful. However, when we examine the different families in any good collection, we shall find that by the side of the prevailing type of the slim antelope, there are various kinds of cow-shaped forms, with head and limbs in no way 
resembling the Gazelles, yet almost all with horns strikingly different from those of Oxen. Finally, the gnu completely breaks down any systematic boundary, for by the form of its hindquarters and tail it resembles the horse. And into this group sheep and goat have to be brought. We can, it is true, distinguish them among one another by the characteristic traits of the family; for instance, by the peculiar form of the skull. The ram, owing to the form and solidity of the nasal, lachrymal, and frontal bones, is able to give and to receive those tremendous blows of forehead against forehead which would break the skull of the male goat. But there are sheep with goat-like horns; and an animal that is clearly a sheep from the form of its skull has up to within recent times been called the musk ox.

These resemblances-it may positively be asserted-do not proceed from recent derivation or crossings, but must be traced back-except in the case of the closely allied Sheep and Goats-to convergences. Moreover, the Antelopes-the most varied group of the living Ruminants-have not been so carefully studied in connection with their nearest fossil relatives as the Oxen. ${ }^{1}$

' Rütimeyer's valuable investigations of this group may here be mentioned. 


\section{The distinguishing feature in the skull of the} ox is most strongly developed in our domestic

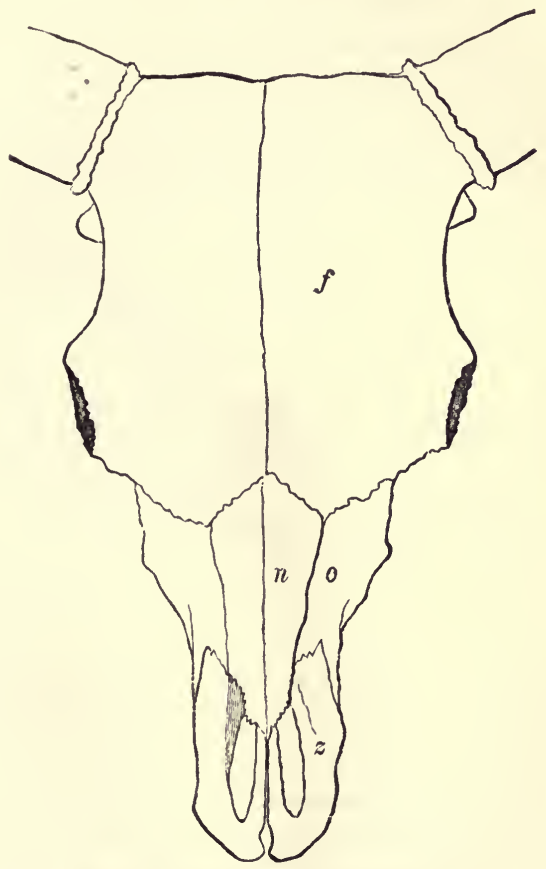

FIG. 26.-Skull of a Short-horned Bull.

$f$,Frontal bone; $n$, nasal bone; $a$, upper jawbone ; $z$, mid jawbone. 
animal belonging to the genus Bos (Fig. 26). Here the parietals are pushed completely back from the top, or all but a small portion, to the abrupt incline at the back of the head. From a front riew, or looked at from above, they cannot be seen at all. On the other hand, the frontal bones (Fig. 26) form great plate-shaped cover-

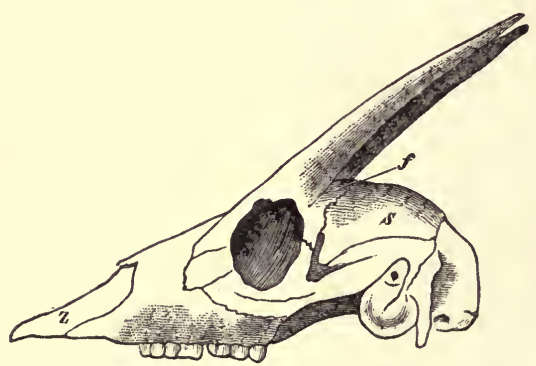

Fig. 27.-Skull of the Gazelle (Antelope arabica).

$s$, Parietal; $f$, frontal bone ; $z$, mid jawbone.

ings to the forehead, and the bony processes rise upon their outer edge. As compared with the skull of an antelope (Fig. 27), the skull of our domestic ox has reached the extreme of a formation which is still repeated pretty perfectly in the individual development of the calf to the cow. It consists in this: that in the calf the skull is still 
rounded, the frontal part is not, as yet, elongated, and the crown portion still forms actually a part of the upper covering of the skull. Only upon the appearances of the horn-cores and the lengthening of the frontal bones do we find the first indication of the abrupt rising up of the main back wall. The calf is therefore still antelope-shaped as regards the formation of its skull, as is shown in Fig. 27, where the whole length of the parietal bones are still to be seen from above, and the horncores do not occupy the backmost or outermost corner of the frontal bones. Sheep and goats also keep within the boundary of this type of the Antelope family. Calf and cow, therefore, again corroborate the most important proposition of our doctrine of descent: that the individual development is an abridged repetition of the historical development of the species.

On the accompanying table of Rütimeyer's we lave the sub-families of the Oxen classed according to the form of their skulls. It $b$ ins with the buffaloes, which, as regards skull and the position of their horns, have deviated $y$ ast from the Antelopes, and closes with the domestic ox, which has differentiated the most. We gather from this table-which contains the quintessence of all the 
Tabelar View of the Fossir and Living Oxey (AFTER RütIMEYer).

\begin{tabular}{|c|c|c|c|}
\hline & $\begin{array}{l}\text { Mliocene? } \\
\text { Pliocene }\end{array}$ & Pleistocene & Living \\
\hline $\begin{array}{l}\text { I. Bubalina } \\
\text { Bubalus }\end{array}$ & & & caffer \\
\hline Buffelus & & $\begin{array}{l}\text { antiquus } \\
\text { sivalensis }\end{array}$ & $\begin{array}{l}\text { brachyceros } \\
\text { indicus (domestic } \\
\text { ox) } \\
\text { sondaicus }\end{array}$ \\
\hline Probubalus & & $\begin{array}{l}\text { Pallasii } \\
\text { triquetri- } \\
\text { rostris } \\
\text { antelopinus }\end{array}$ & (Anoa) celebensis \\
\hline $\begin{array}{l}\text { Amphibos } \\
\text { II. Portacina }\end{array}$ & acutiformis & & \\
\hline $\begin{array}{l}\text { Leptobos } \\
\text { III Bibovina }\end{array}$ & $\begin{array}{l}\text { Falconeri } \\
\text { Strozzi }\end{array}$ & Frazeri & \\
\hline Bibos & etruscus & $\begin{array}{l}\text { Palæo- } \\
\text { Gaurus }\end{array}$ & $\begin{array}{l}\text { Gaurus } \\
\text { ? Gavæus } \\
\text { sondaicus } \\
\text { indicus } \\
\text { grumniens (Yak) }\end{array}$ \\
\hline Bison & sivalensis & $\begin{array}{l}\text { priscus } \\
\text { latifrons }\end{array}$ & $\begin{array}{l}\text { europreus } \\
\text { americanus }\end{array}$ \\
\hline $\begin{array}{l}\text { V. Taurina } \\
\text { Bos }\end{array}$ & planifrons & $\begin{array}{c}\text { namadicus } \\
\text { primigenius }\end{array}$ & $\begin{array}{l}\text { taurus f. primi- } \\
\text { genius } \\
\text { f. trochocerus }\end{array}$ \\
\hline
\end{tabular}

investigations made on the subject-that our knowledge is still meagre enough, inasmuch as at the Pliocene stage--where true oxen are first met with -we already find the transition from the buffalo to the ox in its narrower sense. The different 
European oxen ' have all, perhaps, to be traced back to the Diluvial Urus, or wild bull (Bos primigenius), and the races which branched off as early as the Diluvial period. ${ }^{2}$ If, in accordance with the above standpoints, the skull of the domestic ox, of the bison, the yak, and the Indo-European buffalo, be compared with that of the antelope, it will be found that the resemblance to the antelope will become more and more apparent. Thus the bison (Fig. 28) is still so like the ox that, as we shall see, it might be doubted whether one of our races, the Dux cattle of Eastern Tyrol, is to be traced back to the wild bull or to the bison. On the other hand, the Anoa of Celebes, which Rütimeyer calls the Probubalus celebensis, is indeed still an ox in all its ontward characteristics ('the dwarf of the ox family '), but is a complete antelope as regards the position of its frontal and parietal bones (Fig. 29). This agreement in the outward parts must scientifically

1 The three most important races of oxen which have to be traced back to Bos primigenius are:

$\begin{array}{lllll}\text { Brachyceros race } & \text {. } & \text {. } & \text {. Appenzell cattle } \\ \text { Primigenius race } & \text {. } & \text {. } & \text {. Holland cattle } \\ \text { Frontosus race } & \text {. } & \text {. } & \text {. } & \text {. Bern cattle }\end{array}$

2 A good survey of the investigations and opinions as to the origin of the domestic ox is given in Frühling's Landwirthschaftlicher Zeitung, Feb. 1878; Pagenstecher, Studien zum Ursprung des Rindes. 
be regarded as a convergence, in the skull as an homology.

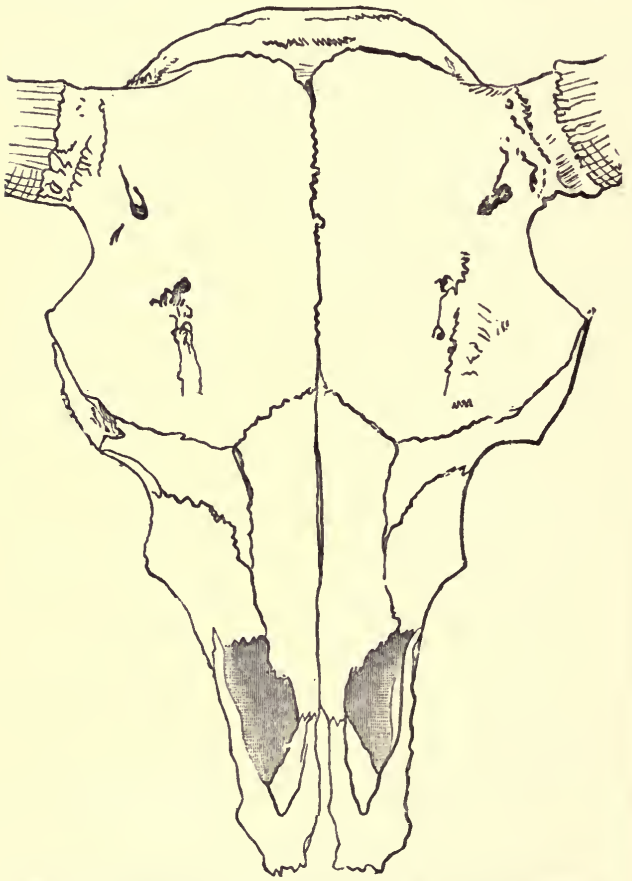

Fit. 28.-Skull of the Bison americanus. After Wilckens.

It has been stated that the separation of the 
antlered from the horned animals is met with first in the Miocene, or, in other words, that deer and antelopes are difficult to distinguish before that period. Ląter we have the branching off of the oxen, but we cannot closely define the point of

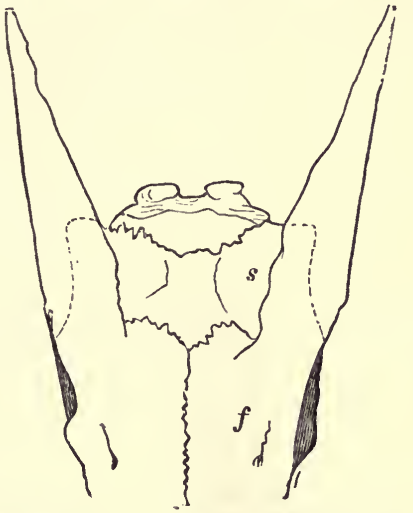

FIG. 29.-Skull of the Anoa. After Rütimeyer.

$s$, Parietals; $f$, frontal bone.

attachment. In the Lower Miocene and Eocene, the Ruminants are represented by distinctly pairhoofed and crescentic-toothed animals, which, although absolutely without horn-cores on the frontal bones, are distinguished by a very full dentition without gaps, some being without the 
prominent eanine teeth which serve the others as weapons. An early Selenodont (crescentic-toothed) animal of this lind for the primeval pair-hoofed group-one which, like the Hyopotamus, does not belong distinctly to any special type-is the genus Cainotherium, an animal of the most graceful shape; we have probably a correct picture of its appearance in the living dwarf musk-animals (Fig. 30). That Cainotherium and its relatives, e.g. Xiphodon, Xiphodontherium, were Ruminants, cannot be doubted from the position and nature of the tranverse ridges of their molars, also from the character of the joints of the jaw upon which depends the peculiar action of the grinders. The dental formulæ is $i \frac{3}{3}, c \frac{1}{1}, p \frac{4}{4}, m \frac{3}{3}$, and in most specimens they stand in closed rows in both jaws. Now our present hollow-horned animals have no incisors in the upper jaw, and no canines either in the upper or lower jaw, and, moreover, they occur in the upper jaw only in some species of deer. The diminution of the teeth-a very general phenomenon-must, therefore, have taken place gradually in the course of ages. How and when this occurred, Filhol ${ }^{1}$ has very elearly pointed out with

1 Compare p. 64, note 2. 
respect to the above-mentioned animals. The Cainotheria, to judge from the quantities of their remains, must have lived in herds after the manner of the Antelopes; hence hundreds of skulls and thousands of lower jaws could be compared. Further, an extraordinary variability was found

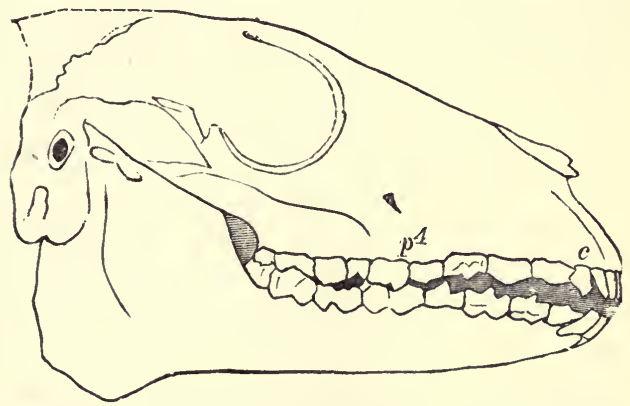

Frc. 30.-Skull of Cainotherium metopias. Nat. size (after Filhol).

in the canine tooth (Fig. 30,c), and in the front premolars. The normal row of teeth, i.e. the teeth inherited from early times, begins to show gaps; a small gap occurs between the canine and the first premolar; the latter then moves towards the canine; frequently the second premolar follows; both thus obviously become useless, and the next 
stage is their total disappearance. Further, we then see indications of the brow weapons, in correlation with the loss of the canines. Filhol here reminds us of the proposition expressed even by Aristotle, and formulated again at the beginning of this century by Etienne Geoffioy St. Hilaire with regard to the balancing of the organs (balancement des organes). With the loss of the front premolars, the permanent molars become more regularly developed, and it is thus that the now typical ruminant jaw has been farther and farther developed; the ancient form-owing to complete rows of teeth and the more marked canines-still, in some measure, resembled the jaw of the Omnivora and the Bunodonts (animal with tuberculate teeth).

From Filhol's observations we find that this process of the gradual formation and the fixing of the gap in the dentition of the Ruminants has repeated itself-that, at first, individual modifications became established by inheritance, and led to the formation of races. And although we cannot, in every instance, trace the given advantages connected with the modifications, and that led to the selection, still, as was shown above, we have some idea, as well as some explanation, of 
the advantages, and they account for the gradual disappearance of the primary groups and for the origin of new species.

In America we find the same circumstances. Antelopes and oxen have, it is true, decreased in a remarkable manner among the present American fauna, but the abundance of the fossil forms is so great that we can scarcely find fault with the patriotism of the American naturalists, when we find them, in this case also, claiming their country to have been the cradle of this group of Hoofed animals. Of purely American types we will name only the very numerous family of the Oreodonta, which combines traits of the pig-shaped pairhoofed, or thick-skinned animals, i.e. the large canines as weapons, and molars of the ruminant type. They were so numerous in the Middle Eocene that one stratum has been called after them, and, together with this force of numbers, they show that tendency to differentiate into races and species which seems to be characteristic of primary forms.

Although America was rich in the still indefinite precursors of our present Ruminants, it has remained absolutely unproductive as regards Oxen. For even the Diluvial ancestor of the North Ameri- 
can bison might be disputed as belonging to America. This naturally touches upon extremely important points in anthropology and the history of civilisation, particularly in connection with the other circumstance that the line of horses was broken off precisely at the point where the American Man first appeared on the scene; and moreover when he was still in so rude and helpless a state that he could not have brought either one or the other of his fellow-workers with him from his Asiatic home, to aid him in his further advance in civilisation. Hence the same phenomenon, as was shown above to have occurred in Australia, has been repeated here, even though in a less striking manner. Even at the heginning of our century, buffaloes (Bison americanus) crossing the prairies were to be counted by hundreds of thousands. Nothing points to the fact that the American aborigines ever made any attempt to tame these wild creatures. It would seem rather that throughout the whole of North America the Indian was, in a manner, chained to the buffalo, and that from year to year he had to pass from one pasture to another with the animal. Hence it was impossible that the higher civilisation of a settled life could take the place of a huntsman's career. Only those tribes which wandered from 
the north southwards, to central and to one part of South America, could attain any comparatively high development of civil life; and this was owing to the more favourable climatic circumstances, and to various species of llamas having been made use of as domestic animals.

The introduction of oxen and of horses from Europe was the beginning of the end of the American bison. The bison has found its biographer in Professor Allen, ${ }^{1}$ who has clearly pointed out its relation to the Diluvial races; and as regards this relation Allen arrives at a somewhat different conclusion to what Rütimeyer ${ }^{2}$ does. The earliest form is the gigantic Bison latifrons from the Diluvial strata of North America, where also are found the remains of mastodon, megalonyx, mylodon, and others. It produced species (races?) not very different from one another, the Bison antiquus of the New World, and the B. priscus of the Old World. The latter is the progenitor of the Europe-Asiatic urus or wild bull; the Bison antiquus, which lived contemporaneously with the Elephas primigenius, is the progenitor of the Bison americanus.

It is very probable, as already remarked, that

1 Allen, The American Bison. Cambridge, Mass., 1876.

2 See above, p. 178. 
the original inhabitants of America did not make any attempts to tame the buffalo. At all events, they did not succeed in doing so. Very different have been the results of the attempts of the European immigrants, who have repeatedly been engaged in this task since the middle of last century. They have succeeded pretty easily in obtaining a cross between the wild and the domestic animal, by allowing the captured young ones to grow up in the herd; and it seems certain that this will produce a strong cross-breed. A Mr. Thompson, who, according to Allen, had watched the attempts at domestication of the unmixed species during fifty years, has expressed his conviction that the animal is capable of being employed for work as well as for yielding milk, while the earlier attempts at crossbreeding were made principally with a view to the horns and skins of the animals.

Under these circumstances, it seems natural that the question should arise as to whether one or the other race of the European ox must not be traced back to the bison. All those who have carefully studied the question declare the bison to be unfit for domestication, and have referred all the different races of the domestic ox-with the exception of the yak-to the genus Bos distinguished by the 
characteristic formation of the forehead. Wilckens alone $^{1}$ has drawn attention to the resemblance between the skull of the short-headed cattle of Eastern Tyrol (Dux) and that of the bison, and thinks that further investigations would furnish a complete proof for this derivation.

Perissodactyla, or Odd-hoofed Animals.

The Odd-hoofed animals are at present represented by three groups: Tapir, Rhinoceros, and Horse, all of which are poor in species. The reduction in the fore and hind-foot has advanced farthest in the horse; the middle toe, owing to the complete disappearance of the others, has become the sole support for the weight of the body. There exist only the mere rudiments of the metatarsals of the second and fourth toe. The tapir comes first with four toes on the fore-foot, and three on the hind-foot; the rhinoceros has three toes on both the fore and the hind limbs, and both these groups have preserved very ancient characteristic features. But in spite of its transformation having advanced so far, no other mammal of the present

1 Wilckens, 'Ueber die Schädelknochen des Rindes aus den Pfahlbauten des Laibacher Moores, 1877 ' (Communications to the Anthropological Society of Vienna). 
day can show as distinct or regular a pedigree as the horse. By means of the accompanying table we will endeavour to solve our problem. The connections are, upon the whole, so simple and clear that, although palæontologists may differ in the explanation of the relationships, these differences refer merely to subordinate points.

Table showing the Connection between the Odd-hoofed Antals.

Present Time Tapir

Diluvium

Eocene

Tapir

Miocene
Rhinoceros

Elasmotherium

\section{Horse}

Pliohippus ${ }^{1}$

Hipparion Protohippus

Anchitherium Miohippus

Mesohippus

Palæotherium med. Orohippus

\section{TAPIR AND RHINOCEROS.}

Of Tapirs we have two or perhaps three species in South America, and one in India. Their favourite haunts are moist forests. Their dentition is very complete in spite of a considerable gap between the canines and molars. The dental formula is : $i \stackrel{3}{3}, c \frac{1}{1}, m \frac{4.3}{3.3}$. 
The incisors and canine teeth are, as usual, not of any special form or construction, whereas the cheek-teeth show a very peculiar type by the marked character of two transverse ridges, the tops of which, bòth inside and outside, become tolerably sharp tubercles (Fig. 32). The ridges of the upper teeth are situated on the front and in the middle

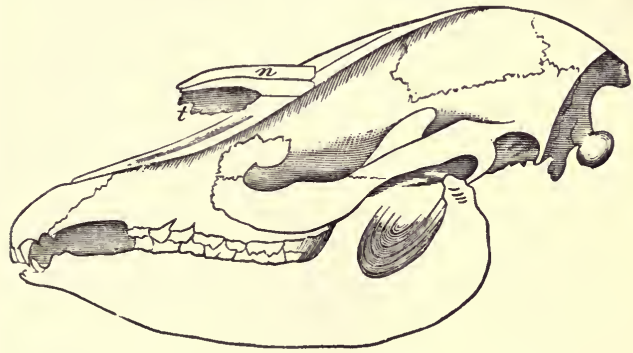

Fra. 31.-Skull of the Tapir (Tapirus americanus).

$n$, Nasal bone; $t$, bony wall separating the nasal cavities.

of the crown; they fit into the grooves of the lower molars, where the back ridge rises from the back wall of the tooth. The grinding movement peculiar to the Ruminants can be accomplished by the tapirs only in a very slight measure; on the other hand, their teeth are specially adapted for crushing vegetable substances, which can also be roughly cut by 
the sharp ridges of the crowns of their teeth. Although the fore-foot of the tapir possesses four perfect toes, still, from an examination of the skeleton of the foot, it becomes evident at once that the second toe from the inner side, corresponding with the middle toe of the five-toed limb, is more strongly developed than the rest, and that it stands in that peculiar position which we have shown to

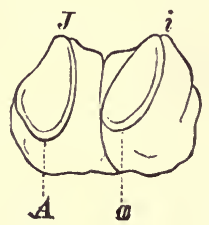

FIG. 32.-Back Molar of the Lophiodon parisiensis, on the left from below.

$A, a$, Front and back outer tubercle; $J, i$, front and back inner tubercle.

be the distinguishing feature in the Odd-hoofed animals. A five-toed genus with the middle toe in this position has, as we have seen, been preserved in the Coryphodon from the Eocene formation. Now, as the lowest known tapir-shaped animals possess at most four toes, the unknown primary forms must, of course, be looked for in the secondary divisions. The tapir, in addition to having lost the inner toe, has also lost the fifth toe; this 
is another instance of the law laid down on p. 169, that the hind extremities are more readily and more frequently reduced than the fore limbs.

In the tapir we have an animal from the Early Tertiary period that has remained almost wholly unchanged, one of those species which have been called permanent, and which are more frequently met with in the lower animal world. They do not prove the invariability of the species, but prove only that under certain circumstances the stability of the species can be of an extremely long duration. In the Miocene the genus is represented by several good species. In the Middle Eocene, we havc in its place the Lophiodon, which is characterised by a still greater simplicity of the ridges of the teeth, and, as regards appearance generally, may have been scarcely distinguishable from the tapir. The European Lophiodonts naturally, in the first place, lead over to the Indian caparisoned tapir. The American ancestral line of the tapirs is more complete. Two genera, Helaletes and Hyrachyus, closely related to Lophiodon, belong to the Eocene. They may be called tapiroid forms. At a somewhat later period appears Lophiodon, one of the few genera we have in common. Still more tapiroid in form is the Miocene Tapirarus, which in the 
Post Tertiary is followed by the tapir itself. That the animal migrated to its present home in South America is probably certain. Now Eocene races existed in the Eastern as well as in the Western Hemisphere, whose origin and separation is indeed unknown, but the form and character of the feet and teeth would require but small changes to produce the genus Tapir. Hence it is here again merely a matter of opinion (owing to the present state of our knowledge) whether, with Marsh, we consider it more likely that the original home of the tapirs is assigned to the New World, and that they are supposed to have migrated to Asia, or vice versâ ; or again, if, with Carl Vogt, a parallel development is considered the more probable hypothesis.

By the side of our present tapirs, and unmistakably allied to them in the formation of foot and dentition, stand the Rhinoceroses, which are distributed over Southern Asia, with its large islands, and Africa. The head weapons are solid horny projections of the nasal bone, which rise into a flat hump within equalities of the bone substance. From this characteristic feature it can in most cases be determined whether the fossil animals of the Rhinoceros species possessed horns. 
Throughout the whole of the Diluvium and the Tertiary period up to the Palæotheriæ and Liophodons, there existed rhinoceroses, or hornless animals closely related to them. Midway in the line stands the hornless Aceratherium. Its connection with the Palæotheridæ and the Tapiridæ becomes at once apparent from an examination of the skull; still, a diminution of the front and canine teeth has taken place. In fact, the whole family of the Rhinoceridæ, up to the present day, shows more variability of the incisors and canines than any other group. The dental formula of the Aceratherium is $\frac{2 \cdot 0 \cdot 7}{1 \cdot 1 \cdot 7}$. Also by possessing four toes on the fore-limbs it stood closest to its five-toed ancestors. Aceratherium is followed upwards by the true rhinoceros with enlarged nasal bones capable of supporting heavy horns. In several of the Diluvial species-above all, in Rhinoceros tichorhinus, ${ }^{1}$ which ranged across Central Europe as far as the Asiatic Polar Ocean---the otherwise gristly

1 A rhinoceros, with a bony partition between the nostrils, lived in Europe with the mammoth up to the period of Man, and its fossil remains, like those of its contemporary, helped our forefathers in their conception of giants and dragons. On the market place in Klagenfurt is a very old stone image of a dragon, the head of which has most unmistakably been modelled from the skull of Rhinoceros tichorhinus. 
partition between the nostrils became a firm bony support for the horn, an ossification, which is not unfrequently met with in the tapir, as was shown on Fig. 31.

America, too, had its family of Rhinoceroses, which seem to have branched off from the Middle Eocene Tapiridæ, and comes forward distinctly in the Upper Miocene as Aceratherium. Forms similar to it are found in the Pliocene, but did not leare any descendants to the following period. The causes of its extinction in the New World are not clear. But the reason of the dying out of the Diluvial species in the Old World, or its withdrawal from the temperate zones to tropical regions, seems to be pretty obvious. For even though individual forms-such as the rhinoceros with the bony partition between the nostrils-were, like the mammoth, able to endure a rougher climate, still they were not able to face the coming of the Glacial period. What prevented them withdrawing before it we certainly do not know; still we may, at all events, look upon them as having been the victims of climatic changes. Others, which were able to avail themselves of the land bridges for withdrawing southwards, survived.

An animal of the rhinoceros type, which was 
perhaps a contemporary of Man, and one of the most gigantic phenomena of the primeval world, is the Elasmotherium. It likewise possessed a bony partition between the nostrils, and was armed with an immense horn, as is proved by the rough and huge elevation on its forehead. Its skull is over three feet in length. The form of the molars, with elaborately folded plates of enamel, is another

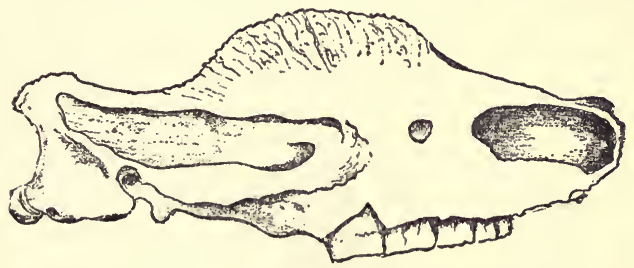

Fig. 33.-Skull of the Elasmotherium. One-twelfth nat. size. After Brandt.

peculiarity. This giant of the Diluvial period was also unable to preserve its existence. The few remains-among which is an almost complete skull-have scarcely been found anywhere except in the southern basin of the Volga.

The size of the present animals of the Rhinoceros species, and of most of the primary species, will seem less striking if we take into consideration the 
smaller species of bygone days, for instance, the Rhinoceros minutus.

Before passing on to the most docile and important group of the Odd-hoofed animals, the horses, let us first turn our attention to a few of the American forms, which are distinguished partly by their size and partly by the, in most cases, very unusual form of their skull ; in the struggle for existence these animals, however, neither changed nor left descendants which adapted themselves to circumstances. Their existence reminds us of the Elasmotherium, inasmuch as they neither explain the present (hence in reality stand apart from our subject here), nor do they awaken in us other ideas for understanding the organic world; but they bear witness to the incredible exuberance, we may almost say the capriciousness, of organic productivity during the Late Tertiary and Diluvial periods while the animals were becoming extinct, and which periods were followed by our Present age, with a certain stability of the inorganic and organic worlds. In this stability of forms, moreover, we see one of the preliminary conditions of the morphological and social development of mankind.

The lowest strata to the east of the Rocky Mountains contain the remains of the Brontotherida, 
gigantic animals, whose bodies exceeded that of the elephant in bulk, but they had shorter limbs with
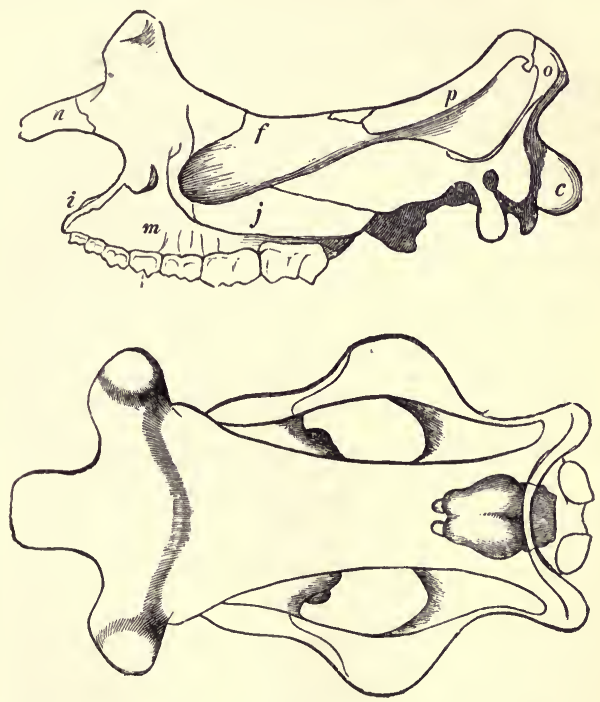

Fig. 34.

A. Sknll of Brontotherium ingens. One-tenth nat. size. n, Nasal bone; $i$, mid jawbone; $m$, upper jaw; $j$, cheek bone; $f$, frontal bone; $p$, parietal bone ; $c$, condyle.

B. The same looked at from above, with the brain given in outline. After Marsh.

four toes on the front feet and three behind. The skull (Fig. 34), which is elongated after the manner 
of the Rhinoceros species, shows a pair of bony protuberances (the supports for mighty horns) on the upper jaw, in front of the eye-cavities, and probably the nasal bones and the intermediate space between the horns permitted the addition of a proboscis.

Both in the case of Brontotherium as well as in some members of the family of the gigantic Dinocerata, to be spoken of presently, the relative size of the brain to the skull is known from fossil impressions. According to these the size of the actual brain substance must have been extremely small (Fig. 34, в.). Its extent reminds one of the relative proportions of the reptile brain, and points to an incongruity which must certainly have had its effect upon the dying out of this and of similar species. It was in this manner that all the huge reptiles of the middle geological periods became extinct, especially as land animals. The few huge but small-brained reptiles of the present day, such as the crocodiles, clearly owe their existence to the fact that they have continued to live in water, also to their marked stability. A transition to life on land would lead to their extinction.

From the circumstance that one of the more recent strata of Oregon contains the remains of a 
perhaps kindred genus, the Chalicotherium-which is discovered also in Western America, in China, India, Greece, Germany, and France-Marsh concludes that the places where these remains were found were the stages by which, in this and other cases, the so-called 'Old World' received its animal forms.

\section{THE EQUIDE, OR HORSES.}

On Fig. 35 we have a drawing, made by Owen in 1857 , to explain to his audience the derivation of the one-hoofed animal from its three-hoofed ancestor, a drawing which has been made use of countless times since then by recent writers. The three-hoofed animal is the Palcotherium medius discovered by Cuvier ; in outward appearance the foot is precisely like that of the tapir, but possesses four toes on its fore-foot, and thus represents an earlier form. The Palæotheridæ are essentially Eocene; to judge from their teeth, they obtained their food like the tapirs, and (with a numerous kindred) inhabited the marshy forests which had originated with the upheaval of the weird depths of the Jura and Chalk oceans. They, too, had found their way to Southern America. It is, we know, perfectly useless, at the present state of our geological knowledge, to endeavour to determine by means of 
which land-bridges this migration took place; all that can be done meanwhile, is to trace the line of the descendants of the Palæotheridæ, which, it seems, soon came to an end in South America, but became very numerously and continuously de-
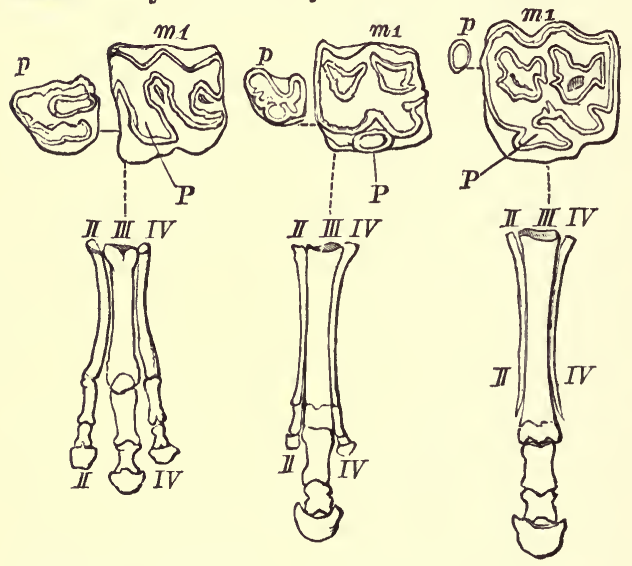

FIG. 35.-Palæotherium. Hipparion. Horse (after Owen). $p$, First premolar ; $m$, first molar.

veloped in North America; and in tracing this line we must do so independently of those branches which run parallel with them in Europe and Asia. Palæotherium is a distinctly three-hoofed animal. Certainly the middle toe is somewhat larger than 
the two side toes, which, although shortened a little, and accordingly somewhat more perpendicular, yet fully touch the ground, and take their share, in the work as bearers of the weight of the body. Now in the genera which gradually arose in the course of time-Palcotherium, Anchitherium, Hipparion, and Horse-we can trace how the two side toes, II and Iv, were more and more withdrawn from the ground, and became rudimentary, whereas the middle toe increased in size, stretched out, and finally became that of the Horse, the incomparable runner and fellow-worker of man. Owen looks upon this as a providential transformation designed for the benefit of mankind; we look upon it as an adaptation to the formation of the ground, to the incoming of plains, which originated during the Tertiary period. Thus in Anchitherium aurelianense (Fig. 36), which is still met with even in the Eocene, the tips of the outer toes are scarcely withdrawn from the ground, hence might still have been of use to the animal in walking through a less firm soil.

The Hipparion also, from the Middle Tertiary, possesses the lateral toes (Fig. 35), but these are only rudiments of the original toes. They have become wholly useless, and in accordance with this inaction 


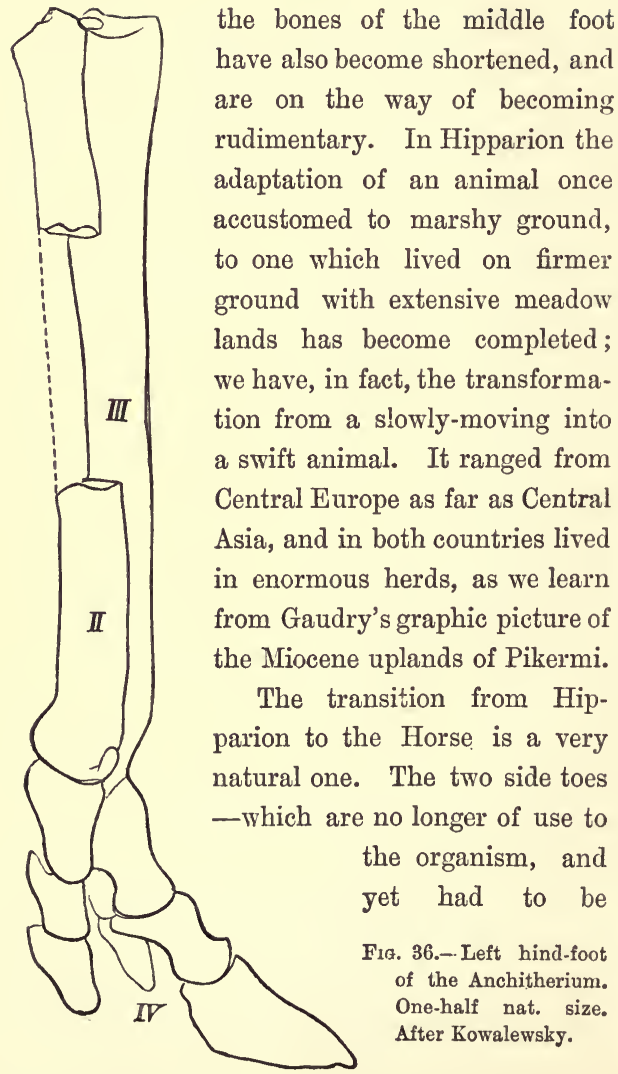


nourished-have been eliminated as ballast. They are not yet quite cast off. The metatarsals, or so-called 'splint bones,' are still attached to the middle toe. The horse of the future will certainly have cast off these rudiments, even though it may take a few millions of years to accomplish this, owing to the extraordinary perseverance with which organisms drag about with them these useless inheritances. The Hipparion has not even yet wholly disappeared from the scenes of life.

Now and again horses have been met with, with more than one toe, which must not rashly be considered as a malformation; it is simply a proof of that repetition of or reversion to the original form which in scientific language is called atavism. This kind of Hipparion-horse, which is looked upon by the common run of people as a curiosity and monstrosity, has, as Siebold ${ }^{1}$ has shown, been repeatedly exhibited at horse-markets. The following is a description of an animal of this kind given by Frank, Principal of the Veterinary College of Surgery at Munich: "The so-called splint bones (the metacarpals and metatarsals of the second and fifth toes) are not reduced to the same extent. On the fore-foot the mediale (м $c 2$ ) is the least

' Siebold, Hipparion auf Jahrmärkten. München, 1881. 
reduced, on the hind-foot the lateral (мc 4) is the least reduced, as even Hensel pointed out. Now cases of atavism are not unfrequently met with in the horse, where the medial splint bone on the fore-foot has a digit more or less distinctly developed. And as the hoof of this second digit never touches the ground, and, accordingly, is not worn . off in any way, the horn-substance becomes long and irregular, precisely as in the case of the lateral toes (the second and fifth) in old cows. Atarisms of this kind on the hind-foot are of extremely rare occurrence.

- When it was said above that the horse no longer shows any trace of rudimentary toes, this is not altogether correct; the rudimentary hoofs do still exist. Thus the so-called " chestnut," a flat horny wart on the skin above the carpus, seems to correspond to the hoof of the lost thumb; at all events, I found it in cases where a second digit existed. Another formation that must be included here, is the so-called "spur." This spur is a small cylindrical horny substance, which in our present horse is concealed by the hairy tufts of the fetlock. It seems to represent the coalesced horn-shoe of the rudimentary second and fourth toe of the horse. 
' During the sixth decade of the present century, there was exhibited in Munich a horse under the name of a "stag-horse," which had veritable hipparion feet. The splint bones of the four extremities had digits, that is, toes. The so-called " chestnuts" existed on all the four limbs, and were strongly developed, whereas all the four "spurs" were wholly wanting. ${ }^{1}$ On the fore-feet the medial side-hoof (second digit) was most fully developed, on the hind-feet it was the lateral or fourth toe. As the side-hoofs of all the extremities did not reach the ground, and hence were not worn, they had grown to a considerable length, and were bent like horns. Such cases are of great rarity; still they had been observed even in earlier times. The famous Bucephalus of Alexander the Great is said to have been an animal of this kind. Moreover, the atavism is said in some instances to have been transmitted to the offspring, which of course is very probable. It is more than probable that from a single animal of this description a breed of Hipparion-horses might be reared. There would,

1 This observation would certainly support the opinion, which we are inclined to doubt, that the 'chestnuts' and 'spurs' were rudiments of the first, second, and fifth hoofs. If, nevertheless, I hold to my doubt, at all events as regards the atavism of the thumb, I do so because it would be a unique phenomenon. 
however, be absolutely nothing to be gained by such reactionary measures.'

The same indications of the transformation from Palæotherium to our present Horse-in an uninterrupted line from the Eocene to the present -are manifested by the teeth. In connection with this point we must first of all mention Rütimeyer's classic studies on this question,' which have been admirably supplemented by ForsythMajor. Owen had already recognised the change in the formation of the jaw that accompanied the transformation of the organs of locomotion. The teeth of the Palæotheridæ, which show less complicated folds of enamel, and are adapted for crushing juicy plants, gradually change into the pillar-shaped molars of the horse, which, owing to their strength and the foldings of enamel, are suitable both for grinding corn and for chopping gritty grasses. The principal parts of the crowns are given on the accompanying drawing (Fig. 37). Even from Owen's illustration it is evident how the complicated enamel lines of the horse's tooth originated from the simple tracings on the tooth of the Eocene animal. The much more careful

' Rütimeyer, Beiträge zur Kenntniss der fossilen Pferde, 1863. 
comparisons of recent times have shown us these changes down to the minutest detail; and from the geological series, which is being made more complete year by year, the complex formation of the horse's molars becomes perfectly intelligible from the outlines on those of the Palæotherium. Rüti-

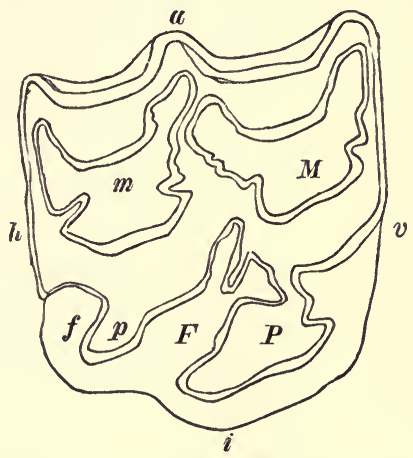

FIG. 37.-Right Upper-jaw Molar of the Horse.

$a, i, v, h$, Ontside, inside, front, back ; $M, m$, front, back crescent ; $P, p$, larger and smaller inner pillar; $F, f$, inner main-and side-fold. After Branco.

meyer further gives special proofs that the species in question transmitted the relative peculiarities of their molars to the milk-teeth of their offspring and descendants, whereas the descendants transmitted the new inheritance specially to the molar teeth. 
It is only in its historical connection that the peculiarity of the horse's dentition acquires a peculiarly significant interest, and-as in the case of the three-toed foot-when viewed apart from the historical course of its development, seems simply an incomprehensible peculiarity, of no importance either to the horse itself or to the horse fancier. Palæotherium, Anchitherium, and Hipparion possess, when full grown, seven cheek-teeth above and below on both sides of the jaw, $p \frac{4}{4}, m \frac{3}{3}$. On the other hand the normal formula in the horse's dentition is $p \frac{3}{3}, m \frac{3}{3}$; it changes only three of its milk-teeth, and gets three other molars. Now it has long since been known to breeders and veterinary surgeons that, pretty frequently, the horse's row of cheek-teeth begins with one stump too many, the so-called 'wolf's tooth' (on Owen's drawing marked by the letter $p$ ). This most perfectly expresses the fact that it occupies the place where, in Palæotherium among others, we have the first premolar. When it appears in the horse, however, the 'wolf's-tooth' is not deciduous. It is most obviously a tooth in the last stage of disappearance, an irregularly appearing descendant from the 
days of a full dentition, and its disappearance probably stands in causal connection with the increased strength of the other teeth.

Before discussing the American line of horses, let me here quote W. Kowalewsky's opinion regarding the connection between the genera mentioned above; his remarks are as careful as they are convincing: 'Nothing is further from my intention than to maintain that the animal which we call Palcotherium medium directly produced an Anchitherium, the latter an Hipparion, and so on. But among the number of individuals which we call Palæotheridæ, there must always have been some forms which would incline more towards the Anchitherium than the others. In the same way I have been able to determine-owing to the large number of species I was fortunate enough to be able to compare-that among the Anchitheridæ a few still remained completely within the limits of the species, although they showed some characteristics by which they resembled the Horse on the one hand, and the Palæotherium on the other. A few trifling flattenings of the bones, certain peculiarities of a joint which are met with in some individuals, are not to be found in others. Without doubt there was at one time a transition between two individuals which resembled 
each other most; but to expect, as is generally asked by those who believe in the invariability of species, that we should be able to show the last Palæotherium, and his descendant the first Anchitherium, is to demand an impossibility. An originally normal characteristic sometimes begins not to occur, then it becomes unimportant, i.e. is found wanting as often as it occurs, then it appears rarely, and finally disappears completely. Thus, for instance, the small front premolar of Palæotherium is smaller still in Anchitherium, but still occurs regularly; in the Hipparion it is met with as often as it is found missing, and in our present Horses it is extremely rare (as the "wolf's tooth ").' This very careful comparison of the differences in the dentition has been further worked out by Kowalewsky. 1

We have now again to turn to America, to the well-known fields of discovery to the right and left of the Rocky Mountains, where to all appearances a group of Odd-hoofed animals lies buried, much more numerous in members than the group in the old World, showing no gaps, and terminating with the horse. Compare the table on page 190. The

' W. Kowalewsky, 'Sur l'Anchitherium Aurelianense Cuv.,' Mém. de l'Academie imp. de St. Pétersbourg, 1873. 
line begins in the Early Eocene with the Eohippus of the size of a fox, which possessed, in addition to the four well-developed toes of the fore-foot, the remnants of a fifth. According to a remark of Marsh's, this animal, in foot and dentition, already shows unmistakably that with it commenced the branching off of the progenitors of the horse
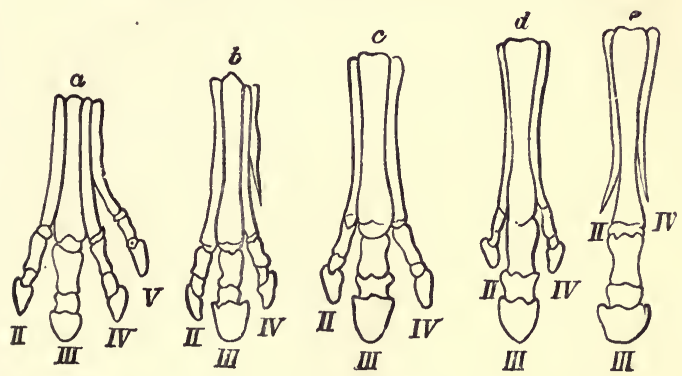

Fro 38.-Foot of the Fossil Horses of North America.

a, Orohippus; $b$, Mesohippus ; $c$, Miohippus ; $d$, Protohippus ; e, Equus.

from the other Odd-hoofed animals: 'in the next higher division of the Eocene, another genus (Orohippus, Fig. 38) makes its appearance, replacing Eohippus, and showing a greater though still distant resemblance to the equine type. The rudimentary first digit of the fore-foot has disappeared, and the last premolar has gone over to the molar 
series. Orohippus was but little larger than Eohippus, and in most other respects very similar. 'Near the base of the Miocene we find a third closely allied genus (Mesohippus), which is about as large as a sheep and one stage nearer the horse. There are only three toes and a rudimentary splint bone on the fore-feet and three toes behind. Two of the premolar teeth are quite like molars. The ulna is no longer distinct, or the fibula either, and other characters show clearly that the transition is advancing. In the Upper Miocene Mesohippus is not found, but in its place a fourth form (Miohippus) continues the line. The genus stands close to the Anchitherium of Europe, but presents several important differences. The three toes in each foot are more nearly of a size, and a rudiment of the fifth metacarpal bone (of the second series) is retained. All the known species of this genus are larger than those of Mesohippus, and none pass above the Miocene.

' The genus Protohippus of the Lower Pliocene is still more equine, and some of its species equalled the ass in size. There are still three toes on each foot, but only the middle one, corresponding to the single toe of the horse, comes to the ground. This genus resembles most nearly the Hipparion of 
Europe. In the Pliocene we have the last stage of the series before reaching the horse, in the genus Pliohippus, which has lost the small hooflets and in other respects is very equine. Only in the Upper Pliocene does the true Equus appear and completes the genealogy of the horse, which in the Post-Tertiary roamed over the whole of North and South America, and soon after became extinct. This occurred long before the discovery of the continent by Europeans, and no satisfactory reason for its extinction has yet been given.' ${ }^{1}$

So far Marsh, and, owing to the quantity of his discoveries, he proclaims the horse, above all the other hoofed animals, to be clearly a native of America. That the European line discussed above is more incomplete is very evident; however, it must be assumed that with further discoveries the difference will be equalised. And, indeed, an important beginning has already been made during the last few years. The gap between Hipparion and Equus, which clearly existed, and was filled up in the American line by Pliohippus, no longer exists in the European series either. For Forsyth-Major ${ }^{2}$ has pointed

' Marsh, The Introduction and Succession of Vertebrate Life in America (1877).

${ }^{2}$ Forsyth-Mrajor, 'Rivista scientifica industriale, 1876,' Kosmos, ii. 
out that the races from the Quaternary period of Upper Italy, classed together as Equus stenonis, include all therequired intermediate stages between Hipparion and our present Equus caballus. It is of the utmost interest to be able to prove that in Equus stenonis the reduction of the side metatarsals preceded that of the tarsals: for while the metatarsals do not differ from those of our present horse, the tarsals show all the intermediate stages between Hipparion and Equus caballus; they have not yet had a sufficient length of time to accomplish the complete change which renders the foot of our horse so eminently more suited to the activity of the one-hoofed animal than was the Equus stenonis. In fact, it may be affirmed that in the case of the Diluvial horses, the splint bone (i.e. the rudiments of the metatarsals II and IV) had not yet coalesced with the mid-foot, which coalescing of the bones occurs in our present horse with its seventh or eighth year. ${ }^{1}$

I Nehring remarks, on the other hand, that in our present horse, the splint bones do not coalesce nearly as often as is supposed, and that, for instance, among the skeletons in the Berlin collection, the coalescing is the exception, the non-coalescing the rule. That, therefore, the supposed difference between the Diluvial and the present horse is not an essential one, and that it need only be admitted that the coalescing of the splint bones occurs more frequently in the domestic horses of the present 
That the two groups, the European and the American, run parallel, perhaps without any intercourse during the longest of the Mid-tertiary periods, must not only be admitted as probable, but be granted as possible. The probable colonisation of America by the original inhabitants of Asia took place before they had learned to make use of the horse as a domestic animal. In America the Horse no longer existed then. It may be that the long-continued ice-formations of the Diluvium had forced it to leave the highlying plains to which it had been accustomed, and driven it to regions where it succumbed in the struggle for existence. The Spaniards reintroduced the horse to the New World, and now it there also fulfils its mission as a companion to man-if we may for once use a teleological expression. In addition to all this, however, it must also be stated that the American members of the genus Horse have never advanced as close to our present horse as the Diluvial members of the European family; hence, that the true horse of our

than in the Diluvial horses. Now, as Nehring, among other things, proves that the splint bones of the Diluvial horse, of Westeregel, are considerably larger and longer than they are usually found in the domestic horse, the circumstances we endeavoured to prove above remain essentially the same. 
day-Equus caballus-never existed in America before its importation. Branco ${ }^{1}$ has lately published a very remarkable treatise on this subject. $\mathrm{He}$ has shown that in the Equus andium-which lies buried in the volcanic tufa of Ecuador, and is of the same age as the Diluvial Pampas horses and the species found in the caves of Brazil-the eye is placed considerably deeper, whereas in the Equus caballus it has moved considerably farther back. Here, again, it is our grand Goethe-a naturalist not nearly often enough quoted, in spite of what an eminent Berlin orator may say-who sixty years ago pointed out this ideal character of the horse from an artistico-scientific point of view, and thus anticipated the wearisome labours of palæontology. Goethe's words are ${ }^{2}$ : 'In the horse's head of the Elgin Marbles (of the Parthenon), one of the most splendid relics of the grandest period in art, the eyes stand out freely and are placed near the ears, whereby both senses, sight and hearing, seem to act together directly, and the sublime creature is enabled to hear as well as to see what is happening behind it. It looks so majəstic and spirituel,

1 Branco, Die fossile Säugethierfauna von Punin und Ecuador, von Reiss und Branco. Berlin, 1883.

${ }^{2}$ Goethe, Ueber die Anforderungen an naturhistorische Zeichnungen (1823). 
almost as if it had been formed contrary to nature, and yet the artist has, in reality, given us a primeval horse, whether he saw it with his own eyes or conceived it in his mind; to us, at all events, the animal seems depicted in the spirit of the highest form of poetry and reality.'

The horse, in all its various forms of development, from the dwarfish pony to the Percheron and the huge English cart horse, has been regarded as a single species ever since it was found in the service of man. We talk only of different races of Equus caballus. The taming and breeding of horses may be said certainly not to have taken place for thousands of years after the time when man first came into contact with the animal. The period during which prehistoric Man, in Europe, fed chiefly upon horse flesh is that which has also been called the Reindeer period, owing to the wide distribution of that animal. This division of time follows the period of the fullest development of the mammoth, and was in many localities-e.g. in Central France-extremely favourable for the increase of the genus Horse, in spite of an evidently rough climate. Nowhere in the world are such accumulations of remains found as near Solutré in the neighbourhood of Macon to the north of Lyons. 
The lower stratum of this remarkable deposit contains a whole fauna of larger and smaller mammals-mammoth, cave tiger, lynx, cave bear, brown bear, cave hyena, wolf, fox, polecat, marten, badger, Canadian deer, primeral ox, horse, hare, and saiga-antelope. All the bones are broken and mixed up together; and the rude flint implements likewise found there, also point to the fact that the grass-eaters fell victims not only to the teeth of the beasts of prey, but to the hand of huntsmen as well. In the upper strata the mammoth and his huge flesh-eating contemporaries disappear from the scenes. Primeval Man entered the Reindeer period from the Mammoth period, and thereupon horses were slain by the thousand.

The opinion which found favour in France that the horse of Solutré had been tamed and domesticated is untenable, as has again lately been pointed out by Pietrement, who has carefully considered the question in all its bearings.' Nevertheless, the horse from Solutré is of great interest, as we most probably have in it one of the races which subsequently became domesticated, and which left descendants that probably still exist. The pieces

1 Piétrement, Les chevaux dans les temps préhistoriques et historiques. Paris, 1883. 
of skeletons found at Solutré point to the socalled Ardennes horse, one of the long-headed races of the domestic horse. One feels tempted to look round and see whether there are not other horses that approach as close to the Solutré branch. In doing this we think, in the first place, of the small horse that lives in a semi-wild state on the Carmargue, in the delta of the Rhone. There also exist in Alsace the last offshoots of an old race of this kind. In stature and proportions these animals resemble large ponies. The head, in the specimens which seem most purely to represent the race, is large and ugly, but the body, in spite of the want of actual care, is well formed; the limbs very powerful. The animals, which are goodnatured and easy to manage, perform extraordinary feats in the way of drawing weights. At times, when there is little work doing, they are kept for weeks in the meadows to the east of Schlett-stadt, and are met with, in fact, in other districts besides Schlett-stadt as far as the Rhine.

To throw proper light upon this possible connection, it would be necessary to make the most careful examination and measurements of the various parts of the skeleton, and this has not yet been done. How this would have to be done has 
been shown very recently by the distinguished authority on the Diluvial mammals of Central Europe, Professor Nehring of Berlin, in his exceedingly interesting studies on the fossil horses of the German Diluvial deposits, and their relation to the living horses. ${ }^{1}$ The Italian palæontologist, Forsyth-Major, had, somewhat previously, in an admirable manner, compared the Diluvial horse in Italy with the present animal. In order to obtain a good starting-point for an investigation of this kind, it is necessary first to understand a few of the principal species of the domestic horse. Of these we require only the two groups in which, according to French investigators, the domestic horse appears, and into which, moreover, the eight races may be subdivided. In the horses of the principal Oriental race, the portion of the skull covering the brain is strongly developed, the facial part of the head is smaller, which circumstance is expressed mainly by the breadth of the forehead. The inner side of the crescents of the molars of the upper jaw (Fig. 37) has a covering of enamel with but few folds; the bones of the limbs are graceful, but of a very firm structure. An admirable represen-

1 Nehring, Fossile Pferde aus deutschen Diluvialablagerungen und ihre Beziehungen zu den lebenden Pferden. Berlin, 1884. 
tative of these qualities is found in the Arabian horse.

' The Occidental Horse,' says Nehring-following Frank of Munich, who was the first to distinguish this main race-'shows itself, as regards the two first mentioned points, to be the exact reverse of the Oriental horse; for its distinguishing character is the much larger development of the facial portion of the skull, as compared with the part covering the brain. The skull seems to be comparatively long and narrow with a small breadth of forehead. The rims of the eye-cavities stand somewhat forward. The enamel folds of the so-called crescents of the molars of the upper jaw are very complicated. The bones of the limbs of the Occidental horse are of a thick and massive build, while in structure they are less substantial and hard than in the case of the Oriental horse.'

To this Occidental race, in Germany, belongs our common-middle-sized horse, which of late years has been more and more set aside to make room for a mixed race; for the State and private persons have taken the breeding of horses into their own hands and introduced foreign animals, more particularly of the Oriental species. Thus, for example, during some decades, crossings from the Arabian 
breed, especially with the famous stud at Graditz near Torgan, was systematically encouraged in the districts on the Elbe in Saxony.

The heavy horse of Central Germany has been termed the Equus caballus germanicus by Sanson, and by Piétrement after him. There were only uncertain conjectures as to its origin, yet the general opinion appeared to be that, like all the medium-sized and larger European races, it was of Asiatic origin, and that it had been tamed and introduced by different nomadic tribes in prehistoric times.' This question, which elaims our whole interest, for it affects the history of the noblest of our domestic animals, has advanced one stage in clearness. Nehring has undeniably proved that a Diluvial horse of Central Germany-numerous remains of which have been discovered at Westeregeln

1 'The Roman authors, Cæsar in particular, distinguish in Gaul and Germany between a native race of horses, which was small and unremarkable although hardy, and between foreign breeds that were larger and nobler in appearance. And many other writers of ancient and later times speak of foreign horses in contradistinction to the native breeds, so that there is, probably, no doubt that there existed in those days, in Germany, two races strikingly different in outer appearance. That the small native race must be traced to the tamed wild horse of Europe, may probably be considered as certain, so that the only remaining question is, of what origin was that foreign horse, and whence did it come to us ?'-Al. Ecker. 
near Magdeburg, and at Thiede in Brunswicktallies in all characteristic features with the heavy Occidental horse. Hence it had not been introduced, but had been tamed and reared by our ancestors from the wild race which they found there. This narrow-browed animal lived also on the Rhine, in the neighbourhood of Remagen; ' in the form of its skull and the rims round the eye-cavities it resembles our old medium-sized lowland races.'

Nehring sums up his views regarding the German Diluvial horse and its relation to the present tamed and wild races, in the following passage of general interest: "The Diluvial horse of our country, like that of the neighbouring European lands, was an untamed, wild animal which roamed about, and seems to have lived in especially large numbers in the districts round the Hartz Mountains. These districts, during one distinctly longer division of the Diluvial period, possessed a vegetation of the steppe species and a corresponding climate. The forest had become greatly reducerl during the Ice period (i.e. the first ice period, if we are to admit of there having been two). On these steppe-like tracts wild horses lived in large herds, together with jerboas, steppe-susliks, logamys, harerats, numerous wild mice, and other characteristic 
inhabitants of the present steppes beyond the Volga. ${ }^{1}$

- Their existence was now and again endangered by a few isolated lions, also by wolves, whereas hyenas (remains of which are not unfrequently met with at Westeregeln) probably seized only the carcases and scarcely ventured to attack the live horses.

'The worst enemy of the Diluvial horse was man. We know by numberless investigations, that the human inhabitants of Central and Western Europe in those days lived almost entirely upon the hunting of horses; the bones and teeth-very probably the skins, hair, and sirews also-were made use of in a variety of ways.' Nehring, whom we have been quoting, goes on to say how all this was done, what proofs we have of the occasional visit of nomadic tribes to certain localities, and how a regular system of breeding arose gradually from single attempts, and then adds :

'Those of my readers who are accessible to scientific proofs will, I hope, find my detailed comparisons sufficient to convince them that an essential portion of our so-called heavy (common) horses must be traced back to the heavy, thick-boned Diluvial horse.'

' Compare above, p. 76, fol. 
The horse from Solutré, and the thick-boned animal of Central Germany, are two local races very nearly related, but yet distinguishable. There is another race which has been found most complete round about Schussenried in south-western Würtemberg; it has been described by the eminent man of science, Fraas, who also gives an account of many of the other Diluvial inhabitants of that district. This horse is distinguished by its comparatively broad forehead and by the gracefulness of its limbs, and hence agrees in important points with the Oriental domestic horse. Now there have been discovered in many of the prehistoric deposits of the Bronze period, the remains of a tamed, thinboned horse, which has universally been supposed to be of Asiatic origin. It cannot well be doubted that this horse was imported by the tribes that overran Europe from the East; yet it is equally possible and probable, that a portion of the slimmer, tamed horses of the Bronze period had been produced through the taming of the broad-browed Diluvial horse of South Germany.

\section{THE PROBOSCIDA, OR ELEPHANTS.}

The circumstances of nutrition which determine the general character of the dentition and of the 
structure of the feet of animals, account for the fact that the trunked-animals have always been classed with the genuine hoofed animals; but any attempt at a closer definition of the older system, with its many-hoofed animals and thick-skinned animals, always led to the isolation of the elephants. Their dentition shows no link whatever with those of the present animals. And in causal connection with the dentition we have the strange shape of the skull, and again connected with the latter the development of the proboscis, which in a wonderful manner counterbalances the weight and awkwardness of the head and neck. Probosces are met with in other mammals: thus we have the lip-finger of the rhinoceroses and the prominent lip and nose of the tapirs and of the saiga-antelope. Moreover, our excellent anatomist Burmeister (whether rightly or wrongly I do not venture to say) has equipped the Macrauchenia, probably one of the horse family from the Pliocene deposits of Patagonia, with an appendage resembling an elephant's trunk (Fig. 39).

Be that as it may, at all events our present Elephant is one of the strangest and most enigmatical forms, which, moreover, must have impressed uncivilised nations in an extraordinary manner. 
We do not put much faith in the Indian legend, according to which the monsters which the Great Spirit destroyed by lightnings, and which died without leaving offspring, were Mastodons (which existed in America as the earliest contem-

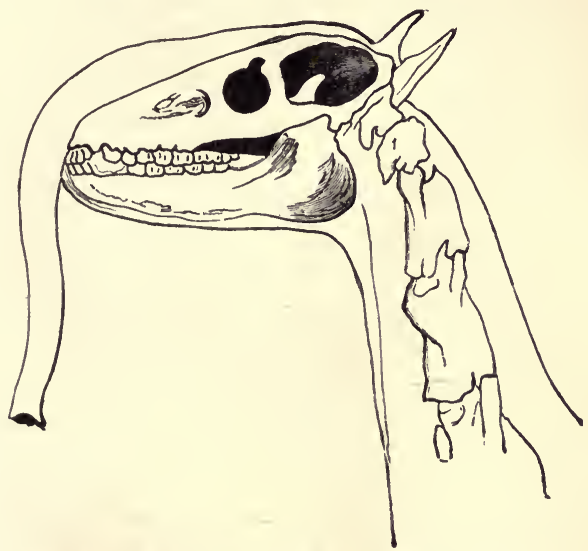

Fra. 39.-Macrauchenia patagonia. After Burmeister.

poraries of man), still, A. W. Schlegel as early as $1883^{1}$ pointed out in one of his classic inquiries that the influence exercised by the elephants upon the imagination of the Hindoos was positively all-

A. W. Schlegel, Indische Bibliothek, 1823. 
powerful. The Hindoos marvelled at everything in the animal, not only at its sagacity, which made it seem to them the embodiment of the god Ganesa, but also-and more justly than we-they admired the neatness of its feet.

Its zoological singularity is, as already stated, mainly centred in the character of its head. Together with an unusually small breadth of head, the facial portion shows a remarkable height. The narrowness is caused by the very limited number of teeth. In the upper jaw there are only the two tusks (incisors) and one molar on either side; in the lower jaw there are molars only, powerfully developed, it is true, but, as regards length, show comparatively far less dimension than is seen in the full dentition of a grass-eater. All the more powerful and higher are the roots, not only of the tusks but of the molars. The latter are changed six times, so that the succeeding teeth from behind and below claim a position in the inside of the jaw till the animal is tolerably advanced in years. The structure of the molar, even when worn smooth by use, shows it to be an exceedingly perfect apparatus for crushing leaves and grasses. Zoology terms it 'complex.' It appears to be formed of a large number of high and narrow 
cases of enamel which are filled with dentine and joined into one mass by cement. This account of the formation of the tooth, which is universally accepted by descriptive zoology, is, however, as we shall see, not correct, and very unnecessarily makes the gap-which does exist between the Elephants and the other plant-eaters-appear greater than need be.

Even Cuvier distinguished among the Elephants a group of fossil trunk-bearers, perfectly of the elephant type, but with a more complete dentition; the molars, although less large than those of the elephants, being characterised by nipple-shaped eminences or tubercles in pairs, forming a number of transverse ridges. Cuvier called the genus Mastodon. ${ }^{1}$ A mastodon tooth of this kind (Fig. 40) presents nothing specially striking apart from its often remarkable size. The crown, however, is distinguished by the extraordinary strength of the connecting layer of enamel which does not penetrate in folds into the interior. Now, as three molars of this kind with huge tuberculated crowns

1 The most important contributions on this subject are: Vacek, ' Ueber österreichische Mastodonten und ihre Beziehungen zu den Mastodonten Europa's,' Abhandlungen der geologischen Reichsanstalt, vii.: most admirable also is the chapter on the Eléphantoïdes ' in Gaudry's Mammiferes tertiaires. 
are met with in a row at the same time (for instance, in the widely distributed Mastodon angustidens) ; and as, moreover, they follow upon one another as milk teeth and permanent teeth; and, further, as several typical mastodons of this kind

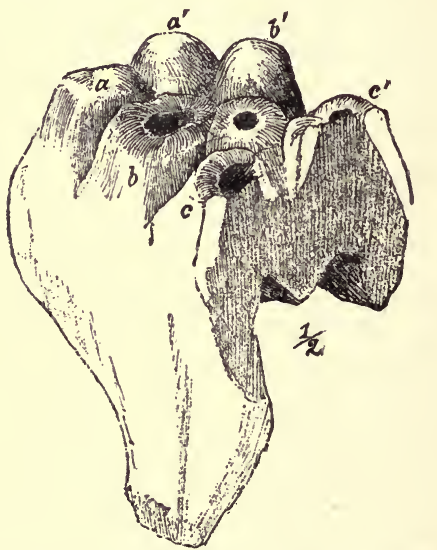

Fro. 40.-The used Molar of Mastodon angustidens. $a a^{\prime}, b b^{\prime}, c c^{\prime}$, Transverse ridges; one-half nat. size.

have, besides the upper tusks, lower ones as well, and between them other two smaller incisors, this species of dentition moves wholly within the limits and forms known to us. The mastodons referred to are those of the Middle and Upper 
Miocene, which survived longer in America than in the Old World, and one of which continued to exist up to the period of the Diluvial deposits and turf formations, most probably even up to the prehistoric times of the human race. This is the socalled Ohio animal, the Mastodon giganteum.

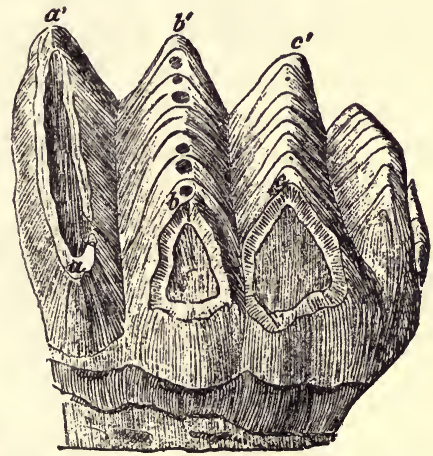

FIG. 41. - Portion of a Molar of Mastodon elephantoides. One-half nat. size. After Clift.

As early as the Upper Miocene we meet with animals of the Mastodon species, with molars, the ridges of which are much more sharply defined and resemble rows of miniature roofs (Fig. 41), inasmuch as they consist of numerous small tubercles, which almost coalesce with one another. The tops 
of these tubercles become more or less rubbed off with age. Only in some cases are the furrows between the ridges of the tooth somewhat filled with cement. These differing varieties and intermediate forms have obviously proceeded from the earlier mastodons, and in order to simplify the arrangement have been classed as the genus Stegodon. Their home was chiefly in Italy, whence they spread abroad as far as Japan.' The discovery of their remains in the Japanese Archipelago is a proof that these islands did not lose their connection with the continent till comparatively recent times.

These teeth prepare us for the molar of the true elephant, the latest form of the group. It originates-and indeed not in theory but in the actual transition forms up to the living speciesby the ridges continuing to become steeper, drawing closer to one another, and sinking down almost to the root of the tooth, and by these furrows becoming filled with cement, which thence covers the whole outward surfaces of the tooth. The enamel parts of the still unused tooth-although in form and extent extraordinarily changed-nevertheless show the same connection as in the species from

1 Naumann, Ueber japanische Elephanten der Vorzeit Palcontographica, vi. 1882. 
which we started. A comparison of Figs. 40, 41, 42 will make the homology of the spaces $a a^{\prime}, b b^{\prime}$, $c c^{\prime}$ perfectly clear.

Europe, before the appearance of the Glacia

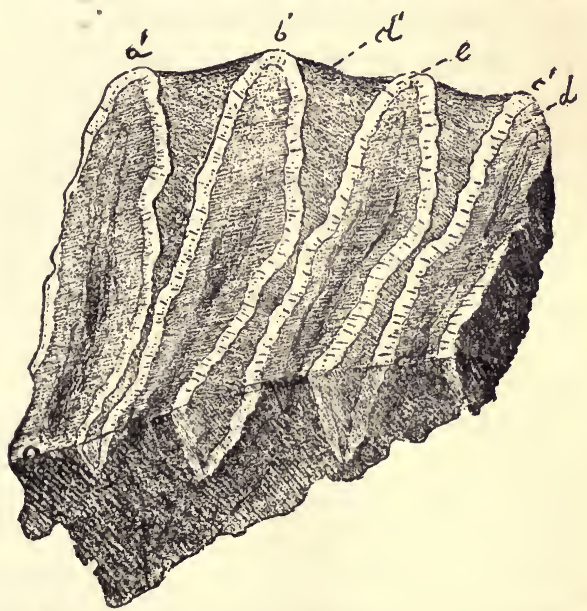

Fig. 42.-Piece of a Molar of the Mammoth, cut longitudinally, Nat. size.

$e$, Enamel ; $d$, dentine; $c$, cement.

period, possessed several elephants, and Britain, which at that time had not yet been rent asunder from the continent, possessed the Elephas antiquus, and Italy the Elephas meridionalis. The Mammoth 
also-the Elephas primigenius, the most frequently mentioned and most widely distributed animal of the group-had been driven from Asia into Central Europe, whether as far as England is still uncertain. It had an associate in the Elephas antiquus; but in any case the mammoth survived it up to the period of man. Yet it can scarcely be said whether -at the time the human immigrant took possession of Europe, and the struggle began between the tamed and the wild races, between man and the wolf in England, and the lion in Thessaly-the mammoth was exterminated in this kind of struggle, or whether it succumbed to climatic, i.e. to natural influences unknown to us. ${ }^{1}$

In entering upon a discussion of the elephants as a class, it was our wish to do away with what mystery seemed to encompass the existence of the present animal, and we have done so by pointing out their undoubted descent from the Miocene mastodons. There is but one other step backwards that we can take in explanation of the connection, by bringing forward another of the colossal, thickskinned animals, the Dinotherium. Up to within very recent times only its skull was known (Fig.

' Dawkins, 'The British Pleistocene Mammalia,' Palcontographical Society, 1878, xxxii.; Adams, 'Monograph on the British Fossil Elephants,' Ibid. 1877. 
43), from which it was supposed to be a footless, aquatic animal, and that, by means of its two tusks which projected from the lower jaws and curved downwards, it probably moored itself to the shore while resting or sleeping. No whole skeleton of this animal has, it is true, yet been discovered in connection with the skull, but to judge from various remains of bones, which in all probability belonged to it, it seems certain that the structure of the Dinotherium was of the Elephant species, and that

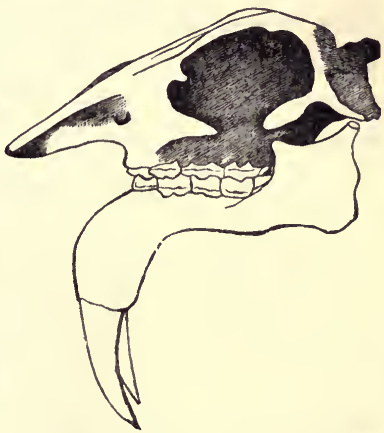
some kind of pro- Fra. 43.-Skull of Dinotherium gigan. boscis must be supteum. One twenty-fourth nat. size. posed to have been suspended from the elongated nasal bones. It is restored thus in our most eminent works on palæontology, and the correctness of the supposition is confirmed by a comparison of the molars with those of the early mastodons. The form and manner of succession of these molars, five being able to be in use at the same time, lead to 
the conclusion that the molars of the older mastodons originated from those of the Dinotherium by the loss of one or more of the front milk-teeth as the result of the strengthening of the true molars. But as the known Dinotheridæ and the earlier mastodons occur in almost the same geological horizons, the supposed descent cannot, of course, signify that Dinotherium giganteum had changed into the Mastodon angustidens, but only indicates the waywhere and how-the mastodons have originated from ancestors of the Dinotherium species.

As is evident from Weinsheimer's classification ${ }^{1}$ -our latest authority for the species-remains of the Dinotherium, and more especially molars and lower jawbones, are found in various parts of the Old World; but in all cases, only in the Tertiary deposits, and in no case higher than in the Upper Miocene strata; it ranged from France as far as India. In England no traces of it have been found, and its southern limit in Europe is Greece (Pikermi). Notwithstanding the different forms and sizes of the teeth-according to which fifteen species have been distinguished-still, owing to the transitions met with everywhere, we are in-

'Weinsheimer, Ueber Dinotherium giganteum, K, Berlin, 1883. 
clined, with Weinsheimer, to assume only one species, the Dinotherium; we are also glad to be reminded by him of Suess' words: 'We can readily convince ourselves that physical changes occur without the mammal of the district being much affected by them, but we find no change in the animal world without a change in the outward circumstances, without some recognisable episode.'

The changes in the dentition of the Dinotherix (which appear somewhat earlier than the mastodons) to the elephants proper, correspond with the gradual change in their food and mode of life. The Dinotheriæ and the older mastodons had to subsist mainly upon the roots and stalks of waterplants, which they tore up with their lower tusks in the morasses of tropical climes, like the rhinoceroses. Harder grasses demanded and produced the transformation of the simple ridged tooth, the tuberculate teeth of the mastodons, the falling away of the front milk-teeth, and finally a concentration of the material force, and more especially the peculiar conformation of the molar of the later and present elephants. ${ }^{1}$ They certainly

1 'All the changes of the organisation which we may observe in the later forms of Mastodon as compared with the earlier ones-for instance, the different forms of the incisors, the reduction of the symphysis (i.e. the connecting parts of the lower 
have differentiated much more from the original form than the other plant-eaters; but even in the case of these latter, a similar course from the general disposition to the specialised form of to-day has been pointed out. Thus, at the close of this short chapter, our elephants cannot any longer be said to stand as inexplicable wonders of creation.

In the Middle Eocene deposits westwards of the Rocky Mountains, there have been discovered, among many other animal forms, numerous remains of powerful plant-eaters of the size of elephants ; their skull possessed two or three pairs of horns, and the upper jaw showed gigantic canines (Fig. 44). These Dinocerata are believed by Marsh and Cope (and with some degree of probability) to be descendants of the Coryphodonta (see above, p. 199), and although the possibility of their being related to trunked-animals is not excluded, still meanwhile it is a mere vague analogy. The Brontotheriæ from the Lower Miocene eastwards of the Rocky Mountains, which are likewise colossal creatures,

half of the jaw), the increased slowness in the succession of the teeth, and the corresponding increase in the number of ridges, in short, the dentine which by degrees becomes worn off-point to the fact that the later mastodons had discontinued the mode of life practised by their ancestors, and had adapted themselves to a life on land.' 
but less striking as regards the formation of their skull, may, with somewhat greater certainty, be classed as a branch of the Rhinoceros tribe (see above, p. 199). Both groups, however, strike us nevertheless as somewhat strange, chiefly because their brain can be compared only with that of certain fossil reptiles, considering the size of the

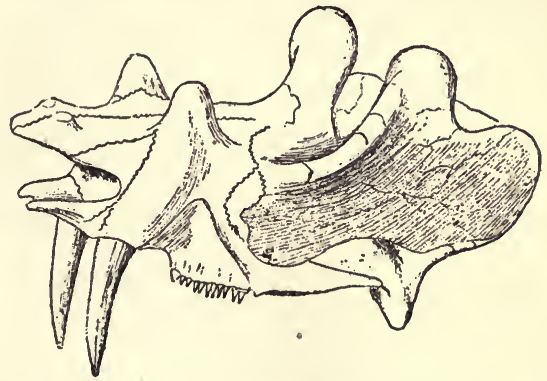

Frg. 44.-Skull of Dinoceras mirabile. One-nineteenth. After Marsh.

skull and the thickness and mass of the spinal marrow. It would seem to be a lower form even than that of the Marsupials and the Monotrema.

Two other small groups are allied to the Hoofed Animals, but in regard to one of these, the genus Hyrax (rock conies), no more can be said to-day 
than what was known to Cuvier. Although the two groups, in their outward appearance and mode of life, show affinity to the Rodents with claw-like hoofs, their molar teeth are singularly like those of most of the Rhinoceros tribe. There is absolutely no safe starting point for their historical descent. ${ }^{1}$ We are more fortunate as regards the class next to be considered, the Sirenia.

\section{THE SIRENIA, OR SEA-COWS. ${ }^{2}$}

Of this group the dugong (Halicore dugong) lives in the Red Sea, the Manatus frequents the West Coast of Africa, and another species the

- Cope is inclined to think that the arrangement of the carpals in the Hyrax is a sign of very ancient descent. His main reason for this supposition is the fact that the bones forming the several rays of the fingers still lie one behind the other simply and regularly, as in the case of the lower vertebrates; whereas in other mammals-not, however, in the elephant-the two rows of carpals have been displaced and lie side by side. The cause of this displacing or twisting must, without doubt, be looked for in the loss of the thumb, which again is connected with the cases of adaptive and inadaptive transformations of the carpals mentioned by Kowalewsky. As, however, in the elephants the row of carpals is not displaced, while in the Coryphodons a very marked displacement has taken place in spite of the thumb having been retained, it seems to me that Cope's attempt to arrange and determine the general relationships of the Hoofed Animals, more particularly of the earliest Eocene fauna, from these circumstances, is much too unsafe.

${ }^{2}$ Lepsius, Halitherium Schinzii. Darmstadt, 1881. 
eastern shores of America. Another and fourth species of very remarkable form; the Rhytina stelleri, belonged to our present period, but owing to the smallness of the range of its distribution, seems to have become extinct between the years $1741-48$.

The earlier systems of zoology considered the want of hind legs in Whales and the Sirenia, the paddle-shaped form of their front limbs, and the formation of the end of the body into an horizontally extended fin, to constitute the characteristic features of a distinct order of animals, compared with which other very marked differences in their skull and dentition seemed of little importance. However, nowadays we are so well acquainted with the disappearance of the front or back limbs, or of both extremities (in the case of reptiles) as phenomena of convergence, without this being considered a proof of any near bloodrelationship, that we no longer think of classing the Sirenia with the Whales simply because of the want of the hind limbs. The Whales are flesheaters, the Sirenia plant-eaters; the former, by their relationship to the seals, belong to the order of the Fera, flesh-eaters in the narrower sense of 
the word; the latter are a very ancient branch of the Hoofed Animals.

Of the living Sirenia the Manatus shows the fullest dentition with a change of teeth. It points to an old Tertiary group found in Jamaica, the Prorastomus sirenoides, whose molars are genuine ridged teeth.

The other and more perfect line ends in the present period with the so-called Steller's Sea-Cow (Rhytina stelleri), which has recently become extinct. It had no true teeth for masticating purposes, but, in place of molars, had large fibrous structures on the gums, one on each side of each jaw. These structures occur also in two of the living species, but are less large. The dugong already shows a considerable loss of teeth, but by possessing them stands nearer to the earlier form of Sirenia, which leads in a direct line back to the Eocene Halitherium. The dental formula is :

$$
i \frac{1}{4 ?, c} \frac{1 ?}{1 ?}, p \frac{3}{3}, m \frac{4}{4} \text {. }
$$

When comparing the genuine Hoofed Animals with their ancestors, it was seen that the loss of one or two toes took place as early as in the first Tertiary division. It was only single genera, such 
as Coryphodon, that still showed the old five-toed extremity, an inheritance from Pre-Tertiary times. However all the living Sirenians possess a fivefingered hand. When, therefore, it is said that the molars of Prorastomus are genuine ridged teeth, these do not point to the true Lophiodonta and tapirs, with their already reduced hand, but to earlier ancestors on both sides. Thus things no longer existing point to that very distant past, which extends back beyond our actual observations. Even in the case of Halitherium all that is left of the hind limb is the thigh-bone. This bone, however, is still attached to the pelvis, which is tolerably reduced, but has a socket. The earliest Sirenians, therefore, had a less striking form of skull, but, nevertheless, in their whole appearance were already like the present living species. From this it follows that the fourfooted mammals changed their abode for the sea, and lost their hind limbs, before the Tertiary period.

The living Sirenians have experienced a still farther reduction of the pelvis; it has become detached from the vertebral column; and even the above-mentioned remnant of the hind limb, the rudimentary thigh-bone, has wholly disappeared. 
7. THE CETACEA, OR WHALES.

Up to about the year 1840, our scientific knowledge of the larger Whales was based almost exclusively upon the dissection of a few stranded animals made in most cases in a very superficial manner. Skeletons of the animals could, of course, be procured, and some complete specimens had been set up in some of the museums. Their ribs, lower jaws, and vertebræ had also been collected, and, like the bones belonging to fossil elephants, were chained to town-halls and churches, where they were gazed at as the remains of giants, and probably also (as was the case with a mammoth's thigh bone in Spain) were worshipped as the reliques of saints of giant stature.

Owing to this manner of acquiring scientific material, a fatal confusion had arisen in the names given. It was about this time that Eschricht, professor of physiology in Copenhagen, applied the well-known lines-' If thou the poet would'st understand, Then must thou go to the poet's land,'to the Cetaceans. He did not visit them himself, it is true, but his friend Holböll, who was for many years inspector of the Danish colonies in Greenland, undertook, at Eschricht's request, to make 
collections and observations on the shores of the Arctic Ocean. Holböll furnished the museum of Copenhagen with excellent material in the way of skeletons, together with the softer portions of the body, also whole animals of various ages, with detailed accounts of the biological observations he had made. All this information Eschricht ${ }^{1}$ made use of in a classic work, where he traces the transformation of the skull of the fœtus (only some few feet in length altogether) to that of the full-grown giant, that framework which strikes the on-looker at first as perplexingly strange. He cleared up the relation between the bearded and the toothed Whales by following up Geoffroy's discovery more minutely, i.e. by showing that the fœtus of the Bearded or Whalebone whale possesses a number of small teeth, which never cut through the gums, and subsequently become completely re-absorbed, when the huge sieve-like apparatus on the mucous membrane of the gum appears. The rudimentary teeth of the Whalebone whales, which never come into use, are

1 Eschricht, Zoologisch-anatomisch-physiologische Untersuchungen uber die nordischen Walthiere (Leipzig, 1849), of which work there is an English translation; also Brandt, 'Untersuchungen über die fossilen und sub-fossilen Cetaceen Europas,' Mém. Acad.Petersb., 1873; Van Beneden et Gervais, Ostéographie des Cétacés. Paris, 1868-80. 
final links in the chain of evidence that the Whalebone whales are the last members of a transformed group which commenced with animals with four toes and numerous teeth, and which by the gradual diminution of the dentition have become Whalebone whales.

Still, the skull of the Whalebone whales shows so much resemblance to that of the Dolphins and all of the other toothed whales, that, were it not for the discovery of teeth in the fotal animal, we should be in doubt as to the unity of the two groups. From the head of a dolphin only a few feet in length, we may learn all about the peculiar transformations just as well as from the head of a Greenland whale. The mid jawbones (Fig. 45) do not appear in front between the upper jawbones, but are very much elongated, and frequently lie somewhat irregularly, projecting beyond the upper jawbone. The most striking changes, however, are those of the middle head, and all this can be traced to the rising up of the nasal cavities -in all other mammals these lie horizontally or . obliquely towards the front-which form perpendicular blow-holes close to the crown of the head. Not only has the olfactory bone become raised, but the nasal bones also, in most cases, have been completely displaced from their position as 
coverings, and stand as perpendicular back walls to the nose, while the frontal and parietal bones are compressed and pushed aside in the most remarkable manner. However, it would certainly not require a practised osteologist to construct the skull of a whalle from any certified bone. There is nothing in the skull of the whale that could, in the

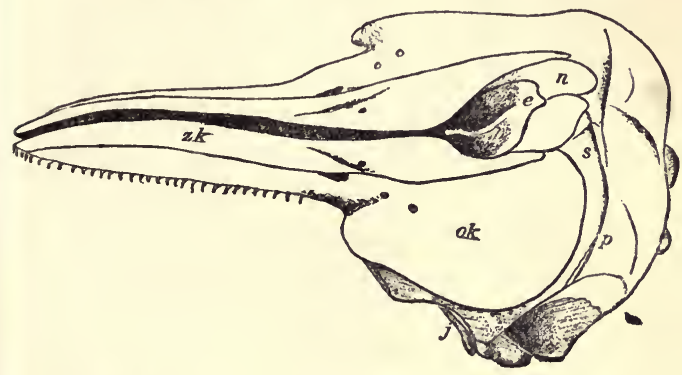

Fig. 45.-Skull of Delphinus lagenorhynchus. Gray.

$z k$, Mid-jawbones; $o k$, npper jawbone; $j$, cheek-bone ; $p$, parietal ; s, frontal bone; $n$, nasal bone; $e$, olfactory bone. One-fifth nat. size.

slightest degree, lead to a connection between it and the Sirenians (p. 243). Nevertheless, their hind limbs, like those of the Sirenians, have disappeared externally without leaving a trace of their former existence; the rudimentary pelvic bones that are concealed in the flesh-sometimes with the last remnant of the thigh-bone, very rarely with the shank 


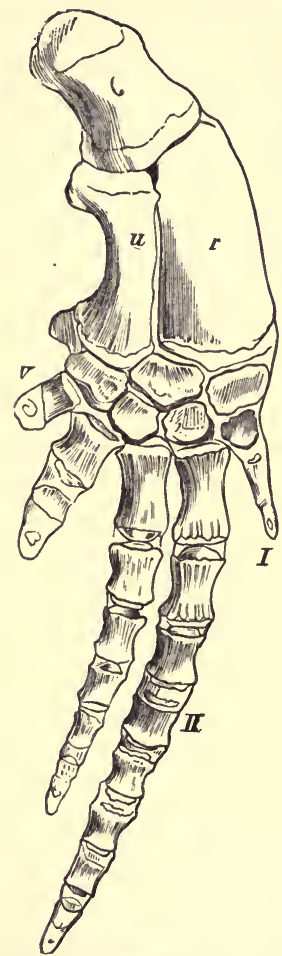

Fig. 46.-Right Fore-limb of Delphinus delphis. After van Beneden and Gervais.
- bear witness, however, to their having possessed ancestors with four legs. ${ }^{1}$ The front limbs remain wholly within the known structure of the mammal leg, as may be seen by that of the dolphin on Fig. 46. The toothed whales are almost without exception five-fingered, even though in most cases the thumb and the little finger appear very much reduced. This, moreover, shows them to be geologically older than the Whalebone whales; for of these only the smooth whales (Balana) possess five fingers; in the others the thumb has completely dis-

1 The modifications which the whales have experienced as mammals in water, have been admir. ably described by Prof. Flower, 'Whales in the Past and Present,' Kosmos, vii. 1883. 
appeared. That the Whalebone whales are geologically younger than the smooth whales is likewise proved by their generic characters, the furrow which extends from the throat to the belly, and the humped or fin-shaped protuberance on the back. Hence not only does the preserved skull of one of the most important group of the Whalebone whales (the Cetotherium) oblige us to maintain the animal to have been one of the smooth whales, but we are also enabled, from this circumstance and the geological period, to conclude that these whales did not possess either furrows on their breast or fins on their back.

The time of the fullest development of the Cetacea belongs to the Miocene period, when they had associates in the large and also numerous small Whalebone whales, for instance, the Cetotherium just mentioned, which is closely related to the present Bearded or Whalebone whales (from two to ten feet long), and also the Dolphins and the Zeuglodonta. The last-mentioned group is formed of the two entirely extinct genera, Zeuglodon and Squalodon.

Brandt has in detail urged it as improbable that Zeuglodon, as is often supposed, can be regarded as an intermediate form between the 
seals and whales, the shape of the skull and the strong nasal bones covering the nasal cavity having been thought to indicate this. Their length varies between twelve to seventy feet. They belong in America to the Eocene, in Europe to the Miocene period.

Squalodon approaches closer to the Dolphins than does Zeuglodon, more particularly by the position of the nasal bones and the corresponding displacement of the other bones. Its teeth (Fig. 47), like those of the Zeuglcdonta, remind one of the Seals. The dental formula is : $i \frac{3}{3}, c \frac{1}{1}, p m \frac{4}{4}$, $m \frac{7}{7}$. The compressed molars, which are pyramidical in form, show a certain external resemblance to the teeth of the Sharks.

As the Zeuglodonta-including the Squalodonta -are not yet as far advanced in the transformation of their skull as the Delphinidae, it has never occurred to anyone to regard the Dolphins as ancestors of the Zeuglodonta. Such a supposition would be as irrational as if we were to imagine the Antelopes descended from Oxen. On the other hand, however, as great a difficulty would have to be faced were we to suppose that animals of the Squalodon species had left descendants of the 
Dolphin species. We do not speak of the dolphinlike whales with reduced dentition-e.g. the Narwhales; these are side branches of the main stem, the members of which are distinguished by numerous teeth of the same shape. The teeth are always growing and have no closed roots, wherein they resemble those of many of the reptiles. Now Baume, for various good reasons, has made it seem probable that the ever-growing teeth of mammals are an ancient inheritance, and that rooted teeth, on the other hand, are a new acquisition. If Baume is right in this, we have no connecting link for the Dolphins,

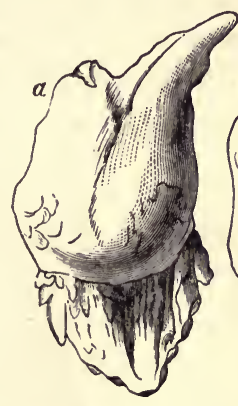

FIG. 47.-Tooth of Squalodon. $a$, From the outside; $b$, from the side. After Stlss. and naturally none either for the Whalebone whales. All the three subdivisions-Zeuglodonta, Dolphins, and Whalebone whales-are found side by side in the Early Tertiary period, and the vertebræ of whales have even been found in the Jura. However, all that can be said with certainty is that we 
have no idea in what period or under what circumstances whales came to be developed. What is improbable is that they were descended directly from reptile-like ancestors, independently of the other mammals. None of their peculiarities point directly to the Reptiles, and are all intelligible as modifications which were effected by the land animal in its transition to a life in water.

But of what kind were these ancestors? Our first thought turns to the Seals, which, of course, have likewise adapted themselves to an aquatic life. However, in their case, the hind limbs have not in any way become reduced, and have only changed their position to the pelvis; whereas the upper and lower parts of the leg are shortened, and the feet have become broad and lengthened paddles. Hence it cannot be imagined that these animals, which are so admirably equipped for swimming, could have struck out a new kind of adaptation. There could not have been any use or necessity for this. Hence a certain resemblance in the teeth can only have been the result of convergence; and Prof. Flowers reminds us that this had long since been pointed out by Hunter, ${ }^{1}$ who says:

1 John Hunter, 'Observations on the Structure and Economy of Whales,' Philoso. Trans. 1787. 
- There are numerous points in the structure of whales which bring them much closer to the hoofed animals than to the beasts of prey-for instance, the complex stomach, the simple liver, the respiratory organs, but mainly the reproductive organs, and the stages relating to the development of the fœtus. Even the skull of Zeuglodon, which we admitted shows a certain likeness to that of the sea dog, shows as much agreement with that of the earliest pig-shaped ungulates, except in the purely adaptive character of the form of the teeth.' The objection raised that whales are flesh-eaters, while most of the Hoofed Animals are true plant-eaters, has been very properly refuted by Prof. Flowers, who points to the former predominance of omnivorous animals, and shows that, with the exception of the Pigs, which have remained most faithful to the ancient type, the Omnivora became more and more true grass-eaters, while the others developed a taste in an opposite direction. Regular flesheaters can either not accustom themselves to vegetable food at all, or only in cases of emergency -as we ourselves see daily with the cat or dogwhereas we not unfrequently find instances of the contrary. Cattle eat dried fish with evident relish during a nurthern winter, as is well-known; 
and, therefore, the whales may, in the widest sense of the word, be classed with the primary Hoofed Animals, which still possessed five toes and differed as much, and even more, from the present group as the primeval horses from the horses of our day.

The period when whales were most abundant was that of the Middle Tertiary, when, as already stated, the present Europe-Asiatic continent was for the most part under water. Brandt gives a very graphic description how the Cetacea of those temperate zones may have ceased to exist with the disappearance of that ancient ocean. And as the account is of general importance we will quote his words: "The dying out of marine animals appears at first sight more strange than the dying out of land animals. We are apt to imagine that the inhabitants of the sea-in their far-reaching element animated everywhere more or less by living creatures - have a better opportunity of withdrawing from such external influences as affected them injuriously, without thereby experiencing a want of food, particularly if the hurtful changes were not sudden. As an example of an earlier ocean of this kind, extending from Western and Southern Europe to Central Asia, we may take the immense ocean 
which existed in the Miocene, and probably lasted beyond that period; when largest it extended to the Arctic ocean, and also communicated with the tropical seas in the south. An ocean of this kind would not only confer a higher temperature upon the central zones, but would also essentially contribute to the warmth of the northern regions, and further, would not merely favourably affect the flora, but likewise give the fauna a very different character to what it shows nowadays. This condition was, however, by no means a permanent one. The gradual rising of the land led to a separation of the southern, sub-tropic or tropic seas, and to a lessening of the extent of the great ocean itself, and its temperature would likewise decrease. This was still more the case, however, with the great connecting sea in the north, more particularly when its separation, and gradual disappearance, resulted in its becoming more or less detached basins. The former luxuriant and fuller vegetation and animal life on the continent, which had been favoured by a warmer and moister climate, changed their character and became less exuberant. Less organic matter being produced on the land, less was carried to the ocean, where it served numerous small marine animals as food, 
while, at the same time, the afflux of fresh water exercised a greater influence upon the lessened amount of sea water. These circumstances, which reduced the food of marine animals-nay, which was obviously detrimental to their existence-were accompanied, moreover, by the gradual separation of the great ocean into numerous basins, occasioned by the rising of the land already alluded to; this prevented the animals from migrating, and the altered condition of the water increased even further owing to the separation. As a proof of this we have the Black Sea, the Caspian, and the Aral Sea, which remained longest in connection, and several other seas in Central Asia. Those species of invertebrates and fishes which, owing to their peculiar organisation, could exist only in large, open seas, and not in an inland sea with a lesser amount of salty substances, and were unable to accommodate themselves to the change in the physical, thermal, and biological conditions, died out together with the Cetacea. Those that survived and were able to adapt themselves to circumstances, like some of the molluscs, \&c., decreased in size.' 
8. THE CARNIVORA, OR FLESH EATERS.

The group of our present flesh-eating mammals which has been most carefully examined as regards specialisation of the dentition, and whose geological appearance has perhaps left most traces and points of connection-is that of the Dogs, or Canida. We shall, therefore, take this group as the startingpoint for our comparative examination.

The dog, like all the other Carnivora, possesses five toes on its front feet and four on the hind feet, with non-retractile elaws. Those who wish to obtain even a limited view of the relationship between the main genus Canis and some of the sub-species, and various other forms allied to these, their geographical distribution, \&c., in the hope of finding some indications of the lines which partly vanish into primeval times without leaving any trace, but again in many instances showing a connection with definite palæontological facts, must first of all make themselves aequainted with the dentition of the group. One tooth more or less unmistakably determines. the date of one or more of the geological periods. The position, size, and disappearanee of the teeth indicate, with almost the same certainty, the relation- 
ship between the species which ranged separated over half of the earth's surface, or they point to the different origin of those which live almost within the same range of distribution. The certainty with which a palæontologist works-by making use of means which appear absolutely valueless to an unscientific person-can be appreciated only by those who have acquired at least some knowledge of the way in which the work is accomplished. This again shows what little weight can be placed in the perpetual assertions of unscientific persons, that the followers of the theory of descent are not in the position to prove the transformation of species.

Everyone knows that the dentition of the fox (Canis vulpes) consists of very differently formed teeth (Fig. 48), which, however, agree in so far that the crowns show an unbroken covering of enamel ; in this the molars, more especially, differ strikingly from those of the Hoofed Animals and many of the Rodents, where the crowns have complicated folds of enamel. The dental formula is : $-i \frac{3}{3}, c \frac{1}{1}, p m \frac{1}{4}, m \frac{2}{3}$. For our purpose here it is the molars almost exclusively that come into consideration, hence $\frac{4}{4}: \frac{2}{3}$. Thus the genus Dog 
has in the upper jaw four premolars or teeth that have replaced the milk-teeth, and two molars. Of the premolars the fourth $\left(p^{4}\right)$ is remarkable owing to its size, compressed form and sharp edge, also by possessing an inner process in front; this is the carnassial or 'flesh-tooth.' Corresponding with it

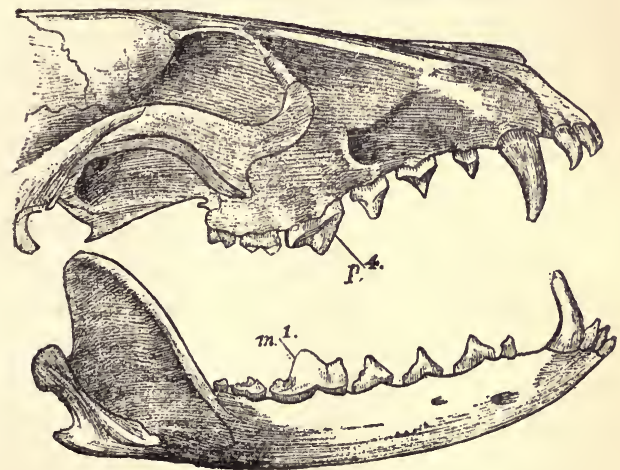

Fig. 48.-Jaw of the Fox. After Huxley.

below we have not the $p^{4}$, but the first of the three molars or grinders, $m^{\prime}$. The connection and origin of the different species of Dogs is determined by the, in some cases, undistinguishable shades of difference in the tubercles and processes, by the distances of these points from each other, and by 
the length and breadth of the teeth, the measurements of which have to be made by the tenths of millimetres, and thus we finally have an animal of the dog species of the present day not with $\frac{2}{3}$, but with $\frac{4}{4}$ molars, and we may therefore draw the very probable inference as to the Eocene ancestors of the present Canidæ. In the above remarks we have principally followed an extremely clear account given by Huxley. ${ }^{1}$

If several small differences are taken into consideration, the various species of the genus Dog (Canis) may be formed into two groups, the one represented by the Common Fox, the other by the Brazil fox (Canis azare). These differences relate to the frontal depressions - which are entirely wanting in the fox and are strongly developed in the other group-and to the form of the front part of the brain. By the side of the fox we have Canis fulvus, argentatus, littoralis, zerda, lagopus and others; on the other hand the Jackals and Wolves, all varieties of the Domestic Dog, Canis anthus, latrans, antarcticus, magellanicus, cancrivorus, varieties of the Dingo. In both groups subdivisions have again to

'Huxley, 'Cranial and Dental Characters of the Canidæ,' Proc, Zool. Soc., 1880. 
be made in accordance with the form and strength of the carnassial tooth. However, even when a good idea of the Fox and Wolf type has been obtained, the differences finally merge one into the other, and thus here again comes an end to all systematic arrangement.

In all the above-mentioned animals of the dog species the dental formula of the molars is $\frac{2}{3}$. The agreement of the lobes, processes, and tubercles of the teeth is such, that blood-relationship appears certain if the alternative of convergence or inheritance is properly considered.

We must now refer to the question of the origin of the domestic dog. ${ }^{1}$ That the whole line of foxes has nothing to do with the dog has long been an established fact. On the other hand, Darwin endeavoured to prove that various wild tribes of men in different parts of the globe tamed native wolf-like animals, and that the crossings of these species and breeding of various kinds produced the domestic dog of our day. This opinion of Darwin's has been somewhat modified by L. H. Jeitteles, a careful authority on the domestic animals. According to

1 Darwin, The Variation of Plants and Animals under Domestication; Jeitteles, Die Stammvater unserer Hunde-Rassen. Vienna, 1877. 
him the wolf (Canis lupus) has no connection with the European and west-oriental races of Dogs, the connection being mainly through the Jackal and the Indian Wolf (Canis pallipes). The races partly lead back into prehistoric times. Closest to the Jackals we have the so-called Turf-dog, known from the turf deposits of the lake dwellings, and which is probably the ancesto: of our Pomeranian dogs. Allied to it we have the terriers and turnspits. From Canis pallipes is descended the socalled Bronze-Dog, which most probably came to Europe with human immigrants from Asia, and with it the sheep-dog of Central Europe, the larger sporting dog, the poodle, cur-dog, and bull-dog. The ancestor of a third group may perhaps be found in the large jackal (Canis lupaster) of North Africa, to which we should also have to refer the ancient Egyptian dog, the Oriental street dog, and the wild dog of Africa.

This does not as yet settle the question as to which fossil forms may be concealed among the numerous races of the domestic dog. Various conjectures have been made, none of which, however, are based upon any special reasons. According to Blainville's opinion, a Diluvial species of a gentle and sociable nature-no longer existing in a wild 
state-must have been the primeval form of the domestic dog; but after what has been said above, this general way of settling the question must be regarded as one that no longer holds good. Woldrich's ${ }^{1}$ views show a greater amount of probability, and have lately been taken up again; he maintains that our domestic races are descended from several wild forms of the Canidæ of the Diluvium, and herein he agrees with what Darwin and Huxley have stated regarding the relation between the Domestic Dog and the living Jackals and Wolves.

It may with certainty be maintained that the directancestors of the European Wolf are to be found in the Diluvial deposits. Formerly a huge animal of the wolf species was distinguished as the Cave Wolf, without there being any distinct character to separate the two forms. A third form of wolfCanis suessii, from the Löss near Vienna-is described as a slim but powerful animal, strong enough even to pursue and overpower the larger species of plant-eaters. It is, in fact, one of the eight species of wolves which can be distinguished during the Diluvial early ages of man. And in addition to these there are about five kinds of foxes.

'Woldrich, 'Wilde Caniden des Diluviums,' Wiener Denkschriften, 1879. 
In now returning to the living Canidæ, several species demand our attention, one of which is described as Icticyon venaticus, a native of Brazil, the other under the generic name of Cyon, inhabiting the countries to the north and north-east of the Altaian mountains. These dogs do not possess the third molar in the lower jaw, and the $m$ in the upper jaw is so small that a reduction appears to be immi-

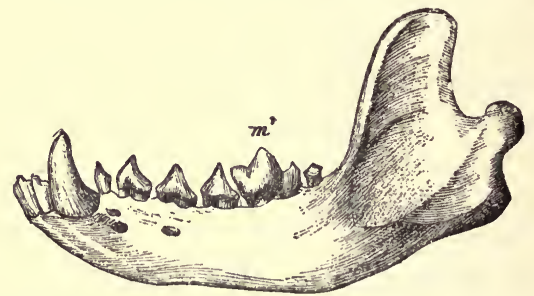

Fig. 49.-Lower Jaw of Icticyon. After Huxley.

nent there as well. It is in the natural course of things that one or both of the first premolars, or the last molar, should become useless and forced to disappear, by the neighbouring teeth being specially taken into requisition, although in most cases we do not know the immediate reason of this. ${ }^{1}$ The

1 Any of our readers who can examine the head of a dachshund may convince themselves of the fact that the first premolar above and below can scarcely be of any use to the animal; 
other circumstances of the structure of this group do not lead us to expect anything special from this concentration of the dentition. In former times, however, as we shall soon see, a most varied development of new genera of Beasts of Prey began with dog-like animals.

Much more interesting for the purpose of our investigation here is the Otocyon lalandii, the spoondog of South Africa, so called from the peculiar formation of the skull. Its habits show an approximation to the Foxes, yet as regards dentition it does not show this affinity, inasmuch as it possesses $\frac{4}{4}: \frac{4}{4}$ molars, and also shows the most remarkable differences in the relative size of the single teeth. As already said, the spoon-dog is in many ways, and as regards dentition, shaped after the fashion of the dog type, and can thus scarcely be dragged out of this connection, and we are compelled to look upon it as a still existing primary form of dog. The whole palæontology of the Vertebrates shows that the many-toothedness of Mammals is an inheritance from their lower ancestors, and that

it is a little stump which does not come in contact with the opposite row of teeth, and is frequently wanting altogether. If the dachshnnd is not forcibly suppressed as a species, its denti. tion will one day inevitablv be reduced by one premolar. 
any increase of the teeth within a class has probably never taken place.

As our dogs, with their $\frac{2}{3}: \frac{2}{3}$ molars, have no doubt been descended from fuller-toothed animals, Otocyon must be regarded as the still living representative of the early type of dog, which in other characteristics shows more affinity to the fox family. But as there also exist species of the group Canis azare with very small frontal depressions, it is, as Huxley says, very difficult not to imagine that these too must be traced to ancestors of the Otocyon type. From this species, therefore, we should have to derive the two lines which diverge into the fox on the one hand, and the wolf on the other. We are supported in this view by the observation that the South American Canis cancrivorus often possesses the $m^{4}$, and thus shows itself to be another remnant of the primary form. A fourth supernumerary molar of this kind is not a monstrosity or pathological phenomenon, but an atavism or reversion of the same sort as the so-called wolf's tooth in Horses, which was explained as a premolar which existed in the primary genus Anchitherium.

Hence the key to the derivation of all the Dog 
tribe is to be found in their relation to the spoondog. What Huxley states regarding the similarity between its dentition and that of the lower bear-like genera is certainly well worth consideration, but is of less importance than the conclusion he draws from a discovery of his own. In several hundred different species of Dogs he found fibrous formations which are said to correspond with the marsupial bones (ossa epipubica), the distinguishing feature of the Marsupial group. If this observation becomes an established fact, the direct descent of dogs from Marsupials would seem in the highest degree probable. However, as one of our first comparative anatomists has maintained, we still require further proofs for Huxley's observation. In imagining the Dogs connected with the Marsupials we should not, in the first instance, have to consider our present carnivorous Marsupials (Thylacinus, Dasyurus), whose row of molars consist of one tooth less than that of Otocyon, and are generally characterised as $p \frac{3}{4}, m \frac{4}{4}$. The Marsupial Rats would more likely have to be taken into consideration. They are the only known animals from the Eocene with four molars. Moreover, by using the flat part of their hands and feet, 
and possessing pointed, tuberculate molars, they point to the Insectivora. For another circumstance to be considered is, that various peculiarities in the teeth of the lower Canidæ show approximation to the dentition of the Insectivora; and the occurrence of rudimentary clavicles and the rudiment of a fifth toe on the hind limb, also clearly point to ancestors with well-developed clavicles, and the full number of five toes. All this is found united in the Insectivora: hence our present dogs have been traced back to the Eocene and Pre-Eocene Insecteaters with certain peculiarities of the Marsupials.

This derivation of the Dog tribe-which is based mainly upon deductions from the present nature and distribution of the group-goes back, therefore, into that dim twilight which, in the opinion of Cuvier and his followers, could alone precede the dawn of true light in the mammal world. We shall have to dwell a little in this Eocene period and look around among the incredible wealth of mammal forms, which seem, as it were, to have been re-animated by Filhol's graphic descriptions (see above, p. 64). We shall obtain some idea of the vigour of that exuberant, plastic life if, in place of the few Carnivora that are now inhabiting France, and indeed Southern and Central Europe, we ima- 
gine in one part of South-western France, of Carnivora alone, some forty species from the size of the marten up to that of the most powerful wolves and bears. They lived, as the vast quantities of their remains testify, partly in herds; and of food there was an abundance in the corresponding numbers and varieties of plant-eaters.

First of all comes the Viverrine Dog (Cynodictis), which, although possessing the dental formula of the Dog

$$
i \frac{3}{3}, c \frac{1}{1}, p m \frac{4}{4}, m \frac{2}{3},
$$

(of which, in the upper jaw the fourth premolar, in the lower jaw the first molar stands for the carnassial tooth) had a very narrow skull, with broad, strong cheek-bones-an admirably developed beast of prey between the size of a fox and a wolf. These animals, Filhol says, are curious and very peculiar forms, in which, after a very careful examination, certain points are at length discovered by which they show affinity with our present Carnivora. But in spite of every effort to bring them under one head, it cannot be done. And hence we have to assign to them an essentially distinctive character, a position outside the customary classification, and one, in fact, which 
approximates the living families. The French investigator means to say that they are dog-like animals, but not dogs; that, in fact, they cannot be classed with any one of the present families of Carnivora, although showing the characteristics of the class in the various parts of their skull with which we are very well acquainted-the mid jawbone, gums, alar processes, tympanic bones -as well as the form of the skull as a whole. We should not exactly say that the animals stand beyond our system of arrangement, but that they do away with existing gaps. This is most obviously the case with their dentition. In most of these forms of Cynodictis-which can be defined as species - the teeth are all well marked and developed according to their position. But in Cynodictis intermedius, the last lower molar, $\mathrm{m}^{3}$, is so small that it is evidently of not much use, and we may rely upon its gradual disappearance. Were this to happen we should then have the dental formula of the Viverræ. And it does happen: the race named Cynodictis intermedius viverroides from the $C$. intermedius has become a Viverra.

With the loss of that molar there arises a small modification, $p^{4}$, hence one connected with the important carnassial tooth of the lower jaw; and 
what is most remarkable, the same loss is met with in two other species (C. crassirostris, leptorhynchus), the same modification of the carnassial tooth. It is not known what change in the mode of life caused these same changes in the teeth in several different species. We are content with knowing in what manner so-called new species and genera appear on our earth; in fact, not suddenly, but by imperceptible shades of difference, which increase in the course of thousands of generations, until, finally, what seemed at first an exception to the rule becomes the prevailing state of things. The objection so frequently brought forward that these 'accidental' deviations would always again be neutralised by crossings with unchanged members of the species-if geographical isolation did not come to assist them-have no foundation whatever; for our discoveries in palæontology prove the contrary. It must be remembered that the expression 'accident' applies only in so far as it conceals our ignorance of causes and occasions. In many cases-for instance, in the transformation of Mastodons into Elephantswe can with some certainty determine the altered conditions of food to which the teeth had to adapt themselves. 
And in the present case we have only to deal with an established fact, that the Viverre are the descendants of the Viverrine Dog, Cynodictis. There can be no dispute about this. Hereupon commences a new series of modifications, and from the Viverræ are descended the Weasels.

We now pass from the Upper Eocene of the phosphate of Quercy to a somewhat later period, which produced the Lower Miocene deposits of Saint Gerard le Puy, on the Allier. Here is found the Plesictis, a carnivorous animal distinguished from the Viverræ mainly by the form of its head. Filhol points out that a 'comb' (crista) of the sagittal suture not previously existing, has been formed by a contracting of the temporal ' combs' of the Cynodictis; in other words, that we have the perfectly justifiable conclusion that smaller species of Cynodictis passed over into the form of Plesictis under the influence of natural causes.

In the races directly descended from Cynodictis a change takes place in the nature of the teeth, and the dentition assumes more and more the character of that of the weasel, while, on the other hand, the peculiarities of the Viverræ disappear; thus the line Plesictis-Stenoplesictis-Palcoprionolon leads in 
gentle modifications to Mustela, and henceforth there exist weasels.

Equally distinct are the intermediate forms by which is accomplished the transition from the weasel's dentition to that of the Cats. The genus Proclurus appears likewise with two tuberculate teeth in the upper jaw behind the carnassial tooth. But single species of the genus sometimes show a loss of the back molar, and herein approach the cats ; the back edge of their carnassial tooth, moreover, loses a tubercular heel or process. By this small modification Proclurus has become Pseudclurus, inasmuch as the modification was general and continued for some length of time. In comparing the following statement of the simplification of the molars of the lower jaw :

$\begin{array}{cc}\text { Premolars } & \text { Carnassial } \\ 4 & 1 \\ 4 & 1 \\ 3 & 1\end{array}$

$$
\begin{array}{cl}
\text { Tubercular teeth } \\
1-p_{4} & m_{2} \\
0-p_{4} & m_{1} \\
0-p_{3} & m_{1}
\end{array}
$$

which have actually been observed, and which shows, moreover, that the front premolar $p^{2}$ has also become reduced-it becomes clear that the only distinction between a Pseudelurus of this kind, for example, $P_{s}$. Edwardsii and our present cats, is that it possesses a minute premolar. Hence the great simplification in the number of teeth which Filhol 
was able to establish in these animals, justifies the supposition that this small piece will disappear later, in the same manner as has happened previously to the one that existed in front of it $\left(p^{1}\right)$, and had previously happened to the tuberculate tooth $\left(m^{2}\right)$. The genus Felis herewith appears upon the scenes.

The concentration of the dentition did not remain stationary at the stage acquired by the cats, $p \frac{3}{2}, m \frac{1}{1}$; the highest degree of specialisation was attained by the so-called Sabre-toothed tiger ( $M a$ chairodus) with the dental formula:

$$
i \frac{3}{3}, c \frac{1}{1}, p \frac{2}{2}, m \frac{0}{1}
$$

with 26 teeth against 30 in the cats. Machairodus, an animal somewhat the size of a tiger, possessed in its upper jaw a powerful sabre-shaped canine tooth which projected from the mouth downwards extending beyond the lower jaw. This lower jaw shows an indentation obviously produced by the pressure of the huge upper canine teeth as they became more and more developed and endeavoured to make room for themselves. The cause of the dying out of this most definite of all the Carnivora of the period, has been attributed to the extra- 
ordinary development of these tusks, the length of which finally may have prevented their opening their jaws sufficiently. In answer to this it can only be said that a bad hypothesis is better than none. The sabre-toothed tiger appears and disappears in the Miocene deposits both of the Old and the New World.

Pseudalurus was shown above to be an intermediate form between the weasel and the cat. This does not exclude other intermediate forms. One of these is the Elurogale, also the size of a tiger and found in great abundance in the phosphate of Quercy. Its upper jaw resembles that of Cats, the lower jaw shows the teeth of the Mustelidæ (weasels and otters). The races arrange themselves in such a manner that, notwithstanding the extraordinary variations in the size of the teethin those which deviate most from the primary form-the lower jaw also has preserved the Cat formula. ${ }^{1}$

1 We shall not refrain from pointing out the difficulty which is met with in this apparently simple line of descent. Of all the living Carnivora the Cats possess the most perfect rudimentary clavicles, the others have either smaller traces of these or none at all. All the ancestors of the Cats must at least have possessed clavicles such as are still met with in the Cats. And it is quite intelligible that the clavicles should have con. tinued to exist in Cats, owing to their have retained the habit of 
In order to illustrate our remarks we have drawn up the following piece of pedigree :-

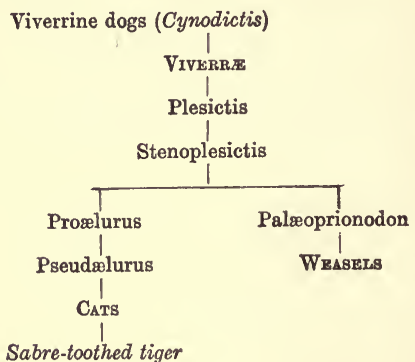

The above is the shortest way of expressing the result of a long series of the most careful comparison of facts, and has as much right in claiming to be credited as any other conclusion deduced from scientific investigations, in whatever province the facts have been gathered. When it is admitted that the philologist can arrange the age, connection, and succession of manuscripts, in a tabular form, from the character of the writing, from the use of signs climbing, while in the other animals they would become more and more reduced. Naturally enough we do not know the particulars connected with this reduction. But should we succeed in establishing the want or a greater reduction of the clavicle in one of the branoh families in the above pedigree (arranged according to the development of their dentition) our whole arrangement would of course collapse. 
and word-forms, \&c., and that the literary historian may conclude that a certain work was written by a certain author, from the style of the composition and certain modes of expression, \&c. ; and further, when it is admitted that a lawyer, by the combination of passages, all of which are obscure, can throw light upon a case of Roman law, then I maintain our procedure also-a zoologico-palæontological method of investigation and drawing conclusions-must be granted as a matter of course.

The descent of Weasels and Cats from those changing forms of Cynodictis, therefore, presents a great degree of probability but no actual certainty ; for different animals that appear geologically almost as contemporaries, may occur parallel with one another with precisely similar dental formulas and reductions in the jaw. However, we come to the certain conviction that the transformations actually took place, and that our present animal could and must have originated in that natural manner. And as it is mainly our wish merely to pave the way for this opinion, it will be almost superfluous to enter any more fully into the primary and transition forms between the present and the primeval Carnivora. 
It may, however, be remarked that our $B$ ars had representatives in the Miocene. In those times there existed the Amphicyon, of the size of a wolf, but in reality a dog with $p^{4}, m^{3}$, the broad crowns of the first two molars showing the incomings of tubercles which point to a definite form of food. This characteristic is even more marked in a later form of bear-dog, Hycnarctos $\left(p^{3}, m^{2}\right)$, and has preserved its full development in the bear (Ursus) from the Pliocene up to the present period. However, the fewer number of teeth of the Hyænarctos again forbids its being classed with the actual ancestral line of the Bears. The latter with their flat tuberculate molars, which point to a fixed food, and their tolerably blunt carnassials, are comparatively a late modification, to a certain extent a reversion to the beast of prey. This character has, however, been retained by the polar bear, which has again become a pure flesh- and fisheater.

Gaudry has pointed out an ancestor for Hyænas in the genus Ictitherium from among the fauna discovered at Pikermi. All that was required in this animal to give its dentition the formula and structure of that of the Hyæna, was the disappear. ance of the second molar above and below (and the 
upper one already shows signs of reduction), also an extremely small difference in the carnassial tooth. Indications even existed in the Ictitherium of the peculiar strength of the premolars of our present hyænas, which show a predilection for gnawing and crunching bones. Animals of the Viverra type seem to have been the ancestors of this branch.

In the Lower Eocene strata of Europe, but more particularly in the corresponding deposits of North America, numerous Carnivora have been found which differ more from the living families than most of the fossil genera that were brought into connection with them above, and which, moreover, can be brought into this connection, although, taken as a whole, they prove to be but the first stages of very highly developed beasts of prey from the Upper Eocene. The characteristic which most distinctly indicates the low position of the Early Eocene beasts of prey, is the small development of their brain, which is known to us from the form of the skull, and from natural fillings and castings. In their case the olfactory lobes appear as broad processes of the fore end of the larger division of the brain, the mid-brain being scarcely covered by it, the back part not at all. As regards Europe, the 
Arctocyon (Palcocyon blainville)' has long since been known as an animal with a brain approaching that of the Marsupial type ; whereas its dentition, which resembles the earlier form of pig-shaped animals, Entelodon, points to the Omnivora, while it has also something of the bear as a flesh-eater. Further, we must mention the Hycnodon and Pterodon, so often referred to, and usually defined as 'mixed forms'; they appear somewhat later, it is true, but, nevertheless, show resemblances to the Marsupials-for instance, in the form of their teeth they are closely allied to the Thylacinæ, though not as regards their change of teeth.

With these animals-which are partly also found in America-Cope classes a whole series of American genera of doubtful position mostly from the Eocene; he gives them the name of Creodonta, and regards them as the ancestors of the subsequent Carnivora proper. In their case the row of molars is not separated definitely by a carnassial tooth, or but imperfectly so: the jaws are lengthened, and the muscles for chewing are placed in such a manner that only a smaller degree of power can be developed than in the subsequent true Carnivora;

1 Lemoine, 'Recherches sur les ossements fossiles des environs de Reims,' Annales des sciences nat., 1879. 
these latter, by the shortening of their jaw and the reduction of their dentition, were all the better able to overpower their prey.

One of the most important forms of these Creodonta-because extremely numerous in New Mexico, and found in three species in the phosphate of Quercy-is Oxyæna. The species vary in size between a badger and a jaguar. The dental formula is : $i \frac{3}{?}, c \frac{1}{1}, p m \frac{4}{4}, m \frac{2}{2}$. Herein, therefore, the Eocene fauna of the Old and the New World again show connection.

We are the less inclined to enter upon an account of the five families of Creodonta, ${ }^{1}$ because the grouping, the assumed connection, and, above all, the derivation of our present large group of Carnivora, the dogs and cats, often seem to be in want of those safe foundations pointing from case to case, from genus to genus, which Filhol's investigations and deductions have made so incontestable.

In order, however, to give those of our readers specially interested in the subject some suggestions for further enquiry, we may here mention the

' Arctocynoidæ, Miacidæ, Oxyænidæ, Amblyctonidæ, Mesonychidæ. 
systematic relationship into which Cope ${ }^{1}$ has placed the Creodonta.

The mammals from the Wasatch beds of Utah and of New Mexico have been divided into fiftyfour species, most of which are distinguished by a very small and evidently low form of brain, to judge from the structure and position of its parts. That of Coryphodon (Fig. 14) appears almost like that of a reptile, and in this character the Hoofed and Clawed Animals agree. They also agree in the structure of their joints, the different parts of their limbs, and also in the number of their toes, of which five were observed in from forty-one to fiftyfour species. In the flesh-eaters there is no earnassial tooth; in the plant-eaters no teeth with crescentic crowns; all the molars belong to the type of tuberculate teeth, either in primitive simplicity, or of that form where the tubercles are compressed to the side, and coalesce into imperfect transverse ridges. On this account the animals have been named Bunotheria, and are arranged in the following manner :-

Insectivora, Tæniodonta, Tillodonta, Creodonta, Mesodonta

Bunotheria.

There can be no doubt that these Early Eocene 1 See p. 72, note. 
animals-owing to the above-mentioned peculiarities-show a certain necessity for being classed together, and it is self-evident that they must stand nearer to one another, were it only on account of the smaller period of time since their separation from the primary stock, which must be assumed to have been common to them all. However, in our opinion, the characteristics specified above go no further than to indicate a most general form of connection. When Cope maintains that the different groups of Bunotheria are related to one another, somewhat in the same way as are the orders of Marsupials, it seems to us that this scarcely applies to the case. To give an example: what has Tillotherium from the Eocene of Wyoming (Fig. 50) in common with the flesh-eaters Arctocyon and Oxyana? By the smallness of its brain most certainly nothing; nor by its five toes, and the circumstance that the whole sole of the foot is applied to the ground. The resemblances in the molars are not remarkable, while the decidedly rodent-like form of the incisors only proves the peculiarity of the animal. Any typical feature-such as the marsupial pouch or the marsupial bones, or the openings of the urinary and genital organs peculiar to the Marsupials-is not met with in any of these animals, 
as far as can be judged from the often great paucity of their remains.

Only one point stands out in this attempt to throw light upon the relationships between the

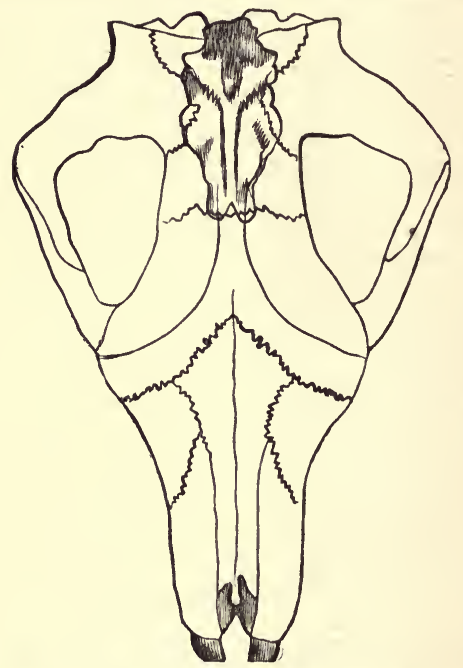

F16. 50. - Skull of Tillotherium fodiens, from above. One-fourth nat. size. After Marsh.

mammals of that early period; the indrawing of the Insectivora, of that type which has been pretty faithfully preserved from the earliest traces of 
Marsupials or Insectivora in the Trias down to the present day, and which seems to have gradually sent out off-shoots in the most different directions, till at length they became unrecognisable.

\section{THE SEALS.}

According to the form of their skull, dentition, and mode of life, Seals are 'carnivorous animals that have adapted themselves to a life in water,' and in this way they are generally described. In order to make the theory acceptable, it is customary to point to our Sea-otter, which, unlike its nearest relative that thirsts for warm blood, has become a pure fish-eater. The Sea-otter uses its hind limbs after the manner of seals, and its skull shows a depression of a similar kind to that which has proved advantageous to the Seals. Hence, so it is said, we have to imagine the ancestors of the Seals on that line which has led them farther and farther from their original forms, which very gradually changed their limbs into fin-shaped rudders (while perfectly retaining the pelvis and the articulation of the skeleton), and whose skull became a light, thin-walled box not burdened with strong teeth. Only the Walrus (Trichechus) has developed a couple of heavy tusks, corresponding with its 
entirely different mode of life, inasmuch as it burrows in the ground for certain kinds of mussels. All the others hunt for fish, which they can readily tear to pieces with their sharp canine teeth and pointed molars, which are compressed somewhat to the side.

Of fossils that might illustrate the gradual incoming of Seals there are none. We conclude that the process must, at one time, have begun with carnivorous land-animals. The idea that the reverse might have been the case by their having, as sea-animals, taken to a life on land, has as little value here as in the case of the Cetaceans, which are mammals, and have never been anything else. The period during which they changed their element lies at an immeasurable distance in the far past, but is probably less distant than that in which the ancestors of the whales took to the sea while reducing their hind limbs.

There can be no question about making the Whales (of course only the toothed group) the primary parents of the Seals. If any comparison of the kind is thought of, the Eocene Zeuglodonta could alone be taken into consideration. But even these latter do not show any points of connection; their skull would have to be retro-metamorphosed to form 
the skull of the seal, and their dentition would have to be fuller; hence the supposed points of connection would be confined to a superficial resemblance in the crowns of the molars, as there was very probably an essential difference in the formation of the hind limbs.

As we are absolutely without any clue to the origin of Seals, we may here mention one other circumstance which seems to speak in favour of the great age of this side-branch of the primary Carnivora. What we yet know of the change of teeth in Seals shows that the change takes place at an extraordinarily early stage of life. ${ }^{1}$ In most cases the change takes place before birth ; the milkteeth never come to be of any use whatever, and the permanent teeth are cut when the young animal is but a few weeks old, and while making its first feeble efforts to join its parents in their repasts. Fig. 51 shows the teeth of a probably still unborn Greenland seal (Phoca grönlandica). The shading shows the limit of the gums. It will be seen that the mill-teeth have already vanished, all but a few unimportant remains; $d \frac{p^{\prime}}{p^{\prime}}$ have wholly

' J. Steenstrup, 'Maelkestandsaettet hos Remmesaelen,' Naturhistorick Foreningens Vidensk. Meddeleser. 1880. 
disappeared, the first and only permanent molas of the lower jaw has already cut the gum.

Teeth of the same kind as these milk-teeth, which are wholly without any significance to the individual as functional organs, but of the highest interest for the history of the group, we became acquainted with when discussing the Whales (p. 247).

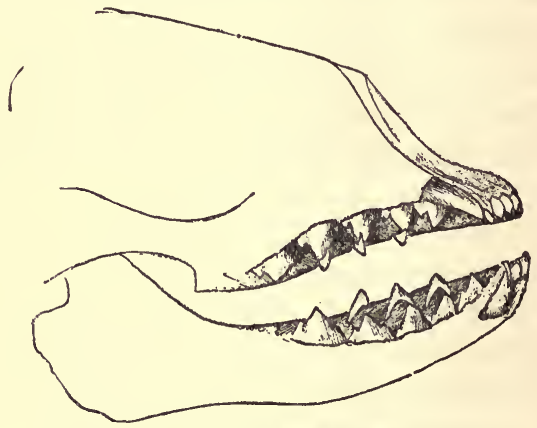

Fig. 51.- Fœtal Teeth of a Greenland Seal.

The embryonal teeth of the Whalebone whales_even though there were no Dolphins or Sperm whalesare an irrefutable proof that the Whalebone whales are descended from toothed animals. In the same way the case before us shows, that the milk-teeth of Seals which have in our day become of utter 
insignificance to the organism, were of actual service to their ancestors, just as the deciduous teeth of most of our present mammals are of use for several years. None of these milk-teeth have the prospect of being preserved like the one remaining deciduous tooth of the Marsupials (p. 94); accordingly the Seals of future periods will undoubtedly not show a trace of milk-teeth.

The Seals belong to the physically weaker groups of mammals, and it is certainly most remarkable, and as yet not explicable, that the other mammals also, which have already been discussed, and are allied to the Seals as regards the suppression of the change of teeth, belong, on the whole, to the less favoured or less strongly developed orders. For, as we have repeatedly remarked, the main feature that runs through the whole world of mammals is the concentration of strength upon a shortened jaw, at the cost of the disappearance of teeth. This is most evident in the case of true Carnivora, where, however, the milk-teeth still play an important part.

10. THE INSECTIVORA, OR INSECT-EATERS.-RODENTIA, OR RODENTS. - CHEIROPTERA, OR BATS.

Of these three orders the Insect-eaters have already been mentioned from time to time. They 
existed in very early times, and had, at the beginning of the Tertiary, already attained a stage of development which has been transmitted to the present members of the group, with but trifling modifications; and it is probable that a transition into hoofed and carnivorous animals had shown signs of incoming as early as the so-called Mesozoic period. The question as to why all the group did not join in the transformation is as obvious as the answer to all similar questions : that the special conditions of life for these animals must have existed uninterruptedly, and that, in addition, they possessed a great amount of adaptability. Thus we find the order of Insect-eaterswhich is represented in Central Europe only by the hedgehog, mole, and shrew, but more numerously in other parts-in many ways similarly adapted to the most varied conditions of existence as the Rodents. In fact, their variability, even in primeval times, explains the fact of their having been able to adapt themselves to entirely new organisations, and Huxley specially traces to them the hoofed and carnivorous animals.

The same remarks apply to the Rodents, except that in all of the periods known to us through fossils, they were far more numerously represented. 
The Rodent type is likewise found perfected at the beginning of the Tertiary period. It may be said that it was then less specialised, that most of the Rodents of those days were more carnivorous than the majority of our day, or, at least, more omnivorous; however, little is to be gained from this for our present enquiry.

The dentition of the Rodents appears to be prepared, and almost perfectly attained, by the Marsupials; ${ }^{1}$ and thus in following their tracks we are again referred to the Jura period, and even further back, where the separation of an already developed mammalian fauna had taken place: into Marsupials (as the main group), Rodents, and Insect-eaters.

The latter order, no doubt, gave rise to the Bats, which have fluttered about in their present shape since the Eocene period. Two of our most common

1 A comparison of the very different shapes of the molars in the Rodents among one another, and the approximation of many of the genera-not as yet decided Rodents-to the Rodent type (for instance, the wombat, the fingered-animal, and rock coney) renders it extremely probable that even our present Rodents are not of one and the same origin. "The fact remains, animals of different derivation have attained a similar exterior, succeed extremely well in the struggle for existence, or even better in their endeavour to obtain food. Unlike as they may be, in one point they are incontestably alike, i.e. in the development of continuously growing incisors.'-BaUsiv. 
genera, Vespertilio and Rhinolophus, were contemporaries of the Palæotheridæ and the Cynodictis of South-western France. As regards their origin we can only confess our ignorance on the subject, even though we can perfectly well imagine the transformation of a climbing insect-eater into a flying one. The elongation of the fingers of the fore limb, and the expansion of the flying membrane to the hind limbs, took place in those early periods from which, as far as our knowledge of the Mammalia is concerned, only a few dim rays of light have found their way to us.

11. THE PROSIMIZ, SEMI-APES.-SIMIE, APES. THE MAN OF THE FUTURE.

The opinion of zoologists of the Linnæan school, and those belonging to the first half of our century, that the whole class of Semi-apes were, in fact, half apes has generally been abandoned; the opinion was based upon the occurrence of hands on the fore and hind limbs, upon the formation of the face, and upon the peculiar dentition, which in most cases shows no gaps. The more recent theory does not exclude the supposition that among the very differently formed genera of so-called Semi-apes, one or other species might claim a closer relationship with the 
Apes, but neither the result of any anatomical or palæontological investigation allows us to draw even a plausible inference of any such probability.

As there are only a small number of genera of Semi-apes, and these are confined to Madagascar (Africa and Southern Asia possess only a few aberrant members of the group), we had to conclude that they are but the remnant of a group. Their dentition and brain point to the Insectivora, of whose morphological capacities we have had such important instances in the course of our discourse.

A true semi-ape-and, as regards skull and dentition, a lemur of our day-was discovered by Filhol among the varied accumulation of mammals in the phosphate of Quercy, and was named $\mathrm{Ne}$ crolemur antiquus. By its side there lived several species of a genus already discovered by Cuvier, the Adapis, an animal whose dentition points to a relationship with the Pig-shaped tribe, but still may have been a creature of arboreal habits. Another animal has had its position assigned to it by the name of Cebochorus, i.e. Hog-ape, owing to its very characteristic molars, the crowns of which show four tubercles. America has also furnished its contingent to this group, which combines the characteristics of the thick-skinned animals with 
those of semi-apes, a combination which has not shown much capacity for resistance or of adaptability to new conditions of life.

That forms of this kind gave rise to the Apes has been conjectured by different palæontologists and also by Gaudry. The Apes found in the Miocene of the Old World belong already partly to the stillexisting group - we dare not say family - and have been called 'Anthropomorphæ' (man-like apes) owing to various peculiarities in different genera. If we hold by the present arrangement of the order, and agree to the opinion-based upon facts that have never seriously been doubted, and are founded upon substantial reasons in the history of the individual development as well as of anatomythat the apes of to-day form a kindred unity, other considerations will present themselves. It is true that lowest species of South American apes, the clawed apes, have thirty-two teeth like those of the Eastern hemisphere, but the form of these teeth and the structure of the hands and feet point to a decidedly close proximity with the Insectivora. Further, they are allied to the Apes of the New World by the fact that they do not, like the Apes of the Old World, possess two, but show three premolars. And all the other American apes show 
$\frac{6-6}{6-6}$ cheek-teeth, not $\frac{5-5}{5-5}$. Even the earliest Miocene apes of Europe and Asia show a reduction in the dentition, hence the American apes stand nearer to the primary forms. Further, the genera with six cheek-teeth, it seems to us, point more probably to ancestors of the Insectivorous species than to the Pachyderma. It is, therefore, not only possible, but has come to seem probable, that our present apes, in regard to their descent, have met from two entirely distinct origins : the American group from the Insectivora, the Europe-Asiatic line, with the Anthropomorphæ, from ancestors of the Pachydermata species.

This would lead up to the question as to whether our own ancestors belonged to the thick-skinned group. - But the very title of our book withholds us from entering upon this subject, and we are all the more justified in postponing any such discussion, as the study of anthropology can in no way boast of having made any definite progress during the last ten years. ${ }^{1}$

1 The relation between the Anthropomorphoid Apes and Man has been admirably discussed by Hartmann, 'Die menschähnlichen Affen.,' Internat. wissenschaft. Bibliothek, $60 \mathrm{Bd}$. Leipzig, 1883. For further accounts of this subject we would refer the reader to Schlösser and Seler, Die ersten Menschen und 
However, we may be permitted to east a glance at the future. Our discussion has repeatedly proved that any advance in the animal groups was connected with a reduction of the jaw or of the limbs. It would seem that any reduction in the fingers or toes of the human hand or foot would be neither desirable nor advantageous in any way; moreover no such loss is to be feared, although it may be, as Darwin says, that baldness is in prospect for men of the English race. It is a different matter as regards our dentition, and we are not so certain of its continuing in its present state, although the human race would seem to have commenced with it as it is, and found it sufficient for the most varied conditions of existence. But nevertheless a few gentle warnings seem to shake the belief in this supposed unalterable stability.

The alternative as to whether Man was created or developed can no longer be raised, now that we are exercising the free use of our reason. Man's dentition has to be judged from our experiences made in the mammalian group. Hence, first of all, it is a reduced dentition. True, we do not know the definite stages by which it was attained

die prähistorischen Zeiten. According to a work of the same name by the Marquis de Nardaillac. Stuttgart, 1884. 
in Man, any more than we do in the case of the Anthropomorphoids and all the other Apes of the Old World, but we shall not hesitate to maintain that the ancestors of Man possessed a fuller number of teeth, as long as deductions are justified from the observation of facts. Our teeth have decreased in number during the course of our geologico-zoological development; we have lost on either side, above and below, two incisors, two premolars, and one molar. By this we transfer ourselves back to those periods from which the jaw of the Otocyon has been preserved (see p. 267). Baume, our eminent odontologist, in a recent work which we have repeatedly referred to, has successfully followed and pointed out cases of atavism or reversion in the human jaw, by tracing cases of 'surplus' teeth-and certain dental formations met with in the jaws in a large percentage of cases-back to those portions of the jaw in the animal ancestors of Man which have disappeared in the course of ages.

If, in former times, more teeth were met with in the group which was perfecting itself into Man, we must be permitted to ask-nay, we are compelled in a purely scientific spirit to ask-whether things have come to a standstill in this part of our 
organisation, or whether a further reduction is to be anticipated? Man is certainly one of the socalled 'persistent species,' but he is not unconditionally stationary. $\mathrm{He}$ varies as regards dentition. Imperfect as are our statistics on this point, this much is certain, that the cases of disappearance or loss of teeth most frequently concern the so-called wisdom teeth and then the outer incisors. We do not of course know how often the question has applied to the actual and complete loss of the teeth, or only to some interference with the teeth cutting the gum, occasioned by a limitation of the necessary space. However, it must be remembered that the shortening of the jaw stands in direct correlation with the reduction of the dentition. A prediction of the Man of the Future is given us by Cope: the lower races of men will retain the dentition of the present day, $i \frac{2}{2}, c \frac{1}{1}$, $p \frac{2}{2}, m \frac{3}{3}$, while the intellectually higher races will be distinguished by the dental formulas:

$$
\begin{array}{r}
i \frac{\mathbf{1}}{2}, c \frac{1}{1}, p \frac{2}{2}, m \frac{3}{3} \\
\text { and } i \frac{\mathbf{1}}{\mathbf{1}}, c \frac{1}{1}, p \frac{2}{2}, m \frac{\mathbf{2}}{\mathbf{2}} \text {. }
\end{array}
$$


We agree with this in so far that, as a rule, the reduction of the dentition-where the disappearance does not affect the whole set of teeth-can be brought into connection with the idea of progress, and many proofs of this have been given in the course of our discussion. Still this higher faculty of resistance and of acquiring food is not necessarily accompanied by an increase in the power of the adaptability and a perfecting of the intellectual faculties. In the Cat we have a more powerful, and hence a higher development of the nature of the rapacious animal than in the Dog, with its more old-fashioned form of dentition. Yet who would think of placing Cats as intellectually higher than Dogs? It is the same with the prospects of the human races. Modifications in the human dentition are sure to take place, as surely as man cannot rid himself of his animal ancestors, even though they may be felt to be inconvenient. But progress in the intellectual and moral domain-and here our well-founded idealism steps in-is not dependent upon the possession or the loss of our wisdom teeth. The correlation is not wanting, but it makes itself felt in an opposite direction. The man who is engaged in making inventions and in scientific pursuits, and is advancing and encouraging all the nobler and 
more refined enjoyments of life, is not improving the instruments for the acquisition of his food; they deteriorate in his hands - a condition which first began to make its appearance with the invention of cooking. The reduction of the human dentition-which has been of advantage to the species in its struggle for existence-has further increased and changed to a kind of atavism or reversion, since reason, acquired with speech, has made Man more and more independent of the direct effects of his natural surroundings.

Hence it is not merely from a purely zoological point of view that an inference is formed regarding the future change of the human race. Moreover, we cherish the hope-which is justified by scientific experiences-and the belief, which rests upon the same foundation, and these convince us of the sure advance of humanity; and of the gradual and general diffusion of morality; culture, and wellbeing among the various races of Man. 


\section{N D E X:}

$\triangle C R$

Aceratheriom, 81, 190, 195

Adapis, 295

Elurogale, 277

Amblyctonidø, 283

Amphibos, 178

Amynodon, 1

Anchitherium, 79, 190, 203, 210

Ancodus, 170

Ancylotherium, 126

Animals, Crescent-toothed, 137

— Odd-hoofed, 189

- Ohio, 233

- Pair-hoofed, 137

Anoa, 179

Anoplotherium, 80, 129

Ant-bears, 124

Antelope arabica, 176

Antelopes, 79, 173

- Saiga, 76

Anthracotherium, 80, 142

Anthropomorphæ, 297

Antilocapra, 161

Appenzell, cattle of, 179

Arctocyon, 80, 282, 285

Arctocyonidæ, 283

Arno, Val d' (Pliocene), 79

Auchenia, 157
CAI

Babirussa, 138

Balæna, 250

Baltavar (Upper Miocene), 79

Bear, 280

Bearded Whale, 247

Bear-dog, 280

Bern cattle, 179

Bettongia, 100

Bibos, 178

Bibovina, 178

Bison, 178, 179, 187

Boar, wild, 138

Bos, 176, 178

Bradypus, 114

Bramatherium, 172

Brontotherium, 81, 199

Bronze-dog, 264

Bubalina, 178

Buffalo, 186

Buffelus, 178

Bull-dog, 264

Bunodonta, 137

Bunotheria, 284

Cadicona Lignite (Lower Miocene), 79

Cainotherium, 79, 182 


\section{CAM}

Camargue, house of, 221

Camels, 154

Camelus, 157

Canidæ, 259

Canis, 259

- antarcticus, 262

- anthus, 262

- argentatus, 262

- azaræ, 262, 268

- cancrivorus, 262

- fulvus, 262

- latrans, 262

- littoralis, 262

- lupaster, 264

- lupus, 264

- magellanicus, 262

- pallipes, 264

- suessi, 265

- vulpes, 260

- zerda, 262

Cattle of Appenzell, 179

$-173,178$

- Dutch, 179

- of Bern, 179

-- Short-headed, 189

- Tyrolese, 189

Cats, 275

Cave Wolf, 265

Central German Horse, 224

Cervulus, 161

Cervus canadensis, 163

Cetotherium, 251

Chalicotherium, 201

Chelys fimbriata, 37

Chlamydophorus, 120

Chœropotamus, 142

Chœrotherium, 142

Cholœpus, 149

Colonoceras, 81

Coryphodon, 80, 81, 132, 284

\section{DEC}

Creodonta, 282, 283, 284

Crescentic-toothed animals, 137

Ctenacodon, 100,

Cynodictis, 271

Cyon, 266

DAsypes, 120

Dasyurus, 269

Debruge, Lignite (Upper

Eocene), 79

Deer, 79

- Red, 162

- Rein, 165

- Telemetacarpal, 163

Diceratherium, 81

Dichobune, 80

Dicotyles, 138, 141

Dicrocerus, 79,161

Didelphia, 93

Didelphys, 97,99

Diluvial Horse, 224

Dingo, 262

Dinoceras, 81, 241

Dinocerata, 240

Dinotherium, 79, 236

Diphyodonta, 43

Diplopus, 170

Diprotodon, 103, 101

Diptacodon, 81

Dogs, races of, 259

- Bear.dog, 280

- Bronze-dog, 264

- Bull-dog, 264

- Viverrine dog, 271

- wild dogs of Africa, 264

Dolphins, 248

Dorcatherium, 79

Dremotherium, 79

Duck Mole, 86 
DUT

Dutch cattle,179

Dwarf musk deer, 167

EchidNa, 86

Egerkingen (Middle Eocene), 80

Eibiswald (Middle Miocene), 79 Elasmotherium, 190, 197

Elephants, 79, 228, 235

Elk, 165

Entelodon, 80, 282

Eohippus, 81, 190, 213

Eohyus, 143

Eppelsheim (Upper Miocene), 79

Equus caballus, 218

- stenonis, 216

Eutheria, 93

FELIS, 276

Fingered animal, 293

Fontainebleau, sand (of the Lower Miocene), 79

Fox, 260

Frontosus race, 179

Gelocus, 79, 164, 170

Georgsmünde (Middle Eocene), 79

Gerard-le-Puy, St. (Lower Miocene), 79

Giraffe, 170

Girdled animals, 120

Glossotherium, 121

Glyptodon, 123, 121

Greenland seal, 290

Günzberg (Middle Eocene), 79
JER

HaLicone, 242

Halitherium, 242

Hampshire (Upper Eocene), 79

Hatteria, 28

Helaletes, 81, 193

Helladotherium, 79, 172

Helohyus, 143

Hipparion, 79, 190, 203

Hippopotamus, 144, 145, 146, 203

Hog-deer, 138

- wart, 138

Hollow-horned animals, 173

Horse, 190, 201

- Diluvial, 224

- occidental, 223

- of the Camargue, 221

- of Solutré, 220

- oriental races of, 223

- wolf-toothed, 210

Hyæmoschus, 167, 168

Hyæna, 79, 280

Hyænaretos, 280

Hyænodon, 80, 282

Hydaspitherium, 172

Hydropotes, 163

Hyopotamus, 168

Hyrachyus, 81, 193

Hyracodon, 81

Hyracotherium, 80

Hyrax, 241

IcticyoN, 266

Ictitherium, 79, 280

Insectivora, 284, 286

JACKAL, 264

Jerboa, 76 


\section{INDEX}

\section{IAF}

LA FÈre, Sandstcin (Lower Eocene), 80

Lama, 155

Léberon

79

(Upper Miocene),

Leptobos, 178

Lignite of Cassino (Pliocene), 79

London clay (Lower Eocene), 80

Lophiodon, 190, 192

Machatrodos, 276

Macrauchima, 228

Macrotherium, 125

Mammoth, 235

Manatus, 242

Mastodon, 79, 231

Mauremont (Middle Eocene), 80

Megatherium, 81, 114

Mesodonta, 284

Mesohippus, 81

Mesonychidæ, 283

Metatheria, 93

Miacidæ, 283

Microlestes, 98

Miohippus, 81

Monodelphia, 93

Monophyndota, 43

Montabuzard (Middle Eocene) 79

Montpellier, marl of, 79

Moropus, 125

Muntjak, 161

Musk deer, 167

Mylodon, 114

Patr-hoofed antmats, 137

Palæochœrus, 142

OCCIDENTAL HORSE, 223

Odd-hoofed animals, 189

Oenigen (Upper Miocene),

Ohio animals, 233

Oreodon, 81

Oriental races of the ho 223

Orléans, sand of (Mid Miocene), 79

Ornithorhyncha, 86

Orohippus, 81, 190

Otocyon, 268

Oxyæna, 81, 283, 285

Oxyænidæ, 283

Palæocyon, 282

Palæonictis, 80

Palæoprionodon, 274

Palæotherium, 80, 190, 201

Palorchestes, 104

Parameryx, 156

Paris gypsum (Upper Eocene) 79

Paris coarse limestone (Up. per Eocene), 80

Pea ore (Middle Eocene), 80

Peccary, 130, 140

Perchœrus, 143

Phacochœrus, 138

Phascolomys, 104 


\section{PHA}

Di 'hascolotheriurn, 99

D 'igs, 70, 137, 141

'ikermi (Upper Miocene), 79

'Iagiaulax, \$9, 100

E lesictis, 274

E lesiometacarpal deer, 163 liauchenia, 157

I. Pliohippus, 81, 190, 215

] Pliolophus, 80

1 Poebrotherium, 159

1 Poodle, 264

1 'ortacina, 178

Srimigenius bos, 179

Proælurus, 275

Probubalus, 178, 179

Procamelus, 156

Procervulus, 160

Prorastomus, 244

Protohippus, 81, 190, 214

Protolabos, 156

Prototheria, 93

Prox, 160

Pseudælurus, 275

Pterodon, 80, 282

QUERCY PHOSPHORITE (Upper Eocene), 79

RED DEER, 162

Rein deer, $16 \tilde{5}$

Rhinoceros, 79, 81, 190, 194

- minutus, 198

Rhinolophus, 294

Rhytina, 243

River horse, 144

Ronzon, lime rocks of (Lower

Miocene), 79

Ruminants, 150
TYR

SABre-Toothed TIGER, 277

Saiga antelope, 76

Sand of Orleans (Middle Eocene), 79

Sansan (Middle Miocene), 79

Selenodonta, 137

Short-headed cattle, 189

Shorthorn bull, 175

Simocyon, 79

Sivalik hills (Upper Miocene), 79

Sivatherium, 172

Sloth, giant, 113

Smooth whale, 250

Soissonnais, lignite of (Lower Eocene), 80

Solutré, horses of, 220

Squalodon, 251

Stegodon, 234

Stenoplesictis, 274

Strata, tertiary, of N. America, 81

Teniodonta, 284

Tapir, 79, 189, 190

Tapiravus, 81, 193

Taurina, 178

Telemetacarpal deer, 163

Tertiary strata of $\mathrm{N}$. America, 81

Thylacinus, 269

Thylacoleo, 102

Tillodonta, 284

Tillotherium, 81, 286

Tinohyus, 143

Toothed whales, 247

Tragulidæ, 167

Trichechus, 287

Tyrolese cattle, 189 
308

\title{
INDEX
}

Uromastix, 28

URO

Ursus, 280

VAL D'ARNo (Pliocene), 79

Vespertilio, 294

Vienna basin, 79

Viverræ, 274

Viverrine dog, 271

WALRUS, 287

Wapiti, 163

Wart-hog, 138

Whales, toothed, 247

- bearded, 247

\author{
ZEU \\ Wild boar, 138 \\ Wild dog of Africa, 264 \\ Wolf, 265 \\ - Indian, 264 \\ Wolf-tooth of horse, 210 \\ Wombat, 104, 293 \\ XIPHODON, 182 \\ Xiphodontherium, 182 \\ $\mathrm{Y}_{\mathrm{AK}, 179}$ \\ ZEUGLODON, 251
}

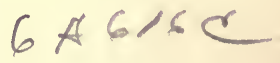

SPOTTISWOODE

PRINTED BY

AND CO., NEW-STREET SQUARB
LONDON 

